\title{
The impact of sustainability on fire safety
}

\author{
By
}

Mohammad Musa Al-Janabi

A thesis submitted to the Victoria University of Wellington in fulfilment to the requirements of the degree of Master of Building Science

Victoria University of Wellington 2013 



\section{Abstract}

There is a growing demand for building green buildings that are perceived to have benefits environmentally through promoting recycling, energy efficiency and efficient use of resources. The green movement has also led to innovative technologies that are focused on reducing cost. However, the fire safety industry has concerns with the use of certain technologies that create passages for smoke and fire to spread such as passive ventilation or materials that can burn severely and release large amount of toxins. The benefit of this research is to determine which features are high risk and are commonly used. The aim of this research is to investigate whether sustainable or green features have an influence on fire safety in commercial buildings and determine which feature or features would have the most significant implications for building safety in regards to tenability. A detailed investigation was done on passive ventilation such as double skin facade and the thesis also briefly discusses other green features and their implications. There were two methods used to collect data. The first was a qualitative study done through sending out surveys to fire engineers to rate and rank the most significant features that have negative implications for fire safety in reference to the New Zealand Building Code Fire Safety Section criteria and objectives. Then, a one hour interview was carried out to determine the reason behind the engineers' choice and their perceptions. The results from the surveys and the interviews were that double skin facade and atrium were ranked the most significant. The surveys established double skin facade has the highest ranking in terms of the worst feature, and the fire engineers reinforced that double skin facade needs to be studied as there is not enough research that have gone into this feature. While atrium issues are known and mitigation measures are well developed. A subsequent analysis for only double skin facade is conducted using Fire Dynamics Simulator (FDS) because little literature is found in regards to fire safety and double skin facade. FDS was used to simulate 14 small models and 2 large models for the best and worst scenarios of DSF. Each of the 14 models, one to three parameters are changed as part of the sensitivity study to determine which parameter have the most and least effect on fire safety in term of Carbon Monoxide (CO) and visibility. The issues the engineers raised and the mitigation measures were modelled, because the engineers had stated their opinions not facts. The output results from FDS illustrated that it is essential that the system shuts off in a fire event to prevent smoke spread to upper floors, which is the same mitigation measure that were emphasised at the interviews. 



\section{Table of Contents}

\section{Contents}

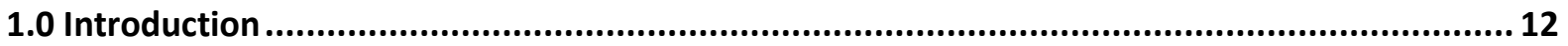

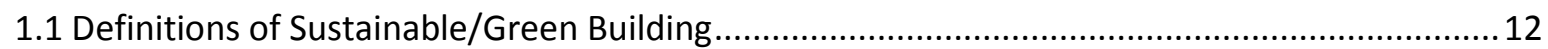

1.2 Definition of Sustainable/Green Buildings in Fire Safety Context ............................................. 12

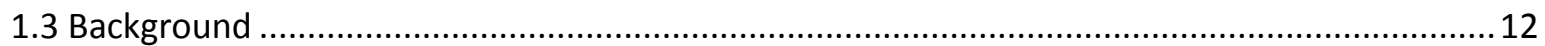

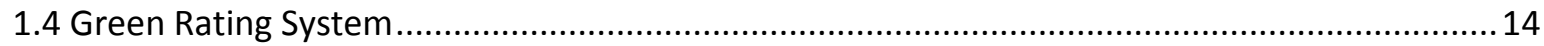

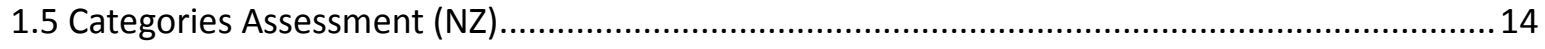

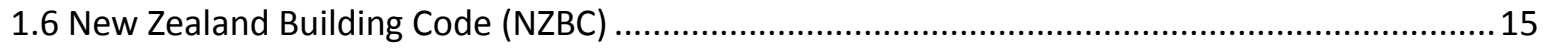

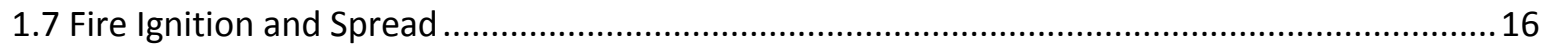

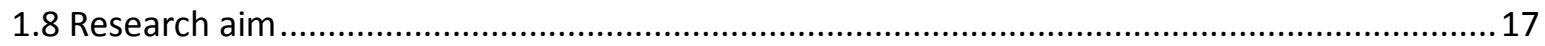

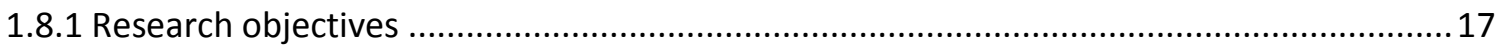

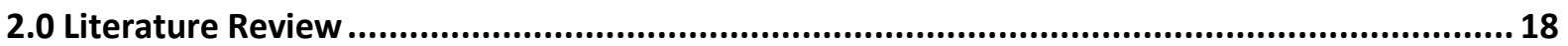

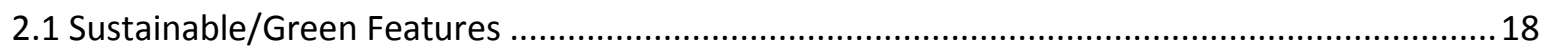

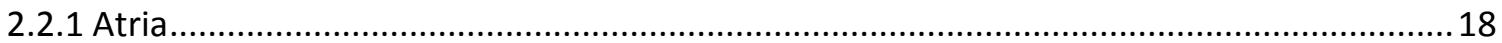

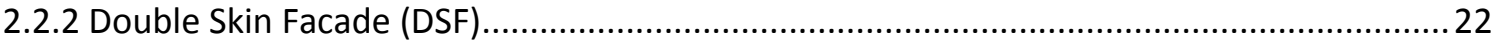

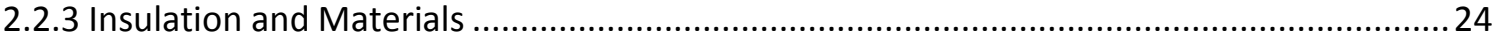

2.2.4 PCM

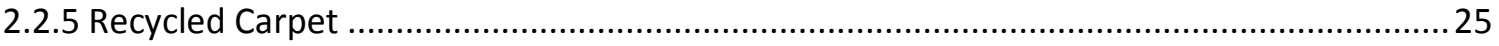

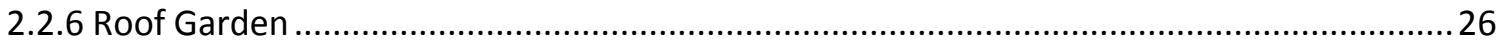

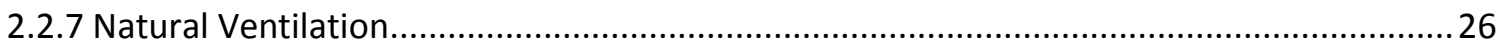

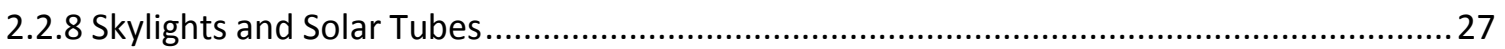

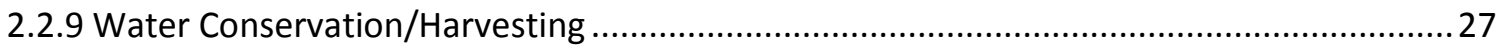

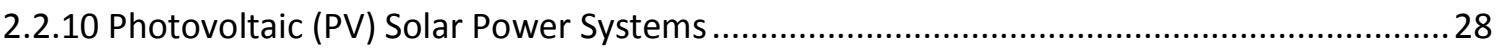

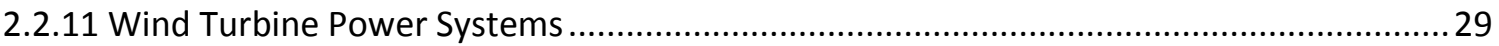

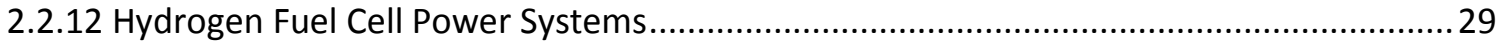

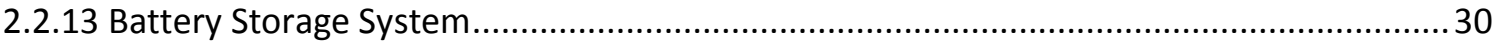

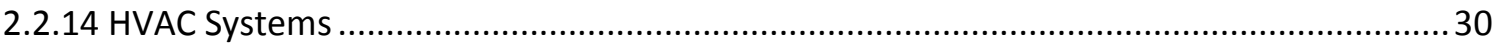

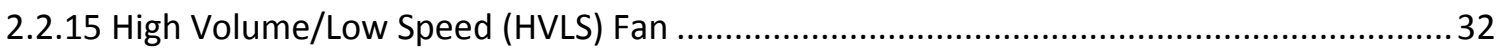

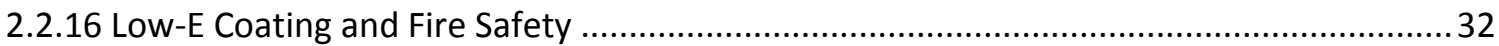

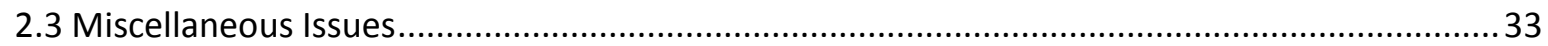

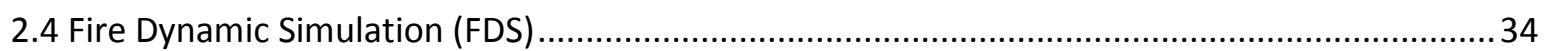

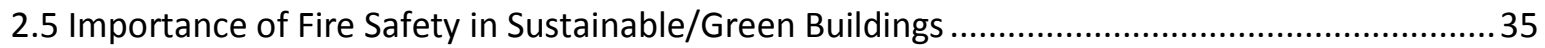




\section{Table of Contents}

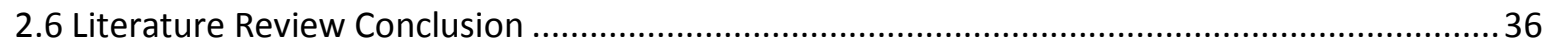

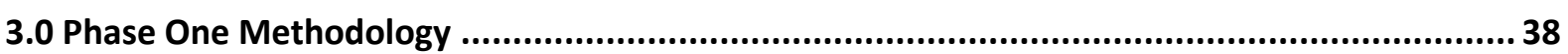

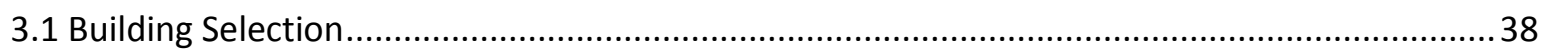

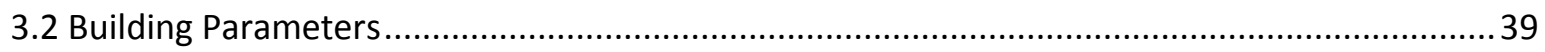

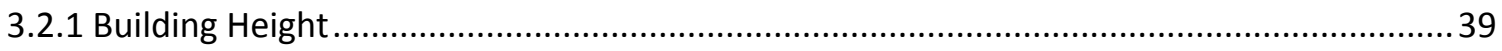

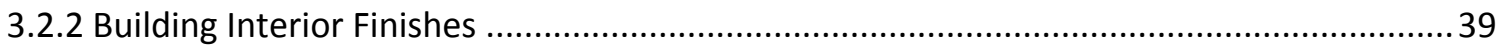

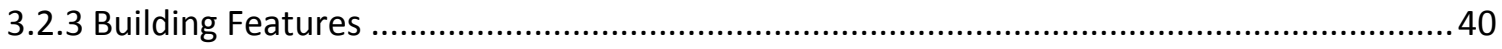

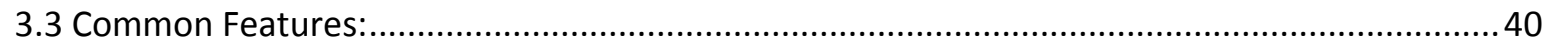

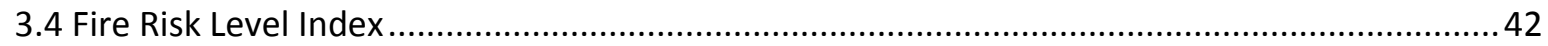

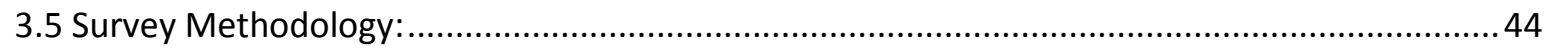

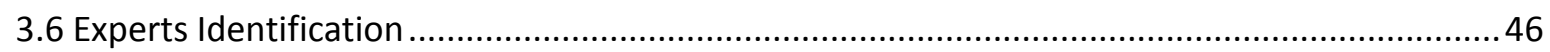

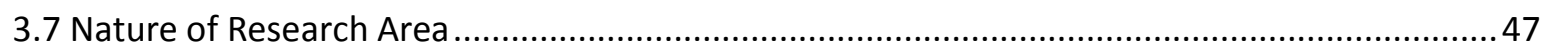

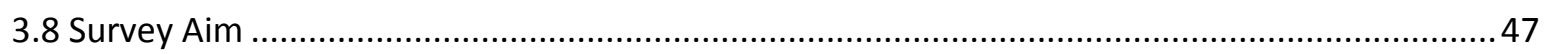

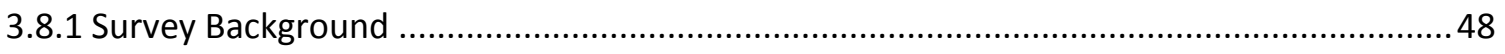

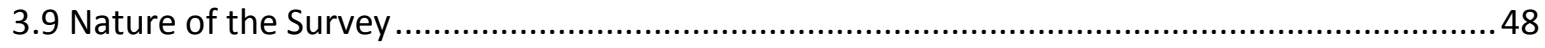

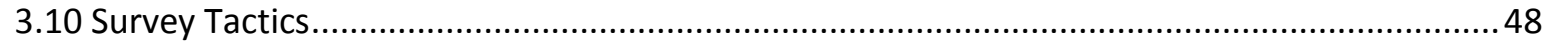

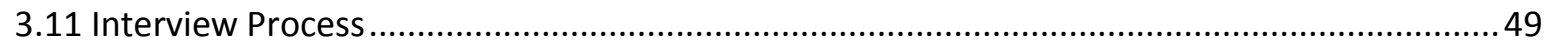

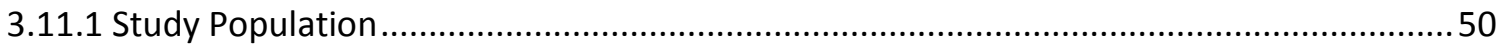

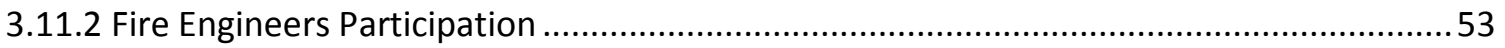

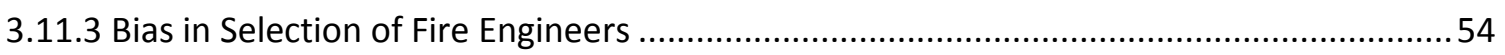

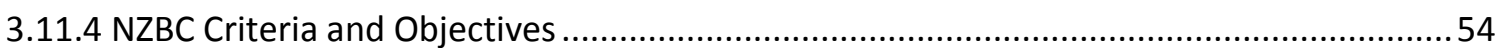

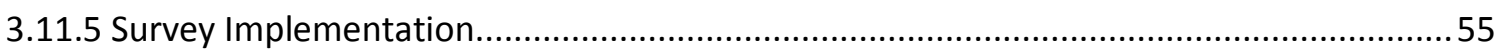

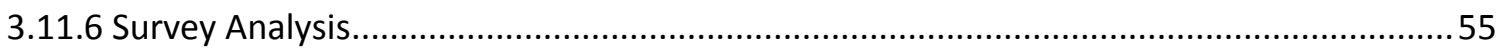

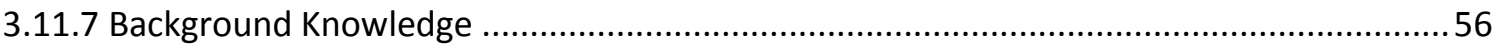

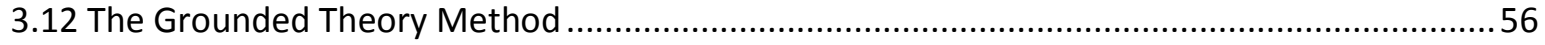

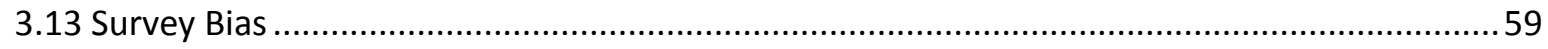

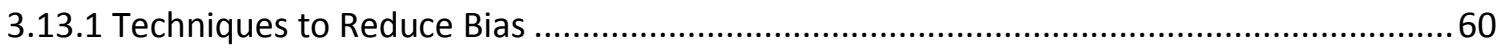

3.14 New Zealand and Prescriptive vs Performance-based Fire Safety Codes................................61

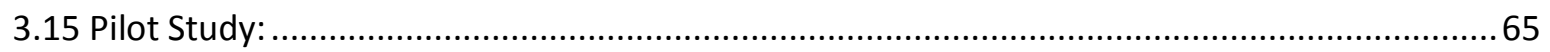

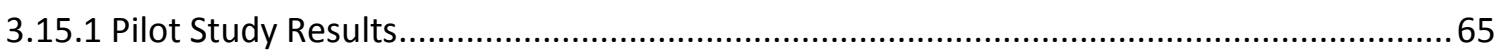

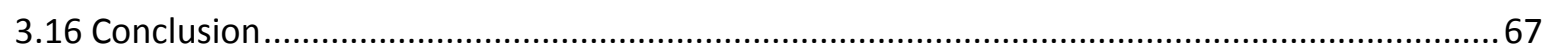

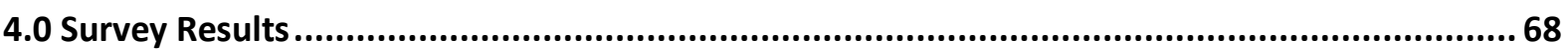

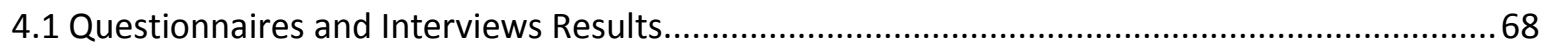




\section{Table of Contents}

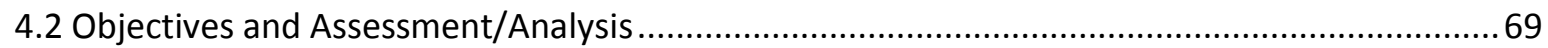

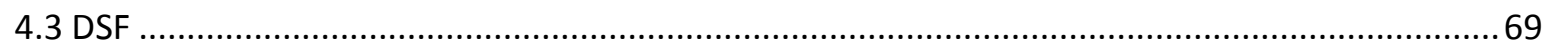

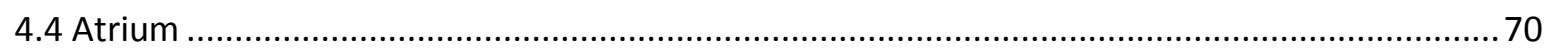

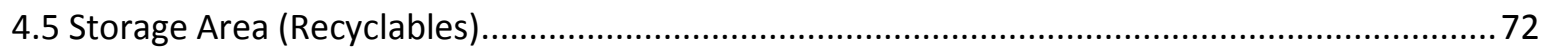

4.6 Sustainable/Recyclable Combustible Materials........................................................................ 73

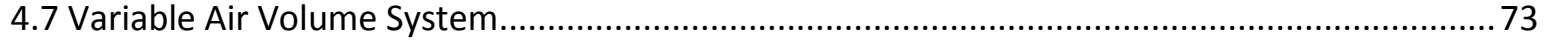

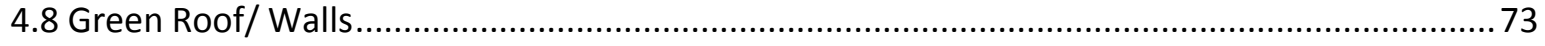

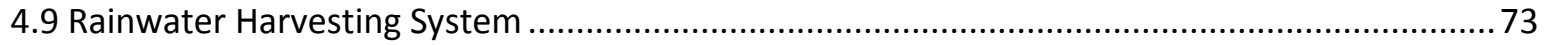

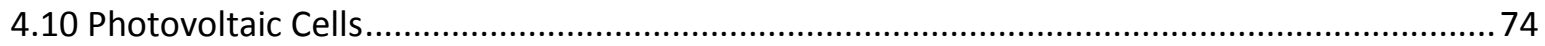

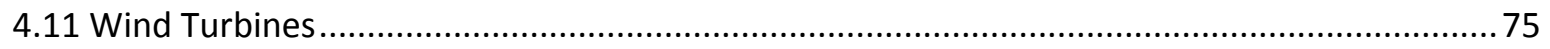

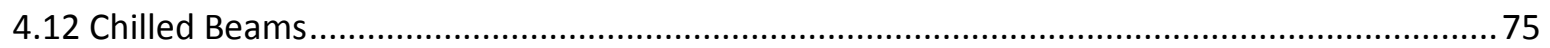

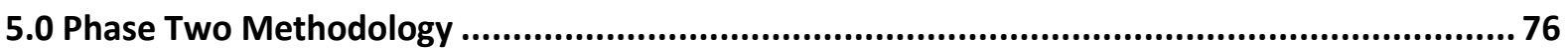

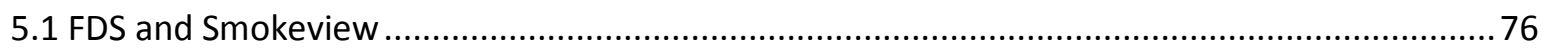

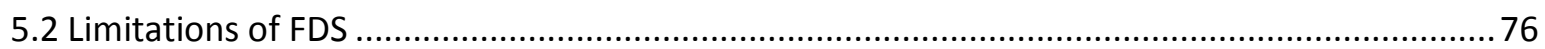

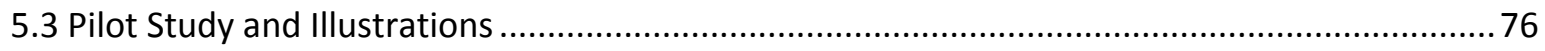

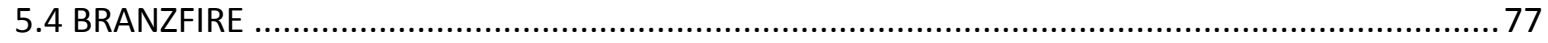

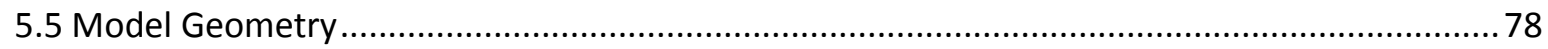

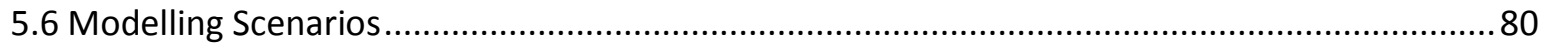

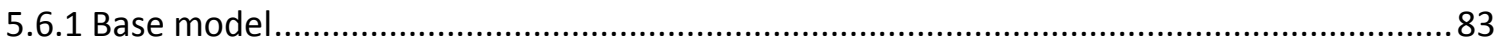

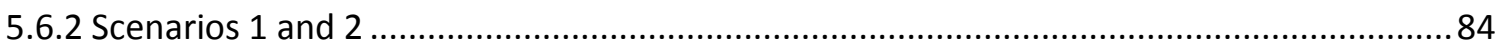

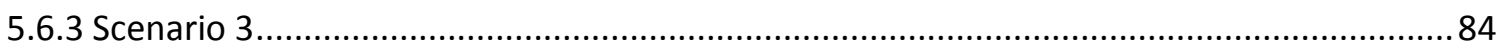

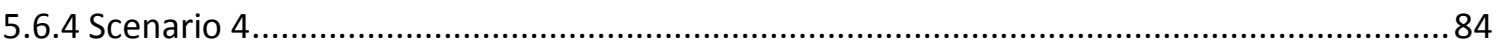

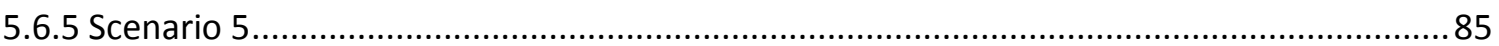

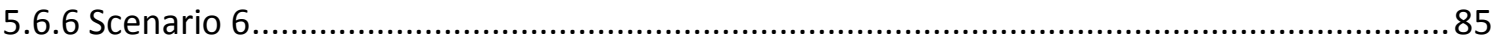

5.6.7 Scenario 7

5.6.8 Scenario 8

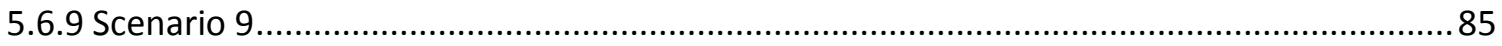

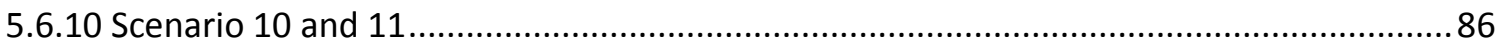

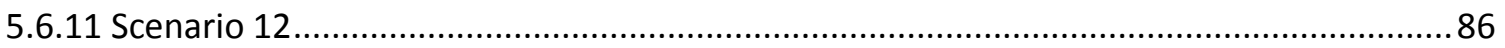

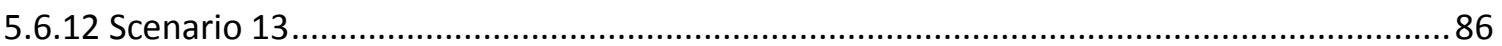

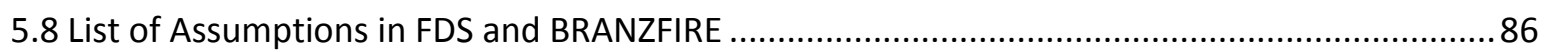

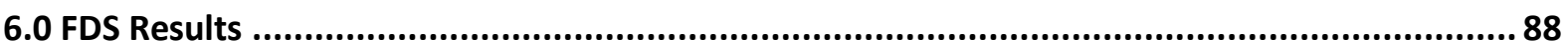

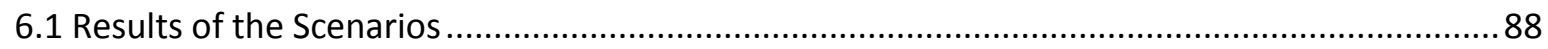




\section{Table of Contents}

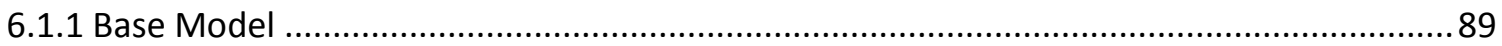

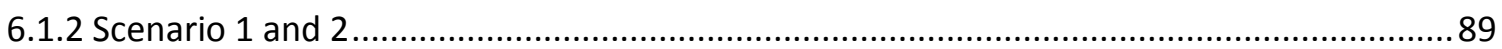

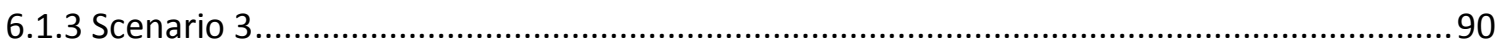

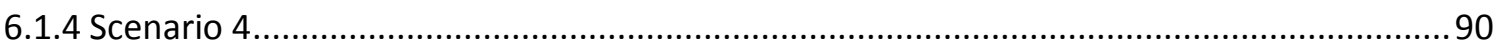

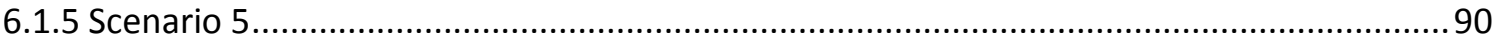

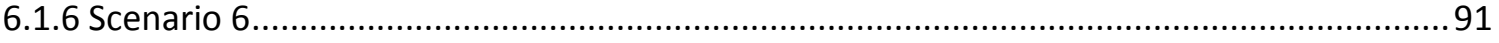

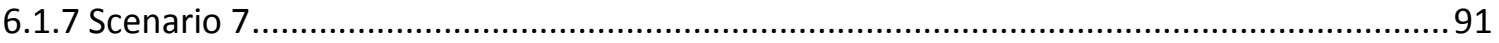

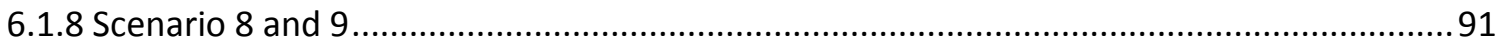

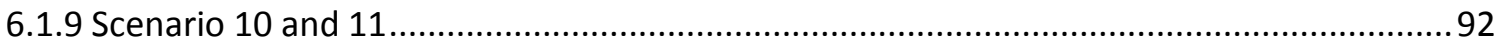

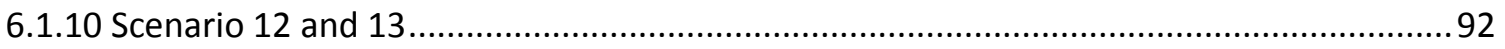

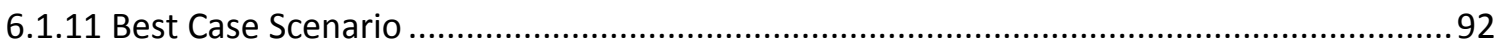

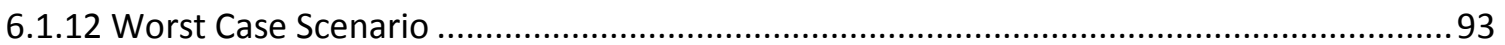

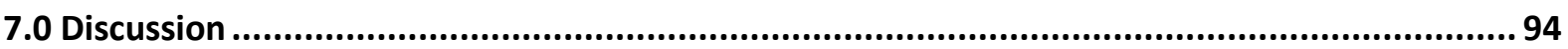

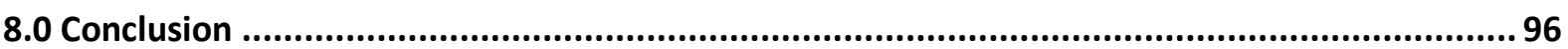

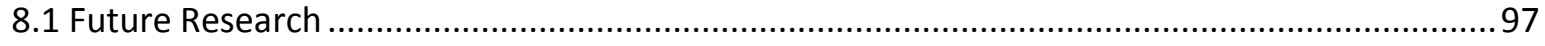

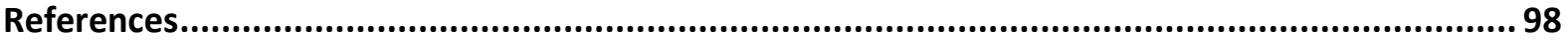

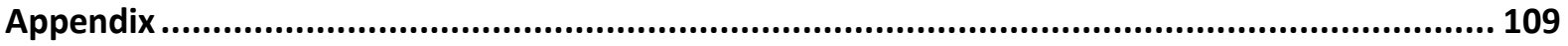

Glossary............................................................................................... 114 



\section{Acknowledgement}

I would like to acknowledge the professional support of my supervisors Dr. Geoff Thomas and Dr. Michael Donn for their guidance and encouragement.

Further thanks to SFPE for distributing the participation notice to fire engineers

Special thanks to the fire engineers that have participated in the survey and interview, it would not have been possible to complete this research without their input.

Thanks to Elisabeth Scoones for proof reading and editing grammatically this thesis.

Finally, thanks to my family and friends for their support and encouragement throughout this thesis. 



\section{Chapter One: Introduction}

\subsection{Introduction}

\subsection{Definitions of Sustainable/Green Building}

Green construction is defined as "the practice of creating sustainable/high-performance structures that is a holistic approach to design, construction, and demolition so as to minimize the buildings' impact on the environment, the occupants, and the community." (Tidwell \& Murphay, 2010, p2).

\subsection{Definition of Sustainable/Green Buildings in Fire Safety Context}

"Sustainability within the fire protection industry involves application of fire safety systems and design measures that support and promote building characteristics that are environmentally friendly during the buildings' daily use. These systems and designs must reduce the fire risk and impact that such characteristics and uses might contribute to throughout the full life expectancy of the building. Daily use characteristics include reducing harm to the environment by minimising energy consumption, water consumption, material consumption and fire risk". (Carter et al, 2011, p26).

\subsection{Background}

In this research the word sustainability and green refers to buildings that use new or innovative technologies, materials, and systems that are perceived as environmentally friendly and efficient. Sustainability is improving life quality through social, economical, environmental and efficient use of resources. Fire safety fits in the definition above in four aspects:

- Socially as it contribute to reducing injury, life loss, and reduces overall risk.

- Economically as it reduce damages to the building structures and aspects.

- Environmentally, the emissions of gases due to building aspects and features burning.

- Use of resources through better material and design choices (Charters, 2007).

The purpose of green buildings is to use non-recycled resources efficiently, increase building users health, long term cost saving and reduce waste that harms the environment. 


\section{Chapter One: Introduction}

However, the fire industry has concerns about the use of some features as they impact on fire safety. For example, atriums provide natural light but it is considered as a hazard as it increases fire and smoke spread. Also, high ceilings make fire sprinklers less effective. Further, the use of lightweight structure can degrade the structure strength and in a fire event it collapses quickly (Carter et al, 2011).

Green and sustainable buildings are seen as two different standards but serve the same purpose. Green buildings are mainly about technology and reducing the effect of global warming. The buildings are assessed on a basic scale compared to conventional buildings in the same region. However, sustainable buildings are assessed on a more comprehensive scale that involves social, economical and global issues. However, safety of any kind is not integrated in the concept of sustainability, as the sustainable term is being promoted. Therefore, the adverse effects of environmental friendly buildings are hidden or blurred. Furthermore, there are issues with green features that have caused conflicts between the sustainability industry and the safety code authorities. An example of this is solar chimneys, in a sustainable view it improves natural ventilation but from a fire safety perspective it increase smoke spread. Natural ventilation is dependent on stack effect and wind induced action which both lead to smoke being spread quickly (Chow et al, n,d). The stack effect or chimney effect are affected by the height of the building and it is more significant in winter than summer due to the temperature difference between the interior and the exterior (Black, 2009). An interview done by Chow and Steemers reveals that fire risk is increased by static extraction of smoke through natural ventilation in buildings.

Sustainable and green buildings concentrate on the design, construction and operational phases to reduce cost in the long run. However, the certification systems such as BREEAM, LEED, Green Star etc do not consider fire safety and protection issues. The purpose of the certification systems is only to increase the efficiency of the building and increase the comfort of end users. Although, it can be stated that building survivability is an integral part of building lifecycle and reduces environmental impact as well. Further, the main driver of building green buildings is to increase the awareness of society to the environmental issues. Wieczorek states "Focusing only on improving sustainable aspects of the building under 


\section{Chapter One: Introduction}

normal operation, without any consideration for off-normal conditions that pose risks to property, can result in unintended consequences and even tragedy." (Wieczorek, 2011, p42). Therefore, mitigations of reducing fire risk can reduce building lifecycle emissions by minimising the levels of air and water pollution caused by fire. There is also a potential to improve sustainability through insulation materials, use of wood, and power or storage resources (Charters, 2007).

\subsection{Green Rating System}

In 1990, the Green Movement started which led to the establishment of many Sustainable Rating Systems around the world. The main systems are BRE Environmental Assessment Method (BREEAM) which is a system used in the UK, Leadership in Energy and Environmental Design (LEED) which is a US Green Building Council (GBC) initiative that also influenced by BREEAM (Smith et al, 2006). In New Zealand, the system used is New Zealand Green Building Council (NZGBC) which is similar to the Australian system that was derived in part of LEED. Currently, the assessment tool in NZ rates design or built phases only. Design phase is what is proposed and what is currently on paper. Built phase is what actually has been built or used in the building. However, there is no performance phase; performance phase is how the building performances in all aspects, which is actual measurements. LEED and BREEAM have developed the performance phase rating system and in Australia performance phase is completed by the National Australian Built Environment Rating System (NABERS). In New Zealand, such rating system does not exist as of yet.

\subsection{Categories Assessment (NZ)}

The NZGBC has the same assessment tools and categories of the Green Star system around the world. The tools include Office, Office Interiors, Education, and Industrial. The categories include Management, Indoor Environment Quality (IEQ), Energy, Transport, Water, Materials, Land Use and Ecology, Emission and Innovation. The rating system score points to each category differently as some are more important than others and some sub-categories do not apply to all buildings such as the re-use of structure or facade. Further, through examination of the categories provided by the NZGBC, it does not provide a safety category. This means there are no considerations for safety into their assessment which increases 


\section{Chapter One: Introduction}

occupants' survival. Moreover, there is potential that some of the features and materials used that are considered green, create more risk in terms of fire igniting and smoke spreading which makes it more difficult for fire fighters to deal with fires in green buildings.

\subsection{New Zealand Building Code (NZBC)}

The objective of the Fire Safety provision of the NZBC is to protect people's lives and wellbeing from fires. The NZBC document specifies the minimum requirements that must be met. It contains provision for commercial and residential building. However, the main focus is on commercial buildings. The NZBC states that every occupied space in the building must have at least two escape routes. Fire door must be installed at escape routes and the doors must swing in the direction of exit. Further, in the document it is outlined that for a commercial building the following must be installed or provided:

- Fire stops must be installed at penetrations.

- Exit ways must be pressurised.

- Fire hydrant systems.

- $\quad$ Fire hose reels.

- Smoke detectors.

- Heat detectors.

- Automatic fire sprinklers.

- Emergency lights.

- Fire cells at floor, wall, and roof separation (NZBC, 1992).

The NZBC does not mention the word sustainability/green or does not incorporate it as one of its strategies. The code concentrates on building fire safety and reducing hazard. The code used to be prescriptive as it prescribes the requirements. However, in 1991 the Fire Safety Clause changed to performance based code which gives the right to use whatever mitigation measures necessary to achieve the requirement for tenability outlined in the New Verification Method 2012 (VM2). 


\section{Chapter One: Introduction}

\subsection{Fire Ignition and Spread}

According to Shipp (2007), New and innovative technologies are perceived as contributors to fire risks. These risks are mainly associated with self-energy generating systems such as photovoltaic cells (PV) and other solar or electronic systems. Since these systems transform solar energy to electricity in a fire event the issue of shutting the cells down arises, as firefighters cannot spray water onto the cells because current will be conducted and the fuse box tend to be in another location. However, from a sustainable perspective PV does not use any power and is non-problematic. Nevertheless, there is confusion between fire ignition and fire spread. Photovoltaic cells and other systems of power generating equipment are classified as fire causing systems. Conversely, internal cladding materials are classified as fire spreading method. Polymeric insulation materials are very flammable and produce greater toxic gases compared to other thermal insulations or wool which burns very slowly and is hard to ignite. Another thermal insulation system used is sandwich panels which have high thermal performance, but the core of the panels contain combustible foam. This issue also arise for wall cavity systems; as a result fire is spread and in some cases fire resistant materials are not used. Also, the use of combustible recycled and non-traditional materials such as rubber and straw bale that are considered flammable and release toxic gas into the atmosphere when burnt. Moreover, whether natural or mechanical ventilation is used smoke spreads if the ventilation system is not designed and integrated properly (Shipp, 2007).

Although the above paragraph outlines fire ignition and spread due to the use of green system, there are other aspects that causes fire ignition and spread that are found in green and conventional buildings. Human Resources and Skills Development Canada (HRSDC) mention on their website that the most common causes of fire in building are:

- Short or overloaded circuits.

- Lighting.

- Combustible materials are accumulated by an ignition source (HRSDC, 2011). 


\section{Chapter One: Introduction}

\subsection{Research aim}

The aim of this research is to investigate whether sustainable or green features have an influence on fire safety in commercial buildings and determine which feature or features would have the most significant implications for building safety in regards of tenability.

\subsubsection{Research objectives}

a) Identify green features that impact on fire safety.

b) Identify parameters that affect smoke spread.

c) Identify scenarios for features to simulate using Fire Dynamics Simulator (FDS).

d) Evaluate the scenarios to determine which is the best and worst scenario compared to the NZBC requirements. 


\section{Chapter Two: Literature Review}

\subsection{Literature Review}

The literature reviews focuses on the green features that are used in green buildings. The focus in particular relates to the effect of such features on fire safety, plus it provides mitigation measures to some of the green features. Also, it reviews other work that uses FDS and validations of the software to establish ideas to configure this research.

\subsection{Sustainable/Green Features}

\subsubsection{Atria}

Atrium is a term that used to be used in the Roman era which meant interior court. Now, it is known as a multi-story building that connects two or more floors. The International Building Code (IBC) defines it similarly but a mall is not included. There are different atria types such as open atria, partially open, and closed. Atria have many advantages that include making a connection between the interior and exterior through open views which increases day light. Also, it is associated with energy efficiency, and increasing people health and productivity. Further, it creates a relationship between floors through the open layout. Atria design is being incorporated in many buildings especially green buildings, as they achieve many of the categories goals for energy efficiency and IEQ. However, atrium configurations are detrimental in terms of responding to fire and smoke management. Thus, it should be a fundamental part of design (Gritch, 2010).

Currently, many sustainable building use such design because it has the potential to reduce energy use, artificial lighting, and increase day light and increase occupants comfort through better ventilation and views. However, although it has some advantages, there are also issues that need to be addressed such as fire safety. Due to the fact that atria lack the method of compartmentation fire tend to spread quickly as it consumes the surroundings. The main issue is smoke spread as inhaling toxins can lead to fatalities. Also, smoke limits vision; this is very important as some atria are designed as part of the egress route, which is a very poor design that jeopardise occupants safety (Basting, 1988).

According to Bastings, every building code requires an installation of sprinklers in atriums to control fire spread and in turn reduce the quantity of smoke produced. Further, quick 


\section{Chapter Two: Literature Review}

response head sprinklers are suggested to be installed into atria and the placement should not be at the roof. This is because it would take more time for the sprinklers to respond and high sprinklers from the source of fire tend to be less effective. However, locating sprinklers above a certain floor is effective only to the floor below it. Further, it is not practical to have sprinklers at every floor level due to cost and aesthetic. Therefore, sprinklers are placed on the side of the atrium to spray water on the walls and windows to prevent fire spread (Basting, 1988).

When a fire starts at a floor, exhausting the smoke is vital, while the rest of the floors must be pressurised to prevent smoke from spreading to adjacent floors. Natural vents on the ceiling must be installed to extract the smoke. A further preference is a mechanical smoke extraction system; however, the fans must be capable of withstanding intense heat of gases and smoke. In reality, there are not many reports thus far about fires in atrium buildings nor there are validations regarding the requirements in the building code or standards that are met to considered a building safe (Basting, 1988).

A study conducted by Qin et al to determine smoke movement in atria using FDS showed that natural smoke exhaust vents are best located on the ceiling of the atrium, but does not mention locations of inlet air. Also, high windows on the sidewalls decrease smoke descent. Further, the locations of fire were examined and the result shows that a fire at the corner of an atrium has slower smoke descending process (Qin et al, 2009).

Geometry is one of many fundamentals of atria which include shapes, and complexity of design which are associated with natural lighting, and exterior envelope. Control over natural lighting is required as it dictates the structural strength of the exterior envelope. Further, openings are required for ventilation and smoke extraction where necessary such as top and bottom of the atrium and exit ways for occupants. Control over these factors will lessen drafts caused by the stack effect in the atrium (Gritch, 2010).

Landscape and building orientation are considered as the fundamentals of atria; as such aspects affect fire protection through the difficult of extinguishing fires by fire fighters. An 


\section{Chapter Two: Literature Review}

example is it is easier to extinguish fire on a flat landscape than on a hill or if the building stands by itself or surrounded by other buildings. Thermal comfort is another issue in atria for green buildings due to individual comfort control that impacts on smoke spread, as regional variations exists in the building which cause drafts and increase the stack effect, which would help in smoke spread around the building. Moreover, designing the HVAC system depends on the smoke management plan which is required to meet the smoke management requirements. Accordingly the potential to use the smoke management system can be considered for thermal comfort purposes. Still, smoke management systems should not be jeopardised and compromised to be used as a thermal comfort system. Pressurisation and air balance in atria is very significant for smoke control. Due to the fact that an atrium is open to other floors, a lack of pressurisation occurs in the building which causes the smoke to spread easily through floors. Thus, there must be a thermal stratification to allow the smoke management system to be able to draw smoke. This is done through maintaining pressure relationships between floors and atrium, exterior and atrium which is done through enhanced and upsized atrium equipments such as a HVAC system or inlet and air exhaust vents sizes. The main issue that arises from having an atrium in a building is fire protection and smoke control concerns. This is because it is difficult to design for life safety as it involves more than emergency exit provision. One of the requirements in the IBC and The Life Safety Code are a boundary layer to contain smoke in the atrium, and an AFS with smoke control system is to be installed. Also, it states that the atrium shall be separated from other areas by a fire rated barrier of 1 hour and if glass is used as separation, sprinklers are to be used to wet the entire glazing area. Every building involves three essential elements 'means of escape, smoke control, and fire control. These elements should be incorporated into the initial design stages along with provisions for fire fighting. The majority of deaths in a building fire are caused by smoke; due to this early smoke detection is required. However, it is difficult for smoke or heat detectors to detect heat or smoke in an atrium because it would require time for the smoke or heat to reach the ceiling. In some cases the height would affect the smoke by cooling it down which will make it sink back to lower floors. One solution to this issue is installing beam smoke detector, however it would require proper placement to enable it to detect smoke and heat earlier and be able to be maintain it easier. In atria, temperature must be controlled to forbid 


\section{Chapter Two: Literature Review}

drafts and energy efficiency should be considered but it should not compromise fire protection and smoke control (Gritch, 2010).

Smoke management strategies for Atria

1. smoke filling

This is used for large volume spaces that are capable of storing large quantity of smoke for a period that ranges between 10-30 minutes until the building is evacuated. The space must be able to store the smoke without it reaching a height that any occupant can inhale while evacuating. Thus, a volume above the highest floor is required to act as a reservoir for the smoke to accumulate at.

2. Mechanical exhaust

This method is used when smoke is lower than the desirable height. Therefore, the fan starts and exhausts the smoke out. Also, the position of the fan and exterior wind would significantly affect the effectiveness of the fan. The best position to place the fan is on the ceiling in the centre.

\section{Gravity vent}

Natural vents relay on the buoyancy force for extracting smoke at the top of the atrium. The rate of ventilation depends on the temperature of the smoke and the exterior temperature. Also, the size of vent and weather conditions would affect the rate of exhaustion. Furthermore, in some cases of air-conditioned atria, the smoke temperature may less be than the exterior. In this case the vent will draw air from the outside to the inside which will aggravate the smoke hazard (Meroney et al, 2004). 


\section{Chapter Two: Literature Review}

\subsubsection{Double Skin Facade (DSF)}

DSF is defined as "a pair of glass skins separated by an air corridor (also called cavity or intermediate space) ranging in width from $20 \mathrm{~cm}$ to several meters. The glass skins may stretch over an entire structure or a portion of it. The main layer of glass, usually insulating, serves as part of a conventional structural wall or a curtain wall, while the additional layer, usually single glazing, is placed either in front of or behind the main glazing. The layers make the air space between them work to the building's advantage primarily as insulation against temperature extremes and sound." (Uuttu, 2001, p25).

A full-scale experiment was done by Chow et al, to find the effect of fire on DSF. It was found that cracks had appeared on the single glazing when the extensive heat had reached the glass. Further, under extensive heat the windows broke which jeopardises public safety. The cavity is a very important factor as smoke and fire can travel up or down to other floors. Therefore, buildings with DSF that extends through the entire height of the building are faced with smoke being spread through the entire building due to the linkage of the cavity to the other floors (Fig 1).

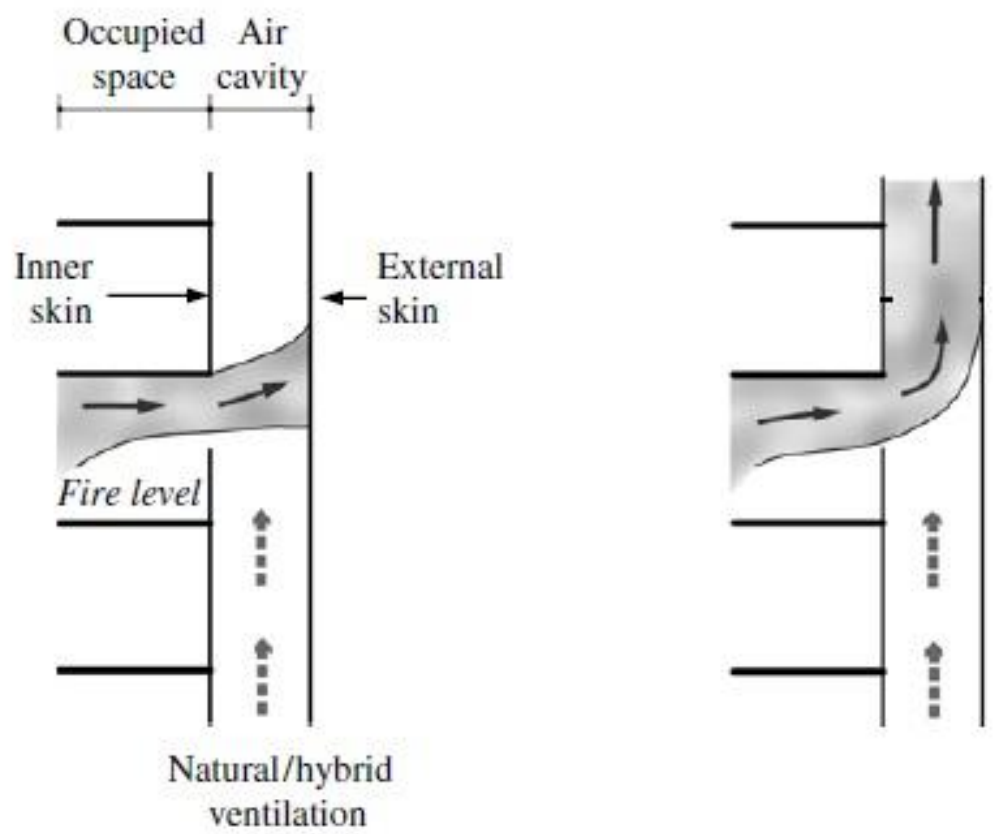

Figure 1: Smoke movement in DSF (Source: Chow et al, 2006). 


\section{Chapter Two: Literature Review}

In regards to the size of the cavity, it was found that the smaller the cavity the more the smoke is impinged on the external skin. The severity of smoke spread through the cavity is due to the stack effect as the temperature difference between the inside and outside is significant. However, the height also plays a role, the higher the cavity the stronger the stack effect. Also, the deeper the cavity the less the insignificance of the stack effect, but the smoke movement will be mainly caused by buoyancy. Thus, the deeper the cavity is the more time the occupants have to egress, but increasing the depth means the rentable area is less which is undesirable for the developer. Moreover, using smaller sheets of glass is more desirable, because the difference in temperature between the edge and the centre is not as significant as in large sheets of glass. It was concluded that the use of tempered glass will give more protection and constructing a vertical spandrel of $900 \mathrm{~mm}$ or more under the opening would be very beneficial as it increases the safety of the occupants (Chow et al, 2006).

It was observed in Chow et al experiment that a $2 \mathrm{~m}$ cavity would not affect the adjacent stories; rather smoke was driven towards the exterior layer. However, $1 \mathrm{~m}$ cavity is very risky as smoke and fire had reached the adjacent floors see figure 2 (Chow et al, 2007).

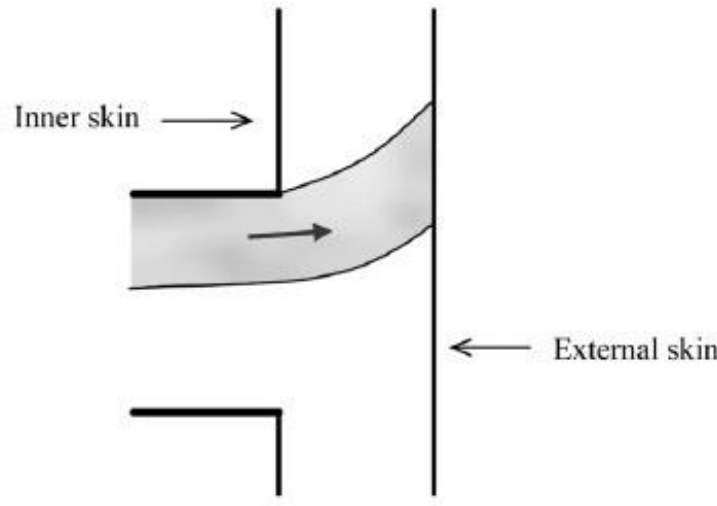

(a) Smoke moves towards outer skin of glass

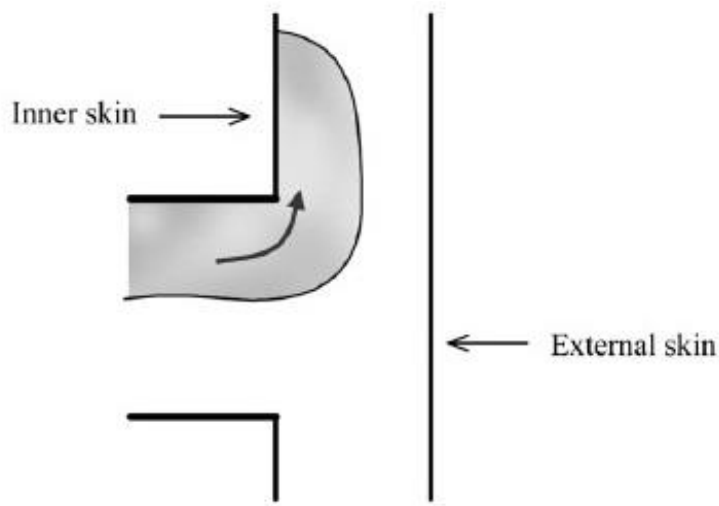

(b) Smoke moves towards inner skin of glass

Figure 2: Smoke movement in DSF initial condition (Source: Chow et al, 2007).

One of the advantages listed for the DSF is 'fire escape'. It is suggested that there is a potential to have a fire escape route through a DSF cavity (Poirazis, 2006). However, many 


\section{Chapter Two: Literature Review}

issues arise in that case as the width of the cavity must meet code requirements for the width and height of the egress route. Also, the issue of pressurisation, fire cells, smoke and fire doors arise, and thus far an issue of cavity filling with smoke and fire leaping to other floors has not been resolved. These issues were mentioned in the disadvantages of DSF which mean that testing needs to be done on DSF to determine whether DSF is useful or not to fire safety. Moreover, there are different kinds of DSF; Poirazis classify DSF in term of the level of risk when used in different designs. Table 1 below illustrates:

\begin{tabular}{|l|l|l|l|l|}
\cline { 2 - 5 } \multicolumn{1}{c|}{} & $\begin{array}{l}\text { Box } \\
\text { Window }\end{array}$ & $\begin{array}{l}\text { Shaft Box } \\
\text { Facade }\end{array}$ & $\begin{array}{l}\text { Corridor } \\
\text { Facade }\end{array}$ & $\begin{array}{l}\text { Multi-Story } \\
\text { Facade }\end{array}$ \\
\hline $\begin{array}{l}\text { Fire } \\
\text { Safety }\end{array}$ & Minor risk & Minor risk & $\begin{array}{l}\text { Moderate } \\
\text { risk }\end{array}$ & High risk \\
\hline
\end{tabular}

Table 1: Fire Safety Design Classification (Source: Poirazis, 2006).

\subsubsection{Insulation and Materials}

Most insulation used is polyurethane or polystyrene foam which are derived from petroleum products. These tend to be untreated and thus when it is exposed to high temperature it ignites quickly and combust vigorously. However, the insulations are closed rigid cell foams which is placed in the cavity between two sheets. Therefore, as long as no fire reaches the foam core the insulation is safe, but it is possible that in the case of fire the entire foam core will be consumed. Open cell foam is softer, but it has the same characteristics of the closed cell as it is manufactured from petroleum as well (Tidwell et al, 2010). Below is a list of insulations that are considered sustainable. It is arranged in order from the least toxic to the most toxic.

- Stone wool (least toxic) is considered non-combustible as approximately $5 \%$ of the material ignites. It is also a natural occurring mineral.

- Glass wool is considered non-combustible as approximately $5 \%$ of the material ignites and it is manufactured from a natural occurring mineral.

- Polystyrene is derived from petroleum which is flammable and emits toxins.

- Phenolic is derived from petroleum which is flammable and emits toxins.

- Polyurethane is derived from petroleum which is flammable and emits toxins. 


\section{Chapter Two: Literature Review}

- Polyisco cyanurate foam (most toxic) is derived from petroleum which is flammable and emits toxins (Stec et al, 2011).

Organic insulation is all non-toxic such as wool, hemp, and wood fibre do not burn easily and can be recycled. Also, the list of insulation above can be recycled as well but some require more embodied energy than others (SIG Insulation, $n, d)$.

\subsubsection{PCM}

Phase changing materials (PCM) are products that been in the market for decades, but it have not been used widely because of various reasons such as cost, life-cycle, aesthetic, and integration. PCM solidify in cold weather to give off heat and melt in hot weather to cool the room. It is associated with IEQ and energy saving. However, the issues stated above create barriers for such materials to be used into buildings as the life-cycle could last up to 20 years. Furthermore, the high cost which makes it less attractive to developers to use PCM (Harland et al, $n, d$ ). One of the issues with PCM is that the materials are highly flammable and some types evaporate in time as it melts and solidifies. Therefore, from a fire safety perspective it is not recommended for such materials to be used in dwellings or commercial applications, as it increases the risk of fire spread and severity. Nevertheless, FABRAL states "Phase Change has an a unique fire suppression element that actually works to help extinguish fire should fire occur in your structure. Phase Change was designed to provide peace of mind." (FABRAL, $n, d, p 5)$. This statement is not entirely true, as there are five types of PCM and the water base helps in fire suppression but the other types are highly flammable.

\subsubsection{Recycled Carpet}

Recycled carpet mainly made from polyethylene terephthalate (PET) or textile fibres. This is seen advantageous by the sustainable industry because minimising the use of virgin material and using recycled products instead would achieve efficient use of resources (NAHB, n, d). However, PET is flammable which serves as fire fuel. On the other hand, wool is a sustainable material and fire safe, but it is not used widely due to cost and resource availability. 


\section{Chapter Two: Literature Review}

\subsubsection{Roof Garden}

A roof garden system is plants and soil that are supported by the roof below and are categorised as follows; extensive, intensive, and simple intensive. There are no incidents such as fire occurring in a green roofs or trees falling down due to wind. In New Zealand green roofs or walls are implemented in some green and conventional buildings. There is still a potential risk when it comes to implementing green roofs or walls especially in Wellington due to extreme winds from Northern and Southern directions. Although there are benefits in using such systems that include control of storm water runoff, enhancing water quality, reducing sound transmission, reflection, and improving thermal insulation (Miller, 2011). Nevertheless, there is an issue of maintenance, leakage, and the most importantly the structure must be capable of carrying the extra weight under a fire situation. The NZBC requires structure strength to be design typically according to the formula:

\section{$1.2 G+1.5 Q$}

Where: $\quad G$ is the dead load

$Q$ is the live load

However, for a structure under fire the formula becomes:

$G+0.4 Q$

Hence, the load ratio is approximately 0.5 which mean that the structure strength is reduced by half before a collapse is expected. The lower the load ratio the more the structure can resist fire (Spearpoint, 2008). The certification system would not award points for using the vegetation concept; however, other aspects can be achieved this way such as irrigation, storm water runoff and helping in achieving better thermal and acoustical environment.

\subsubsection{Natural Ventilation}

The green buildings rating system has encouraged the use of natural ventilation because it lowers energy consumption and lessens environmental impact. Natural ventilation depends on the pressure difference within the building to create a current of air flow. The difference in pressure depends on the number of openings, and temperature differences. Natural ventilation removes odours, brings in more oxygen and increases thermal comfort however it does not reduce humidity which is an issue for humid climates. The way that natural 


\section{Chapter Two: Literature Review}

ventilation works is wind enters the windward walls and air is exhausted out through the leeward wall and roof. The second is by buoyancy which creates humidity difference through cool towers that allows cool air to enter through windows and hot air exits through the roof (Walker, 2010). However, difference in the pressure of the internal and external environment creates an issue for smoke and fire control. The larger the difference in pressure, the faster the movement of air which is advantageous and disadvantageous. The advantage is smoke and toxins will be removed through the supply of fresh air, but at the later stages of fire, a flashover will occur only in small compartments because too much oxygen is being supplied. Thus, natural ventilation creates a challenge to designers and engineers; as a consequence there are currently no buildings in NZ are fully naturally ventilated including green buildings.

\subsubsection{Skylights and Solar Tubes}

Fire and smoke could be transmitted through the opening of the skylights and solar tubes. This could cause fire in other separated compartments. Further, designers should take this in consideration and install smoke or fire dampers at the penetrated spaces (Tidwell et al, 2010). However, a mitigation measure which is required by the NZBC is to install fire stoppage at penetrations.

\subsubsection{Water Conservation/Harvesting}

Water Harvesting System is not usually a significant issue but in some cases underground caverns exists and these are used for fire water supply and in some events the caverns may collapse if excessive load is added, which disables the supply of water. The placement of water tanks on the top floor for rainwater harvesting will result in over straining the structure in a fire event if the extra load is not accounted for. Grey water re-use is unhygienic and could cause serious problems to fire-fighters, as water collection systems uses reclaimed water for fire suppression which contains sediment that may blocks water pipes (Tidwell et al, 2010). Further, if the reclaimed water is untreated it could contain bacteria that can be harmful to the fire-fighters. Another disadvantage is that sprinkler pipes could corrode due to microbiologically influenced corrosion (MIC). This will reduce the life of 


\section{Chapter Two: Literature Review}

the pipes and reduce the effectiveness of the sprinklers due to poor water quality (Mahlman, 2007).

\subsubsection{Photovoltaic (PV) Solar Power Systems}

One of the most common technologies used to generate on site power is PV cells. Photovoltaic is a technology that has been around for 40 years, it converts solar radiation to electrical energy. The advantages of PV include significant cost savings in electricity consumption as it can meet the peak demand of the building (FEMP, 2011). It also increases the value of the property and it could achieve more points in the scoring systems of the green building ratings. Further, there is a growing demand around the world to incorporate and use PV cells according to Strong (2011) because it reduces energy use significantly. PV cells can also be used as building skin to save material and it is aesthetically pleasing. However, PV presents potential fire hazards including:

- Short circuit electrical fires.

- Heat build-up in dead air space (Moskowitz et al, 1983).

- Panels do not shut-off automatically.

- PV covers most of the roof allowing little ventilation, extraction of smoke, and increase the dead weight of the building.

- In case of a fire at the PV array, chemicals will leak through the panels which cause a more intense fire, creating more hazards for the fire-fighters (Tidwell et al, 2010).

In California 2009, two fires broke at a roof of a store that had installed PV cells. After an investigation by an electrician to determine the problem, the two fires were caused due to two issues:

1. PV cells wiring and connections were not installed properly and were loose which caused the first fire.

2. There was not enough ventilation to cool the PV cells which got too hot and melted the insulation then it burnt which caused the second fire. 


\section{Chapter Two: Literature Review}

Further, when the fire service was called, the fire-fighters had an issue with turning the system off as they did not know where the fuse box was until an electrician was called and had to pull out 70 individual fuses. Then the fire-fighters could suppress the fire (Jackson, 2009).

\subsubsection{Wind Turbine Power Systems}

Many years ago people had harnessed wind energy and made different uses of it. Currently, wind turbines have been used on buildings roofs to supply electricity. However, there are issues with such technology for example weight, noise, torque and vibration (Aldrich, 2011). There are many shapes and designs of wind turbines; the most common used for buildings is the helical side mounted turbine. Helical turbines have many advantages including cost benefits, robustness, and high energy output. Nonetheless, the disadvantage of small vertical-axis machine is it would require mechanical start-up. Furthermore, depending on the size it would need substantial support. Proper integration of wind turbines is crucial in buildings, as it may not do what is expected. There are many factors that affect its performance such as the site, height of the building, and the type of turbine (Smith, 2007). The main issue that is associated with fire safety is that it has an automatic braking system that slows the spinning of the blade, but a manual shut-off is not incorporated. This creates an issue for fire-fighters when it comes to suppressing the fire (Tidwell et al, 2010). The issues arise are caused by the generation of electricity if the automatic brakes fail to shut off.

\subsubsection{Hydrogen Fuel Cell Power Systems}

Fuel cells generate electricity through the discharging of water electrolysis to oxygen and hydrogen. Fuel cell works similarly to batteries but it does not charge or run down, instead it stores hydrogen. One of the main advantages is that it can generate enough electricity (depending on its size) to power plant rooms. In a sustainability view, it has zero emission because its main by-products are heat and water. Further advantages include no noise when operating, efficiency, savings in cost and very high quality (DOC, 2011). Fuel cells are combination of heat and power system that is very efficient and environmentally friendly. 


\section{Chapter Two: Literature Review}

The high efficiency comes from the re-use of the waste heat as it can be utilised in buildings (NAHB, n,d). Hydrogen fuel cells are supplied with their fuel in two ways:

1. Stored hydrogen on site in liquid or gaseous form

2. Transporting natural gas on site

Storing hydrogen or natural gas onsite is an issue because it is highly flammable and in the event of a fire it ignites quickly and may explode. This poses two issues; the first is extreme fire spread and fire-fighters must deal with such situations with caution as it is extremely dangerous (Tidwell et al, 2010).

\subsubsection{Battery Storage System}

This system is used when the power is cut off in a disaster or any catastrophic event. It is powered through fossil fuel or is battery based. Depending on its size and battery storage capacity or fuel tank the output power and time of providing power is specified. The advantages of a battery based system are that it is noise free and has little emissions, but the battery runs down eventually. However, fossil fuel keeps running as long as fuel such as coal, petrol, gas etc is provided, but the down side is it is noisy and produces $\mathrm{CO}_{2}$ and other gases which harm the environment (NAHB, n,d). Other issues that involves fire-fighting are:

\section{Shock Hazard}

2. Hazardous materials exposure as batteries contains corrosive acid

3. Combustible metal, the use of rare earth metals and other materials that react with water violently (Tidwell et al, 2010).

\subsubsection{HVAC Systems}

Ventilation is a significant part of design, as it could increase safety or increase the threat of smoke spread in a building. Ventilation systems with modest flow rate increase the chance of survival as it pressurises the floor and thus prevents smoke from entering in between the gaps in the building such as elevator shafts. However, the exterior skin and elevator shafts need to be air-tight, as it affects floor pressurisation (Black, 2009). HVAC is an important 


\section{Chapter Two: Literature Review}

aspect in the green scoring system because it uses a vast amount of energy and the use of Ozone Depleting Potential (ODP) and Global Warming Potential (GWP) refrigerants. There are many HVAC systems that include constant Air Volume system (CAV) which provides constant quantity of air but with varying temperatures. The system is inefficient when used for more than one zone because it would need to reheat the air which increases energy consumption. However, dead air pockets are reduced and the space temperature is controlled due to the reheating. Further, the issue of reheating would be resolved if controls were installed at the cooling coil to keep air warm, or using a bypass which allows the system to act as a VAV with a constant air rate. Variable Air Volume system (VAV) provides variable air rate and it is more efficient than CAV. Nevertheless, it does not meet occupants comfort zone if the air rate is low. In this case, low-flow air diffusers are used to mix the supplied air with the room air. To further increase and improve air distribution in a VAV, fans are installed to reduce stress on the central fan and provide the same advantages of a CAV (Graham, 2009).

HVAC systems contribute to smoke circulation around the building, therefore it is important that systems needs to be designed to prevent smoke spread. Central plants such as VAV systems, consist of a vertical duct that goes through all floors to provide air and a return duct that is mixed with outdoor air and ducted back again through the building. The plant room is located at the top floor, basement or distributed around the building. Due to the fact all ducts are linked and air is supplied from the main fan, in the case of a fire smoke is sucked through the return duct and gets pumped to other floors. For central plants smoke spreads through the entire building because the vertical main duck provides and circulates air from the affected floors to unaffected floors. However, if a floor by floor HVAC system is used such as CAV systems, smoke only circulates within the affected floor. Chilled beams system is local air conditioning. Chilled beams are exposed and mounted on ceilings, pipes of cooled water passes through the beam and cools the air around it which causes air to sink down. This system does not assist in smoke circulation around the floor or building, because the convection current created does not push air around creating drafts. For each system mentioned there are attachments that increase air flow on the floor, for example a VAV system with a secondary fan at each floor to provide constant air rate. As a result, careful 


\section{Chapter Two: Literature Review}

analysis is required when it comes to designing HVAC systems as they are an ideal path for smoke spread through the building (Spearpoint, 2008). The VAV system is used widely and it has been in the market for a long period. Hence, there is a conventional VAV and the efficient VAV. There are many differences between the systems such as, the efficient VAV has $\mathrm{CO}_{2}$ sensors and cooling towers. The sensors control the quantity of air pump according to the amount of $\mathrm{CO}_{2}$ that it detects, in event of a fire the system will keep supplying air until the fire alarm go off and sends a signal to shut of the system. Cooling towers add extra dead load to the roof and it could be an issue if the extra weight is not accounted for.

Under floor air distribution systems are commonly used as a feature in green buildings by taking advantage of the area under the floor to be used as plenum and the ceiling area is used as return air plenum. However, the issue with fire safety is that electrical and data cables are used in the under floor area which leads to an increase in fire hazard. Therefore, authorities suggest installing smoke detectors under the floor, but regular maintenance would be required (Mahlman, 2007).

\subsubsection{High Volume/Low Speed (HVLS) Fan}

The fan can obstruct sprinkler spray and increase the spread of fire by providing more airflow. The National Fire Protection Research Foundation has tested the impact of the fans on sprinkler performance and fire spread. The conclusion was that the sprinklers performance was considered acceptable, but there was an impact on the performance. Also, in an unsprinklered area the fan increase fire spread (Tidwell et al, 2010).

\subsubsection{Low-E Coating and Fire Safety}

Temperature exchange between the interior and exterior has a significant impact on energy efficiency and fire safety. However, fire safety is not the main focus of the owners; their main focus is durability, aesthetic, energy efficiency and low cost (Berdahl, 1995). Further, after the green movement energy efficiency of the base building has become a priority to owners, because the assessment tool awards points for low base building energy use and buildings with green stars have higher values. There is also a relationship between energy efficiency and fire safety, the use of low-E coating has been considered to increase energy 


\section{Chapter Two: Literature Review}

efficiency and fire safety. According to a study done by Berdahl, Low-E coating can exhibit fire safety. A coating inside a double glazing provides resistance against fire by absorbing more heat than a non-coated surface. Therefore, it has more time until it breaks. Conversely, Berdahl then states that this is a theoretic hypothesis and no test has been done to confirm that statement. Also, other paints and coatings that are infrared reflective which are applied on timber, plastic and other vulnerable materials reduce the chance of ignition and fire spread.

\subsection{Miscellaneous Issues}

There are issues concerning alarm discrimination and false alarms. There are types of alarms that are more sensitive than others, therefore, issues such as noise and indoor environment could cause a nuisance. Also, a loud pitch causes vibration in the alarm which causes it to go off and an internal air quality could also trigger alarm due to odour, humidity and temperature (Milke, 1999). Thus, reducing noise and maintaining a comfortable indoor environment would be beneficial to reduce false alarms. Further, maintaining a good indoor environment would raise issues due to the use of mechanical or natural ventilation which increase the risk of smoke spread if not designed properly. Moreover, another issue with discrimination is the sound of the alarm, there is no set standard to specify or suggest the sound of the alarm. As a result, in some buildings when the alarm goes off occupants do not recognise it is an alarm.

Green building uses materials that are considered natural or renewable. These include lightweight structures, maximising natural lighting and passive solar heating through glazing, and the use of polymer composites for bridge and pier structural systems (Krause et al, 2012). These are issues that impact on fire safety as light structures collapse in fire quickly and increasing passive and active ventilation would help in smoke and fire spread. There are many fire safety issues including:

1. Flammability of materials. This includes fire spread rate and ignition.

2. The release of toxics from the products during combustion.

3. Automatic suppression approaches. 


\section{Chapter Two: Literature Review}

4. Resistance to fire. This means the ability of the structure to withstand fire situations.

5. Strategies of fire suppression. This includes fire fighting and awareness of onsite hazards (Krause et al, 2012).

6. Site access, type of building, orientation of building and landscape contributes to fire safety (Tidwell et al, 2010).

\subsection{Fire Dynamic Simulation (FDS)}

There is a lot of controversy about the accuracy of FDS, but the results were validated with experimental data and the outcomes were similar (Qin et al, 2009). Also, a comparative study done by Hao-wei et al, between field experiment and FDS regarding smoke control in atriums. It was concluded that FDS is feasible for large spaces, but the authors noted at the introduction of the article that simplifications and assumptions were required in the modelling. Still, the results of the experiment were similar to FDS, which validates FDS output results. Further a full-scale smoke control analysis was done in FDS but not a field experiment. This is because it is cost effective to model using computer software simulation than building a full-scale size atrium. Nevertheless, the results from the FDS were similar with experiments, but FDS would still need to be validated against actual experiments that are same size as the field experiment. (Gritch, 2010).

Shen et al had reconstructed an arson fire scene in Tiwan using FDS to assist with in the investigation to determine the cause of the fire, plus fire and smoke spread and propagation. The authors simulated the hotel to enable accurate conclusions. Through the simulation two models were constructed with different mesh size, the first was $15 \mathrm{~cm}$ and the second $10 \mathrm{~cm}$. It was found that the temperature reading had differed significantly as the first model indicated $670 \mathrm{C}$ and the second 1020C. Accordingly, the choice of the mesh size was $10 \mathrm{~cm}$ because it was close to the measurements that were taken at the scene. Further, it was concluded that FDS prediction of fire growth and smoke spread were similar to the investigation findings (Shen et al, 2008).

Pope and Bailey had compared FDS with post-flashover compartment data. Their research had illustrated that FDS and other fire modelling software have been validated using full 


\section{Chapter Two: Literature Review}

scale fires. However, their accuracy is only for small compartments; hence, little validation had been completed for large compartments because of the cost associated with carrying out such experiments (Pope and Bailey, 2006).

Many experiments were done to validate FDS results and it was concluded that FDS predictions are reliable. However, there are some aspects that the software over or under predicts such as plumes and near fire source readings. Nonetheless, FDS demonstrated that it is capable of predicting smoke movement and fire development in high rise buildings (Bystrom et al, 2012).

Hu et al simulated smoke spread and carbon monoxide transportation and compared it to measured data. The findings were that smoke spread results were consistent with the measured data, but the CO predictions in FDS were lower than the measured data. Also, CO increases as it obtains leverage but decreases as it is furthers from the location of fire (Hu et al, 2007).

\subsection{Importance of Fire Safety in Sustainable/Green Buildings}

In Europe, installing automatic fire sprinklers has reduced the severity of fire by a factor of 4 to 5 according to FM Global. However, if no fire risk management is integrated the impact of fire in a sustainable commercial building is worse than a conventional building. If no consideration of fire risk is present in a green building, in the case of a fire the nonsustainable building would perform better than the green building. Also, improvements to further increase energy efficiency would have a potential to increase fire risk. FM Global Concludes that risk management should be an integral part in sustainability, as it can reduce environmental impact levels (Gritzo et al, 2009).

A study done by FM Global to determine whether AFS has an impact on the environment; the finding was that AFS does have an impact on the environment by increasing the carbon emissions lifecycle of the building. This is mainly due to the manufacture of steel and the embodied energy. However, in fire situations the formula changes, this is because when a building burns an excessive amount of carbon and other greenhouse gases are emitted. The 


\section{Chapter Two: Literature Review}

damage to the structure and the cost of reconstruction will be incorporated as well as the replacement of materials and disposal of waste which also contributes to embodied energy. The study compares sprinklered and non-sprinklered residential dwellings in a fire situation to quantify the amount of carbon and greenhouse gases emitted. Although, the tests are for residential setting, it would apply to other settings as well, but the severity level could differ. It was found that AFS reduced the energy generated by fire by a factor of 76 and the materials that were consumed was $3 \%$, while in the non-sprinklered test the material that were consumed range from $62 \%-95 \%$. Flashover did not occur in the sprinklered test, thus the total air emissions generated in the sprinklered test were significantly lower than the non-sprinklered test. Also, 50\% less water was used to suppress the fire in the sprinklered dwelling compared to non-sprinklered dwelling. Furthermore, the waste generated from both dwellings is considered hazardous. It was concluded that AFS would be a main factor to achieve sustainability (Wieczorek et al, 2010). Thus, fire safety is part of sustainability and the importance of integrating fire protection would reduce the impact on the environment as:

- Fires are significant contributors to greenhouse gases, $\mathrm{CO}_{2}$ emission and other pollutants to earth's atmosphere.

- Millions of litres of water are polluted due to fire extinguishing and treatments.

- Green features that generate energy onsite increase the risk of fires.

- Fire mitigation techniques and risk management can decrease the impact of fire on the environment (Tidwell et al, 2010).

\subsection{Literature Review Conclusion}

In summary, currently there are many green features that exist and some are used widely, while others are not. It is clear from the literature that an extensive amount of research and testing has gone into atria. This is because atria are an older feature and engineers have seen there is an issue with atria concerning fire and smoke spread. Other features such as double skin facade have not been covered very well by the literature, as it is a newer feature. Further, there are potential issues with DSF such as smoke spread. Also, there is little research that has gone into testing and establishing the affect of DSF on fire safety. On 


\section{Chapter Two: Literature Review}

the other hand, technologies such as solar and wind power generation are not being seen as an issue until the fire starts, for example the issue of the store in California with PV cells on the roof. The issue with technology is that there are often no potential issues seen until a situation occurs. It is similar to the leaky buildings in New Zealand. Although, the buildings had met the Building Code there was still an issue with the design. Hence, PV cells, wind turbines and other technologies of power or heat generating, the main issue is in regard to integration and connections. Moreover, the issue of fire suppression for such systems becomes an issue as it is a source that generates electricity and water is a conductive substance. Thus, electricity and water would worsen the situation; as a result fire-fighters need to be familiar with green building concepts and issues. This research is not criticising green building features but it raises the awareness of the public when it comes to choosing materials and design features to understand their impacts and how to deal with such features in a fire event. In addition, it guides fire-fighters to further understand the issues and the consequences to deal with such technologies when they are on fire. This is done because the public is moving towards sustainability without understand the other side of the story, as the public perceive that if a building meets the Building Code no issues would arise. While in reality the Building Code is the minimum requirement that must be met by building owners. 


\section{Chapter Three: Phase One Methodology}

\subsection{Phase One Methodology}

\subsection{Building Selection}

The hypothesis is to determine whether the use of green features increases fire risk. The literature provides broad issues concerning sustainability and fire safety. However, the theory is that there is potential for green features to have either positive or negative impact on fire safety. A set of requirements are required to distinguish between green and conventional features, but to avoid arguments about whether a feature is green or not, green building were used and identified through the certification of the NZGBC which are published onto their website, then the buildings were analysed to determine the green features. The type of the buildings assessed is commercial office buildings. One of the reasons these buildings hold the largest number of people during the day compared to other types of buildings such as residential, educational or industrial and in a case of a fire it is difficult to locate egress routes due to the lack of familiarity with the building (Chow, 2001). The certification process started in 2007; however, the green movement began in the 1990's. Therefore, there are buildings that have been built with green features but are not certified due to two reasons. The first is the certification tool did not exist in NZ at the time and the second is the owners did not want to pay the extra cost of certification. An example is Victoria University of Wellington: School of Architecture and Design has used atrium, light sensors and natural ventilation to reduce energy consumption. Also, there are many other buildings that have used similar features for that matter, but no certification was done to highlight the building as green or hold a number of green stars. Since, there are many buildings that have green features, it would be very difficult to survey the features used as there are currently no published articles about such buildings. Hence, only the certified buildings were chosen for assessment. There are around 54 certified green buildings and only 50 were possible to be surveyed because the information is publically available. According to Statistics NZ between 2007-2011 4,285 building consents were issued to office and administration buildings. This number includes consent for alterations and refurbishments, because some of these buildings were designed with green intentions. The first building that received a green rating was in 2007, therefore, the number of years investigated is between 2007-2011. As a result, currently green office and administration buildings occupy $1.2 \%$ of the total number of building consents issued in New Zealand. To 


\section{Chapter Three: Phase One Methodology}

determine the common features, the aspect of the building parameters and features are considered.

\subsection{Building Parameters}

To evaluate fire safety in buildings 12 parameters are required to be assessed that are derived from the American Fire Safety Evaluation System. Assessment includes construction, separation of hazards, vertical openings, fire detection and suppression systems (sprinklers, fire alarm, heat and smoke detectors), interior finishes, smoke management system, escape routes and access, compartmentation, and emergency programs for occupants (Chow, 2001). The 12 parameters above assess the entire building fire safety but in this project the impact of the green features on buildings are investigated only.

\subsubsection{Building Height}

Building height effects the pressure through the entire building; the taller the building the more smoke that is spread across the floors. The height of building impacts on the stack effect, the greater the height the greater the stack effect (Black, 2009). Further, the smoke buoyancy is effected as well because the higher the building the more time is required for the smoke to rise to upper floors. As a result, in some cases the smoke temperature cools down and sinks down again plus it would cause greater difficulty in the extraction of the smoke through the roof (Chow \& Steemers, $n, d^{1}$ ). Therefore, smoke behaviour in high buildings differs.

\subsubsection{Building Interior Finishes}

According to Sartori and Hestnes, green refers to materials not building performance. To reduce emission and increase IEQ, more attention to materials is required. The literature review covered the issues of green materials. Most of the sustainable, recycled and recyclable materials are more flammable than conventional materials, because they are derived from petroleum and other flammable sources. However, some materials such as glass fibres, wool and water based paints are less flammable than the conventional materials used such as polyester and enamel paints. Nonetheless, water based paints are

\footnotetext{
${ }^{1} \mathrm{n}, \mathrm{d}$ means that the article is not dated.
} 


\section{Chapter Three: Phase One Methodology}

now more common, mainly due to shorter recoating time. Therefore, interior materials are not considered as a feature but a contributor to fire and smoke spread.

\subsubsection{Building Features}

Features are the most important to be surveyed, also, the focus of this research is in regard to the impacts of sustainable features on fire safety. Further, the features chosen reflect on the brief which is established to convey the owner or developer interest for example cost saving. However, some buildings are tenant driven; in this case their aim is to increase productivity of occupants through comfort and healthy indoor air quality. Thus, many aspects come into play when building green buildings as the owner and tenant expectations from green buildings in term of aesthetic, IEQ and efficiency differ. This is where the issues of fire safety or safety in general arise. There are features and technologies used that increase or decrease building safety such as using a VAV system with central fan; this would decrease fire safety as it circulates smoke around the building, while chilled beams do not.

\subsection{Common Features:}

50 commercial NZ green rated buildings were surveyed in terms of features used. The results are shown in table 2 below:

Table 2: : Common Green Features in Commercial Buildings.

\begin{tabular}{|l|l|l|}
\hline \multicolumn{3}{|l|}{ Number of Features Used into Green Buildings } \\
\hline Building Features & Total & Percentage \\
\hline Atrium & 19 & $38 \%$ \\
\hline Double Skin Facade & 7 & $14 \%$ \\
\hline Sustainable Materials & 50 & $100 \%$ \\
\hline Recyclable Materials & 50 & $100 \%$ \\
\hline Storage Area & 4 & $8 \%$ \\
\hline $\begin{array}{l}\text { Mechanical Hentilation } \\
\text { System }\end{array}$ & 20 & $40 \%$ \\
\hline $\begin{array}{l}\text { Rainwater } \\
\text { System }\end{array}$ & 50 & $100 \%$ \\
\hline Green Roof & 6 & $12 \%$ \\
\hline Power Generator & 6 & $12 \%$ \\
\hline
\end{tabular}




\section{Chapter Three: Phase One Methodology}

From the table above it can be seen that green buildings place less costly attentions towards materials rather than low energy use as Sartori and Hestnes (2007) stated. However, to enable a genuine and thorough assessment the fire risk severity level must be present to choose which features would require a further analysis. Nonetheless, if the choice was for the two commonly used features it would be atrium and double skin facade. It can be argued that atrium and DSF are included under the umbrella of passive ventilation. Also, through surveying the 50 green buildings it was found in NZ that in most cases atria run through the entire building except for where the ground floor is used as retail and double skin facade covers at least one elevation with a minimum of 3 levels and a maximum of 18 levels. As a result, these two features are perceived as having the most significant fire risk in terms of smoke spread.

Double skin facade is considered the first priority because there are only two experimental articles published by Chow (2006 \& 2007) that investigate DSF and fire safety. Further, 14\% of NZ green buildings have used this technology/feature. There has not been much research around DSF and fire implications, therefore, it is important to understand how the facade performs in fire and what the extent of it effecting fire safety. Moreover, as mentioned in the literature review some experts have indicated that there is a potential problem with DSF in terms of smoke and fire spread through to upper and lower floors. Still, it is suggested that DSF could be used as an egress route as Poirazis (2006) states. Thus, to establish whether DSF has a significant effect or not is vital. A confirmation from experts is required as this is a theory only and for further analysis FDS is used to determine if there is a risk and understand smoke movement and behaviour within the cavity of the DSF. The aim of FDS analysis is to demonstrate how smoke and fire travels through the cavity and the duration for the glazing to break.

The second priority is atria. Although $38 \%$ of green buildings use this feature, it has lower priority from DSF because there is extensive literature found and research that has been done in regards to atria and fire safety. Further, the NZBC compliance documents have provisions for atria. This means that the issues of atria and fire safety have been investigated more thoroughly. However, in this thesis atria are investigated due to the fact 


\section{Chapter Three: Phase One Methodology}

that most green materials are more flammable and burn severely than conventional materials. Therefore, better fire safety mitigations are required to satisfy the NZBC. It is logical that in a fire green materials that tend to have lower fire resistance will burn more severely and spread fire and smoke quicker. The more practical method to use is to survey fire engineers and identify how to deal with issues such as:

- Smoke build-up and spread into the atrium and adjacent floors.

- Rapid fire spread horizontally and vertically through the atrium.

- Unprotected escape route via the atrium.

- Fire-fighting issues because of the unrestricted nature of the fire and smoke source (Bednar, 1986).

\subsection{Fire Risk Level Index}

Chow and Lui assessed existing karaoke establishments against the fire safety ranking system in Hong Kong. Then it was compared to National Fire Protection Association - Fire Safety Evaluation System (FSES) which is an American system. The assessment was done on three ground; local fire safety requirements, passive building design and active fire protection systems. The establishments were rated on their architectural features and interior finishes. The authors concluded that both safety assessment systems were similar in terms of fire assessment levels except for the fire spread of the interior finishes. (Chow \& Lui, 2002). The parameters of the assessment were the same as the 12 parameters mentioned in section Building Parameters. The assessment for the karaoke establishment is the criteria apply for an entire existing building, while this research concentrates on the green features and technologies only.

Zhao et al, have established a fire safety ranking attribute on the basis of Analytic Hierarchy Process (AHP). Also, ranking of the attributes was established on a previous survey that included experts' judgements (Zhao et al, 2004). Further, the criteria and attributes used could only be implemented to the building as whole. Moreover, Chow investigated the possibility of using the American Fire Safety Evaluation System for business occupancies in Hong Kong and had compared it to the same criteria Zhao used. The conclusion Chow 


\section{Chapter Three: Phase One Methodology}

reached was that Hong Kong and American systems of fire safety evaluation are similar, apart from the interior finishes (Chow, 2001).

Watt and Kaplan used Building Officials and Code Administrators International (BOCA) and FSES to derive a checklist of parameters that evaluates the fire risk level for heritage buildings. The authors used a fire risk index which is the same as a scoring system to weigh the parameters derived from the two systems mentioned above. The weighing of the attributes is already given by the evaluation systems. Thus, the authors had extracted the information required to assess the building for their case study and awarded scores to the building according to the features and attributes found in the building based on the ranking established by either BOCA or FSES (Watt \& Kaplan, 2001).

Authors such as Chow, Watts \& Kaplan covered different fire risk criteria and attributes. However, each had a different perception in terms of the fire assessment of different building types and assessment systems. Chow had concentrated on the use of the American Evaluation System and Watt \& Kaplan used BOCA and FSES. Further, all authors based their evaluation and ranking on their own opinions and judgements (Ibrahim et al, 2011). Ibrahim et al had looked into Chow, Watt \& Kaplan, and Zhao et al criteria and attributes. A panel of experts were used to weigh the criteria and the authors analysed the data by AHP and its associated software. It was concluded that a scoring system can be used to assess fire risk in heritage buildings. However, the scoring system should be used for decision making only (Ibrahim et al, 2011).

Chow discusses the Hong Kong government's action in reviewing the fire safety requirements for old high-rise buildings. Thirty seven buildings were surveyed and assessed using the Fire Safety Ranking System (FSRS) and the score was compared to the NFPA-FSES. The government provided funding for such buildings to upgrade their fire safety system as well as their fire safety management. One of the management requirements was that occupants must put their rubbish bins at the staircase for collection every night. However, Chow argues that following such requirements would not enhance safety in a fire event, as there is no evidence that would confirm this. Nonetheless, requirements such as repair fire 


\section{Chapter Three: Phase One Methodology}

doors, and reduce on-site combustible storage would reduce fire risk. The issues for old buildings were the cost of implementing the new fire systems and space constraints. Chow suggests that developing a better fire safety management plan would be more helpful than revising the code. The objective of Chow's research was to determine how far old buildings deviate from new buildings. Chow also discusses prescriptive and performance-based fire codes. Chow states it is easier to implement prescriptive fire codes than performance-based fire codes. This is because prescriptive code provides provisions that prescribe what to install. In other words, prescriptive code provisions would not apply for every type of building, due to the different building use. Also, safety ranking systems that follow the local fire codes, which is done through interviewing professionals is not a scoring system for assessing provisions of fire safety. Therefore, interviews with professionals in this regard are unnecessary. Further, the article outlines the difficulties in implementing performancebased code that would include:

- Defining the fire safety objectives and criteria for different buildings.

- Accuracy of models (Chow, 2002).

The indices above illustrates a comprehensive assessment of the building as a whole, but it references particular aspects such as egress routes, rubbish placement etc that are all derived from the local, international or hybrid building code. Hence, different parts were putted together to enable a comprehensive assessment of a building and to assess a single feature, sections from the NZBC can be used for atria or DSF such as concealed spaces and vertical spread of fire to assess the features.

\subsection{Survey Methodology:}

The first technique to further investigate the features listed in the table 1 is to carry out a series of interviews. Such methods of investigation were chosen due to the fact that there are limited resources around the subject of sustainability and fire safety. Interviews provided preliminary information about the issues concerning green features and their implications for fire safety. Hence, a panel of experts provide a background on the issues that were faced in their experience and provided opinions or suggestions to eliminate, 


\section{Chapter Three: Phase One Methodology}

avoid, and manage risks. Meeting the goal of creating features that are sustainable and fire safe, the result extracted and identified from the experts include:

1. Rating and ranking the fire risk severity level of the features.

2. Identifying criteria for evaluation.

3. Identifying features' issues concerning fire safety.

4. Identifying mitigations to the issues that arise.

5. Identifying evaluation or testing techniques.

This information would assist in a further investigation of the features that are considered high risk. Furthermore, the experts' opinions regarding the issues were investigated to determine whether the fire risk severity level rating, issues, mitigations and their testing are genuine or a perceived risk.

As mentioned above, the method of investigation is interviews. The format of the interviews were in three different formats that include statistical, structural and open discussion format and the interviews ran for $30-60$ minutes (Borden \& Ray, 2006). The discussion was around their opinions of why some features are riskier than others.

The issue of concern is still that there is little literature or information about green features and how they impact on fire safety. Therefore, to collate information about such topic and fill in the gaps in the knowledge a survey provided the best information in terms of risk and mitigation measures. The population that were interviewed were fire engineers as they are considered the best source for knowledge in such topic. Also, 50 NZ green buildings have been looked at to find common features. Issues with using green features would have to be covered in some of these buildings as well as what has been done to reduce or eliminate the risk that was posed by these features. The green features were chosen according to how common they are, which have little or no information about, and which seemed to have a high risk on fire safety. Thus, the green buildings have been reviewed in terms of which features fit the criteria above and a list was developed as shown already in table 1 . Then it was proposed that the method of surveying would be face to face interviews as follow up 


\section{Chapter Three: Phase One Methodology}

questions could be asked. The interview was structured and guided by the interviewer that include a list of the green features identified and categories for the NZBC criteria and the engineers were asked to rate and rank which feature has the highest fire risk (see appendix for the survey and interview questions). Accordingly, questions about suitability of criteria, what the risks are and mitigation measures for these risks were asked. This developed a matrix that guide the interviews and establish results for further testing through software. The matrix defines which features are high risk, why, what the building code occupies, mitigations, and evaluation. These were necessary to define parameters on the next step for a deeper analysis that would show data on the behaviour of the features under fire.

\subsection{Experts Identification}

The experts interviewed are fire engineers, because the issues that arise are in their expertise. Their input is in regard to the issues and mitigations of the hazards they identified. A table of features was given to them to rate and rank according to the NZBC Clause $\mathrm{C} 2-\mathrm{C} 6$. The fire engineers were asked to rate and rank the top five features that are considered as a high risk and questions were asked according to their choice. The question would cover; why the features chosen are high risk? What are the mitigations measures for the risks? And how to test the features, to show compliance with the NZBC?

In order to gain a better understanding of the issues, panel of experts were interviewed. The panel of experts were to identify and confirm the issues from the theory and identify mitigations to satisfy the NZBC. Fire engineers were interviewed regardless of whether they have worked or been involved in green building through consulting or safety design, because of the small number of participants available. Fire engineers that have not been involved would have knowledge regarding the impact of the green features on fire safety. The green features listed in table 1 are found in buildings that are not considered or perceived as green. Therefore, although some fire engineers have not been involved directly in green buildings, they have been exposed to such features and the issues in terms of fire and smoke control and the mitigation measures to overcome the issue to satisfy the NZBC. Also, the engineers had a chance to add more green features that are not listed in 


\section{Chapter Three: Phase One Methodology}

questionnaire. These features are mentioned and discussed briefly due to their relevance to this research.

\subsection{Nature of Research Area}

The research aim is to investigate causes and explanations regarding the issue of green features implications for fire safety. A descriptive research was carried out to find gaps in the knowledge. The experts report about their practices, and to evaluate the implications green features have on fire safety for the purpose of documenting their effect using FDS.

Statistical questioning is not used in this research due to the known number of participants, it was necessary to identify and choose the questions for textual analysis in this case. The first method to investigate the research question and test the hypothesis was the qualitative method. This approach was used to collect narrative data (textual) to study the topic. The analysis of such method is verbal especially when interviews are used as a method of data collection. The interviews were designed in accordance to the Victoria University of Wellington Ethics Approval Committee Guidelines to ensure privacy and protections of rights. The data collection was used to establish a preliminary answer to the major research question, establish ideas on testing the hypothesis, and define the gaps in the knowledge that would require analysis. Primary data was gathered from the surveys and according to the results of the survey another primary data was carried out using FDS to analysis the surveys' results further.

\subsection{Survey Aim}

The aim of the survey is to identify and fill in the gaps in knowledge between the practices of experts and the building code requirements. The output provides answers regarding the concerns of using green features and their impact on fire safety. The survey is intended to determine how experts chose the mitigation measures and what methods are used for assessment. 


\section{Chapter Three: Phase One Methodology}

\subsubsection{Survey Background}

There is little documented expert practice, and information around the risk severity level was not found in the literature; as a result this research could not progress unless it identifies which are the common features and have a high risk. Hence, establishing a survey was necessary to have guidelines on which feature would need to be analysed and tested to evaluate green features.

\subsection{Nature of the Survey}

There are two types of surveys that can be used which are questionnaires and interviews. However, questionnaires do not provide comprehensive information on the five features chosen by the engineers, but interviews do. Further, some of the questions weight more than others, hence, what can be done in an interview is better in terms of quality and quantity than questionnaires. Thus, one on one interviews were conducted after the questionnaire was completed by the same engineers because it was easier for the respondents to express their opinions. Open ended and follow up questions could be asked and more detailed answers were gathered than with questionnaires. Respondents had the ability to ask questions for clarification. However, the disadvantage was that it is a time consuming process; as a result some experts were not willing to participate which would potential effect the results. The survey process was divided to two parts; questionnaires were used to establish a statistical analysis of which features has the most significant risk and prepare fire engineers to the next technique which is one-on-one interviews. Interviews discuss in detail why the feature chosen is considered as the most significant in their opinion.

\subsection{Survey Tactics}

In order to carry out successful surveys, tactics and techniques were required to get quality information from the experts. In this case the experts were questioned in regard to their knowledge of the facts and procedures in the area of their expertise. Unstructured interviews are regarded as the best way to extract information from the experts, because the interviewer tends to question the experts methods for resolving or dealing with issues. However, the issue with unstructured interviews is that the interviewer might go back to information that has been already covered by the experts which might create a 


\section{Chapter Three: Phase One Methodology}

misunderstanding. Nevertheless, to resolve such an issue the interviewer should keep notes about the conversation and not depend on recording, also it would enable the interviewer to go back to the notes and ask more questions (Hoffman, 1987).

Structured interviews are a conceptual alternative to unstructured interviews. To have a structured interview the interviewer must have already analysed data and texts around the topic of discussion, then the interviewer asks the expert a series of question around the issues and the topic to find if there is a correlation between the analysed texts and the expert practices. Interviews can generate a lot of quality information, but the disadvantage is that interviews are time consuming (Hoffman, 1987).

Two methods of questioning were used in the interview; the first is the method of Scenarios. This allowed the experts to analyse cases on previous situations encountered. Such method allowed for documentation of practices of the experts and outline common and uncommon practices. The second was the method of tough cases. This method allowed the expert to refine and provide evidence of their reasoning that is not documented or well known. A tough case is when the experts are presented with unusual features or issues that would require the experts to support their reasoning (Hoffman, 1987). A combination of the interview methods and questioning methods were used to extract information of value to the knowledge base and assist in this research.

\subsection{Interview Process}

The interviews were divided into two parts; the first was questionnaires (refer to appendix) that were sent to the fire engineers which they filled out prior to the interview. The first part was for engineers to rate and rank the features according to their potential severity level. Then the engineers chose the top 5 features that have the most negative implication for fire safety. This part was sent electronically and returned with the answers before the interview started. The second part is dependent on the first part. The second part consisted of 4 questions that cover why the features chosen are high risk, defining performance design objectives and methods to achieve the objectives, mitigation measures to reduce or eliminate risk, and finally identifying worst case scenarios to analyse the features. Each of 


\section{Chapter Three: Phase One Methodology}

the 5 features chosen by the engineers goes through the entire 4 questions to establish parameters and guidelines to a subsequent analysis using FDS. However, not all the 5 features were analysed because some features require different computer software program or experiments.

\subsubsection{Study Population}

According to Nielsen who is considered as one of the pioneers in the field of usability; usability is defined as learnability, efficiency, memorability, errors, and satisfaction of using a method as figure 3 illustrates. Usability of the interviews was evaluated in this research through the method of usability testing. This approach is used for software usability by carrying tasks although the design of the software is not completed (Folmer \& Bosch, 2004). In this research usability testing would require the interviewer to carry out interviews with 3 -5 experts according to Turner et al to test the interview, in other words usability testing is pilot study.

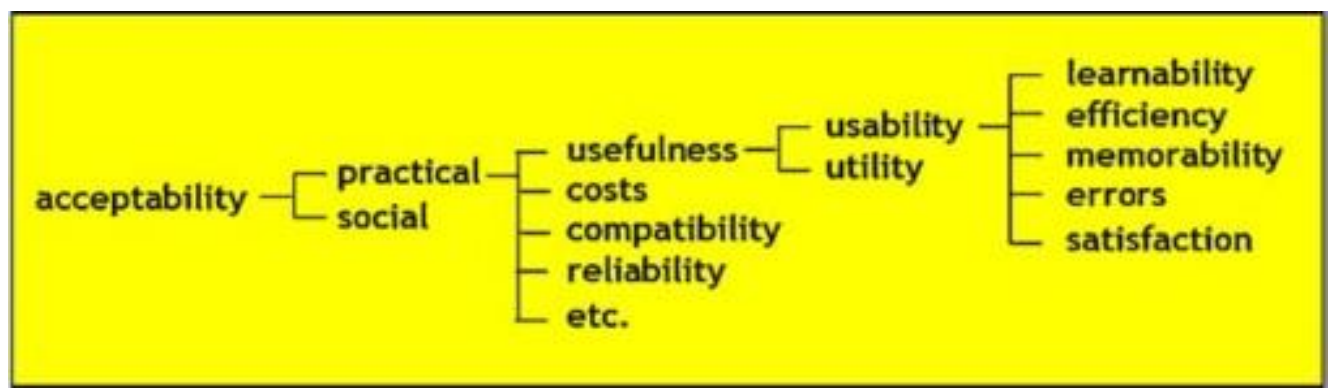

Figure 3: Nielsen definition of usability

(Source: Folmer \& Bosch, 2004).

Further, usability inquiry is also a method of evaluation, Folmer and Bosch describes this method as obtaining information from the users about the system through interviews and observation which are done through evaluators. However, this method is used when the system is completed and running. This method was used to carry out the final interviews as the usability testing method would have already reduced errors, improved and refined the questions asked. The interviewer was the evaluator or assessor in this case and the experts were the interviewees. 


\section{Chapter Three: Phase One Methodology}

There are other usability evaluation methods, however, the chosen method to test and carry out the interviews were considered the most appropriate in this case. This is because the numbers of interviewees are limited due to lack of participants' availability. Nevertheless, according to Turner et al, the first technique (usability test) of evaluation would resolve around $80 \%$ of the issues in the interview if the interviewer is able to test the interview on a population of $3-5$ participants.

Horsky et al discussed methods of system usability evaluation for outpatient clinical documentation software; four methods were employed including interviews. It was found that the methods are useful at different stages of the design, interviews uncovered problems around conceptual and workflow issues and were suggested to be used at the early stages of the analysis. Nielsen's and Schneiderman's heuristics were used and adjusted to suite the clinical software for evaluation plus other heuristics were developed by the authors for a comprehensive assessment (Horsky et al, 2010). Hence, interviews were done at the start of the research in order to determine the risks and mitigation measures.

The topic of choosing a sample size to establish a confidence and a dependent number of participants have puzzled many usability specialists. However, authors such as Virzi, Nielsen, Landaur, and Lewis have published articles that determine usability test sample size through mathematical formula. The four authors have made two claims that are supported by each others' findings:

- Most usability tests requires $3-5$ participants to detect most problems.

- New participants that are given the same test would not necessarily reveal more problems (graph 1 illustrates). 


\section{Chapter Three: Phase One Methodology}

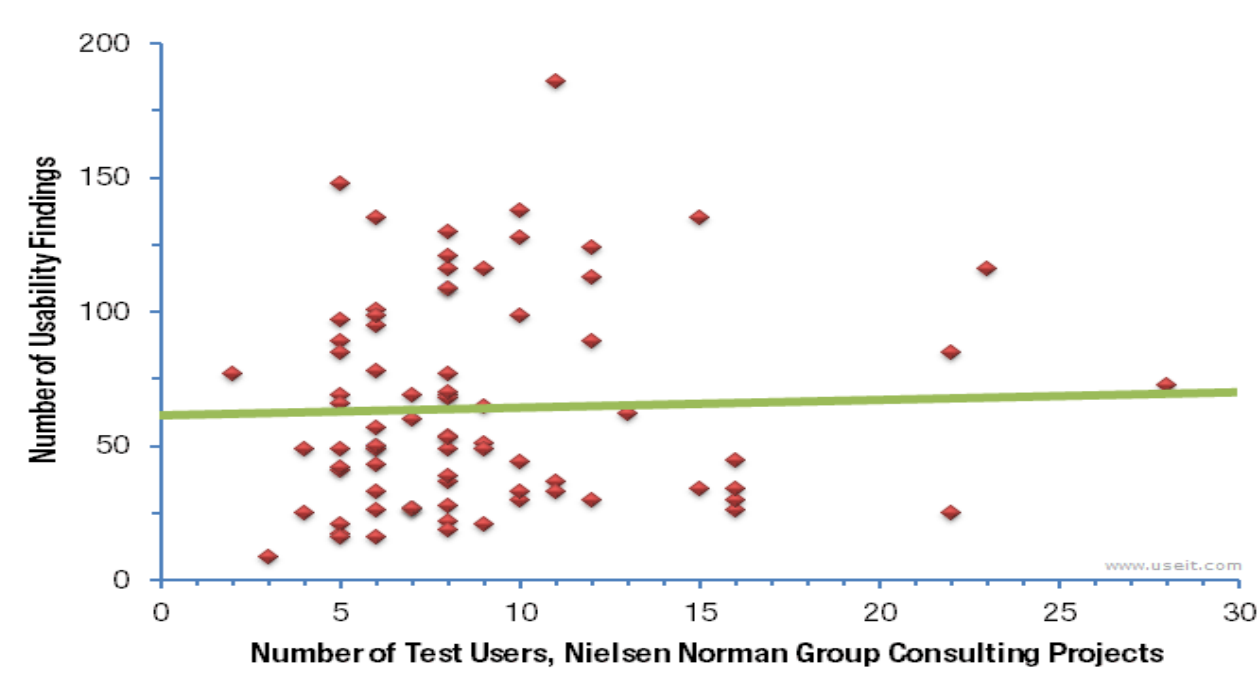

Graph 1: Number of subjects vs usability findings

(Source: Nielsen, 2006).

Further, another claim is made that has been supported by three of the authors except for Lewis that state many of the severe usability problems are found through the first couple of participants. Moreover, Virzi had conducted three experiments and observed that $80 \%$ of the problems are found by $4-5$ subjects. Nielsen had also found that 5 subjects would reveal $77 \%-85 \%$ of the usability problems. Nevertheless, Spool and Schroeder found that 5 subjects are insufficient to find $85 \%$ of usability problems. The main reason for the difference in their findings was caused by the $p$-value (probability), as it was low (Turner et al, $n, d)$.

On Nielsen's website it is stated that 20 subjects would be sufficient to carry out a quantitative study and would have a high confidence interval see graph 2 (Nielsen, 2006). Nonetheless, there is no mention of the sample size required for a qualitative study. However, Mason states that 20 subjects are sufficient to carry out interviews for qualitative data (Mason, 2010). On the other hand, $3-20$ participants would be sufficient to carry out final interviews as there is a potential that $80 \%$ of the answers would be revealed. 


\section{Chapter Three: Phase One Methodology}

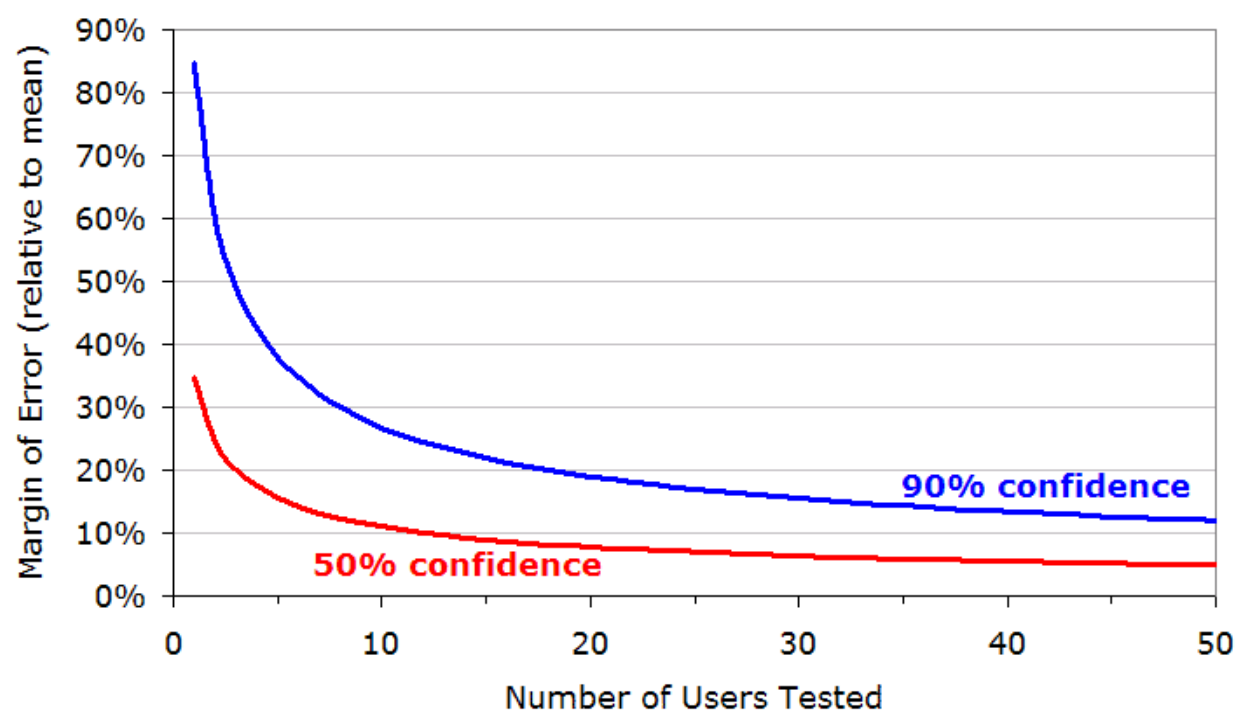

Graph 2: Number of subjects vs margin of error

(Source: Nielsen, 2006)

There were two population samples; the first is the usability test which falls between $3-5$ experts that would reveal the issues with the survey itself and the questions asked. This population would configure about $80 \%$ of the issues according to Turner et al. Three to five experts were to be interviewed in the pilot study to outline not only the issues with the survey but help in refining the questions for better and more accurate answers. The second sample is when the actual interviews are done, it is suggested that 20 experts be surveyed by Nielsen and Mason, but due to the availability and number of fire engineers in the country this number was optimistic, because getting all 20 fire engineers in the country to respond is difficult. Furthermore, if it is not possible to get such number, $3-5$ experts would still be sufficient as it is already mentioned that $80 \%$ of the experts' practices and documentation could be acquired. However, it would be beneficial if 20 or more experts could be interviewed because a statistical analysis would be possible in this case.

\subsubsection{Fire Engineers Participation}

The only technique that was possible and used is sending a notice to the professional body SFPE for distribution to fire engineers around the country. There was no system of choosing engineers; whoever was willing to participate was interviewed because the participation was voluntary. 


\section{Chapter Three: Phase One Methodology}

\subsubsection{Bias in Selection of Fire Engineers}

The criteria used to select fire engineers and to insure that they are representative of fire engineers generally are:

- Must be qualified as a fire engineer.

- A member of the SFPE.

- Have practiced and designed fire safety systems.

- A minimum sample number of 3-5 experts.

Bias in the first bullet point does not exist because fire engineers are the experts in the field of fire safety. Choosing experts from the SFPE only might have caused missing on other experts that are not members and did not receive the notice. Experienced engineers might reflect on their past experience only which would leave other issues that have negative impact. Finally, the sample size would give a benchmark on type of answers gathered. Moreover, not all engineers are familiar with the green features concept and how it would differ from conventional features for example efficient VAV system and common practice VAV system. All these would affect the answers of the fire engineers. The interview included information on the systems used to allow the engineers to distinguish between green and conventional features. Furthermore, follow up questions were asked as well as the interviewer was present in order to explain the questions and guide the interview.

\subsubsection{NZBC Criteria and Objectives}

The NZBC criteria and objectives were used in the questionnaires to enable the assessment and evaluation of the green features. The criteria are C2: Prevention of fire occurring, C3: Fire affecting areas beyond the fire source, C4: Movement to place of safety, C5: Access and safety for fire fighting operations, and C6: Structural stability. These criteria hold the same objectives which are to safeguard people from an unacceptable risk of injury or illness caused by fire, protect other property from damage caused by fire, and facilitate fire fighting and rescue operations (NZBC, 2012). The experts were asked to rate and rank the features according to the criteria and provide reasoning on how the objectives are compromised. The criteria were discussed with the experts in terms of what, why, when, 


\section{Chapter Three: Phase One Methodology}

and how. Also, the experts are asked how fire protection engineers assess new features from fire safety perspective and what sort of criteria other than the building code that are used.

\subsubsection{Survey Implementation}

The interviews started on the $17^{\text {th }}$ September 2012. Participants were contacted via email and phone to confirm their participation date. Also, the possible questions that would be asked were sent a minimum of three days before the interview, except for the follow up questions. Further, the introduction to the survey and a consent sheet were sent when the verbal or a written agreement was received.

\subsubsection{Survey Analysis}

The data from the survey was analysed quantitatively and the interviews were analysed qualitatively. The interviews with the fire engineers were recorded and then it were analysed according to the NZBC criteria and objectives, as the interview aim was to find the gaps in knowledge around the affect of the green features on fire safety. Therefore, the criteria and objectives used are the same as the NZBC to determine whether green features do comply with NZ Clauses and Standards. The engineers were to answer what are the implications of the features listed in table 2 and what the mitigation measures are for the risks if any exists. Although not many fire engineers are involved in green buildings their input on the implications and mitigations is highly regarded as the questions asked are in their own area of expertise. Also, many of the features are also found in conventional buildings or buildings that had gone through refurbishment. The literature identifies little about the implications but no clear conclusions have been drawn. Therefore, the interviews were to identify the implications of the features and fill the gaps in the research. For example, how does double skin facade impact on fire safety? What is the impact? And what are the mitigation measures to resolve the risk identified to satisfy the NZBC? As a result, 5 green features chosen by the fire engineers were investigated accordingly. The results were extracted through a scoring system was developed by the university statistician that produced the features that have the highest risk on fire safety. The features chosen were then analysed further in FDS. This software tests the extent of the risk and generates data in 


\section{Chapter Three: Phase One Methodology}

regards of tenability. Further, two scenarios were chosen from the verification method as they are considered as the worst case scenarios which are challenging fire and robustness check. Challenging fire is fire starting in an occupied space and it develops to become a challenged to the fire safety systems and robustness check is one of the fire safety systems fail.

There are two parts of the interviews to analyse, the first was reporting on the first part. The first part was reported on only as the sample size of the interviewees was small. A scoring system was used to investigate which feature was to be analysed further using FDS. The scoring system established how many times the engineers refer to the feature as the worst e.g. from 5 engineers interviewed four engineers had ranked atrium as having the highest negative significant implication, while one engineers had ranked DSF as having the highest negative significant implication.

\subsubsection{Background Knowledge}

The interviews with the fire engineers were to confirm or disconfirm the theories emerged from the literature review. The fire engineers' participation was voluntary and a notice was sent through a professional body that asked for participation. Theoretical sampling was not used because it is very difficult to get the fire engineers to agree to re-participate. The questions asked in the interview were open-ended and voice recorded and notes were taken as the interviews progressed.

\subsection{The Grounded Theory Method}

Grounded theory is defined as "an inductive, theory discovery methodology that allows the researcher to develop a theoretical account of the general features of a topic while simultaneously grounding the account in empirical observations or data." (Jones \& Alony, 2011, p.95). The grounded theory covers the entire process from bias of the researcher to the extraction of the results from the interviews (Jones \& Alony, 2011). However, not all of the stages are required except for the process of coding and analysis. There are three stages to the process of coding and analysis which are: 


\section{Chapter Three: Phase One Methodology}

1. Open coding.

Open coding is a process of constant comparison, memoing, categories, sub-categories, and themes. The transcripts are broken to sentences, categories and paragraphs which then are collected and sorted under different categories. At this stage, all data are initially examined and no dross is removed to allow the analyst to spot patterns. The main categories are identified through their densities of information which are referred to as 'core categories' (Jones \& Alony, 2011).

When the categories are emerged, the researcher starts constant comparison to reflect and conceptualise on data through memos. This then allows the researcher to accumulate hypothesis and theories. These hypothesis and theories are generated systematically through coding and analysis, but it must be plausible and close to the data. Glaser and Strauss state that "The purpose of the constant comparative method of joint coding and analysis is to generate theory more systematically ..... by using explicit coding and analytic procedures." (Glaser \& Strauss, 1967, p.102).

Memoing is considered the core stage and the most important part of the first stage of the analysis. Memos are about developing codes and ideas; the researcher reflects on the data and records everything, as patterns can be emerged and links could be identified from one concept to another. The next step in the process is theoretical sampling, which is choosing participants in regards to the concepts that emerge, as each transcript analyses concepts that emerges and the researcher then decides which concept to follow. Therefore, a second interview with different or similar participants is undertaken to cover the concepts of interest only (Jones \& Alony, 2011). However, the step of theoretical sampling was not undertaken because the questions asked had already framed the concepts and the researcher had already established the sort of information required to undertake this research.

As soon as each interview completed, the recording is heard and a transcript is written. After, coding starts as already described in the open coding process, hence, data starts to 


\section{Chapter Three: Phase One Methodology}

emerge and similar concepts or themes are established. Then, these concepts or theme are categorised and putted together with similar concepts according to their meaning and relation to the text. In this stage no dross is removed. Constant comparison is used until the theoretical coding stage. This stage starts when other interviews are converted to transcripts and comparison is possible. The goal is to identify similarities and differences between the interviewees input. When the data are fitted into the categories, reflections on the data begins; this then were written to understand initial thoughts of 'how' and 'why' and identify consistencies and inconsistencies in the data.

\section{Selective coding.}

Selective coding is more thorough and produces denser results than open coding although it follows the same process, but the process is more refined. Further, at this stage dross is removed and information that explains the concepts and core categories are kept (Jones \& Alony, 2011).

At this stage core categories should emerge from the data as the interviewers would focus on a main concept and a pattern could be extracted across all the interviews. Further, similarities in which feature has the most negative significant impact have already been established and reflected on at the interview. Also, the coding process and the memos reveal the information that is required to carry out a sub-sequent analysis. Moreover, because the direction of the research is already known, selective coding stage can start earlier. The categories are considered plausible when repetitive information occurs at the selective coding stage.

3. Theoretical coding.

Theoretical coding is sorting the categories with reference to the literature. This stage is putting the fractured information back together to allow a coherent flow of concepts and ideas. Then it allows the researcher to compare, contrast, and make connections to the literature regarding the theories and their justifications (Jones \& Alony, 2011). 


\section{Chapter Three: Phase One Methodology}

Finally, to finalise the data and identify patterns theoretical coding is used which takes what the engineers have said and what the literature states and puts them together. In this case, the literature is limited but through reviewing the literature hypotheses and theories were emerged on how a green feature could increase the risk of fire. The engineers in their turn would state whether they have the same or different hypothesis and theories from the literature through reflection of their personal experiences or opinions. Then, the experts input can be linked to the literature for reasoning on why some green features are a concern. However, while this process is undertaken, a revisit to the memos is required to ensure that the data fits in the category that was assigned to.

\subsection{Survey Bias}

There are two types of survey bias, attitudinal information and response bias; both are caused by the interviewer and the respondents may contribute to one type. Attitudinal information is the way the interviewer presents the information to the interviewee. Response bias occurs due to presentation of the issue which is the interviewer's responsibility or respondents communicate in an ambiguous sense to portray themselves (Chami-Castaldi, 2008). However, the main error would be the response error; these are caused by:

- Question type

- Clarity of the question

- Interview length

- Interview structure

- Interview analysis

The interviewer is one of the main contributors to bias. This is because the interviewer is carrying out a series of interviews, but the interviewer tends to ask questions that are paraphrased for each different interview. To avoid this problem, the interviewer must ask exactly the same question in each interview. This problem would also impact on the analysis of the interviews because the interviewee might understand the question in a different way which would cause different answers than intended. Further, the interviewer might record 


\section{Chapter Three: Phase One Methodology}

the responses incorrectly as the interviewee would have meant a different point which the interviewer carelessly or sometimes deliberately amends to get the response needed. Moreover, the interviewer reaction to the answers could impact on the participants behaviour towards answering the question; as a result, bias occurs. Another type of common error from the participants' side is memory error. Memory error is caused when the interviewee is asked a question regarding their past experience which the engineer is not able to remember clearly (Fellegi, 2003). As a consequence, the answer is either not complete or not entirely correct.

The main focus of the interviews was to concentrate on extracting the engineering tools and methodologies of evaluation, assessment, and testing of new or innovative features. The questions revolved around the criteria, objectives, and engineering tools and methodologies currently used by the experts that would satisfy the authorities. The questions were in three parts, the first were major questions, the second were sub-questions, and the third were follow-up questions that were generated from the open discussion between the interviewer and the engineer. The questions asked were exactly the same in words and content except for the follow-up questions as it depended on the direction of the conversation. These steps reduced bias from the interviewer as well as the interviewee; hence, more accurate responses were recorded.

\subsubsection{Techniques to Reduce Bias}

There are different techniques that were used to reduce bias, but not all are applicable to the interviews carried out in this research. The technique of long questions could aid the respondents to provide a complete answer, because in interviews the participants tend not to know the up-coming questions. Therefore, it is more appropriate to give an introduction to the topic first. Also, long questions could articulate clearly the requirements of the question for the respondent (Fellegi, 2003). For example a short question would be: What are other objectives used to evaluate or assess new or innovative features? However, a long question would introduce the topic and might give a better understanding to the sort of answer required such as: The next series of questions is around performance-based design criteria and objectives. Your answer will be used to investigate green feature further. What 


\section{Chapter Three: Phase One Methodology}

are other objectives are used to evaluate or assess new or innovative features? Nevertheless, the interviewer must make sure that the introduction to the topic does not lead the participants.

In order to further reduce bias, the interviewer needs to be trained around carrying out interviews. In this case the researcher lacked the skill of interviewing; therefore, a pilot study was required to identify any issues with the interview questions and behaviour of the interviewer. Such method would enhance the interview performance as well as giving a chance to train, and teach the interviewer to lead discussions in a professional manner.

In regard of the memory issues, it is wiser to ask the respondent to recall a short reference period than a long period, but it should not be so short that it would cause bias. The memory issue is regarded to be a problem when the respondents are asked about their past experiences. However, asking the respondents to recall happy memories such as going on a holiday and what happened around this reference period could reduce memory error. Another technique that is utilised to reduce memory error is to send the questions prior to the interview. This allows the respondents to prepare for the questions as some questions would require going back and checking their records to answer the questions accurately and recall past experiences clearly (Fellegi, 2003). Also, to eliminate interviewer bias in regards to understanding the experts input. A summary of the engineers input was sent to each engineer for editing and checking (Burnard, 1991).

\subsection{New Zealand and Prescriptive vs Performance-based Fire Safety Codes} The NZBC requirements can be met by 3 different methods. The first is acceptable solutions which are deemed to satisfy; the second is verification method which is approved calculations of practices design, and alternative solutions which persuade the authorities that the design meets the building code requirements. According to Buchanan et al, acceptable solutions are used for most buildings design; alternative solutions are used when the designer moves away from acceptable solution for a more innovative design. 


\section{Chapter Three: Phase One Methodology}

Prescriptive code is defined as "the desired level of performance for health and safety through a set of minimum requirements that are generic by occupancy." (Meacham, 1997, p.21). Due to the fact that this is generic, the objective of the requirements may not apply for every design situation which would not address the objective in a way that was set. On the other hand, performance-based code is defined as "requirements for health and safety through a set of flexibly defined performance objectives and functional requirements." (Meacham, 1997, p.21). Although, performance-based code sounds better, both codes (prescriptive and performance-based) have advantages and disadvantages which are presented in table 3 below:

\begin{tabular}{|l|l|}
\hline Prescriptive codes & Disadvantages \\
\hline Advantages & Instructions are not clear all the time \\
\hline $\begin{array}{l}\text { Requirements and provisions } \\
\text { are already established }\end{array}$ & Complex code structure \\
\hline \multirow{2}{*}{ No special skill are required } & Requirements are not flexible \\
\hline & $\begin{array}{l}\text { Not open to innovate technologies or } \\
\text { alternative solutions }\end{array}$ \\
\hline
\end{tabular}

\begin{tabular}{|l|l|}
\hline Performance-based codes \\
\hline Advantages & Disadvantages \\
\hline $\begin{array}{l}\text { Objective are clear and safety } \\
\text { engineers defines the criteria } \\
\text { and methodology to achieved } \\
\text { the objectives }\end{array}$ & $\begin{array}{l}\text { Performance criteria is difficult to } \\
\text { define }\end{array}$ \\
\hline $\begin{array}{l}\text { Flexible to innovative } \\
\text { technologies and alternative } \\
\text { solutions }\end{array}$ & $\begin{array}{l}\text { Experienced safety engineers are } \\
\text { required }\end{array}$ \\
\hline $\begin{array}{l}\text { Fire design could reduce costs } \\
\text { Innovative fire safety } \\
\text { technology are introduced to } \\
\text { the market }\end{array}$ & $\begin{array}{l}\text { Difficulties in validating models and } \\
\text { methodologies }\end{array}$ \\
\hline Table 3: Prescriptive vs Performance-based Codes pros and cons (Source: Tavares, 2008). \\
\hline
\end{tabular}

Engineering practice documents are defined as "generally considered framework or guidance documents that establish appropriate process and procedure for the undertaking 


\section{Chapter Three: Phase One Methodology}

of an engineered approach to a problem." (Meacham, 1997, p.21). Performance-based approach is considered as an engineering practice because it is based on:

- Agreed on fire safety criteria and performance objectives.

- Evaluation of fire spread through probability and calculations

- $\quad$ Fire and fire effluents properties

- Design alternatives for performance objectives.

These are done through engineering tools and methodologies which are defined as "equations, correlations, models and procedures used for engineering analysis and prediction of fire and fire related phenomena." (Meacham, 1997, p.22).

Prescriptive codes state the requirements needed to achieve the criteria but do not prescribe their intent. For example, to achieve a certain temperature within a room, it would state the R-values of the floor, ceiling and walls but do not show the calculations that have been done to achieve a temperature of $x$. In other words, in a given case it states what to do. However, performance-based codes criteria are deterministic and probabilistic, although, some of these criteria are present in the prescriptive codes. Deterministic criteria calculates fire and smoke spread, while probabilistic criteria is presented through an assessment of the whole building in terms of the levels of life and property risk (Hadjisophocleous \& Benichou, 1999). In New Zealand the acceptable solutions (prescriptive code) also allows for alternative methods or verification methods which are based on performance-based codes. Thus, the level of safety can then be compared to the prescriptive code to determine if the requirements are met.

In China, underwater tunnels are being built to reduce traffic, and the use of many bridges would disturb the water environment. However, the issue with underwater tunnels is smoke control, in the case of a fire it would be very difficult to exhaust smoke and the Chinese building code has no provisions for underwater tunnels. Therefore, performance-based design is required to resolve the issue (Yuan et al, 2011). The same issue arise in this 


\section{Chapter Three: Phase One Methodology}

research as the NZBC does not include provisions for using green features and it does not allow for other features to be used. Although, there are performance-based codes in NZ, it is still difficult to satisfy the authorities because there is not a set of design approach for innovative features to base the performance criteria on. Furthermore, if criteria and objectives were to be established it would be difficult to state if the green features are life threatening. For example FDS would establish fire growth and smoke spread and an indicative Available Safety Egress Time (ASET) but the need to know the Required Safety Egress Time (RSET) is not established (Yuan et al, 2011). Although, these times could be calculated in different software, the main issue is that prescriptive codes would state the required length of the escape route but would not state RSET. Thus, performance-based codes are required; nevertheless, the literature lacks documentation of engineering practices.

Prescriptive codes do not allow for new innovative or cost effective design, it would not be possible to examine the green features against the prescriptive fire code. Therefore, performance-based code is used to investigate green features and determine their impact on fire safety. The process of a performance-based design would involve but would not be limited to the following steps:

1. Identify criteria, objectives, and goals

2. Identify worst case scenario

3. Assess consequences of the scenarios

4. Identify performance criteria

5. Effectiveness of suppression systems according to engineering data

6. Robustness check of fire protection systems (Liew, 2004)

Previously, before the 2012 amendment the authorities had allowed fire engineers to choose their performance criteria, objectives and scenarios for testing. However, the new requirements from the building code have limited this through specifying the performance criteria, objectives and scenarios that guide the design as illustrated in figure 4. 


\section{Chapter Three: Phase One Methodology}
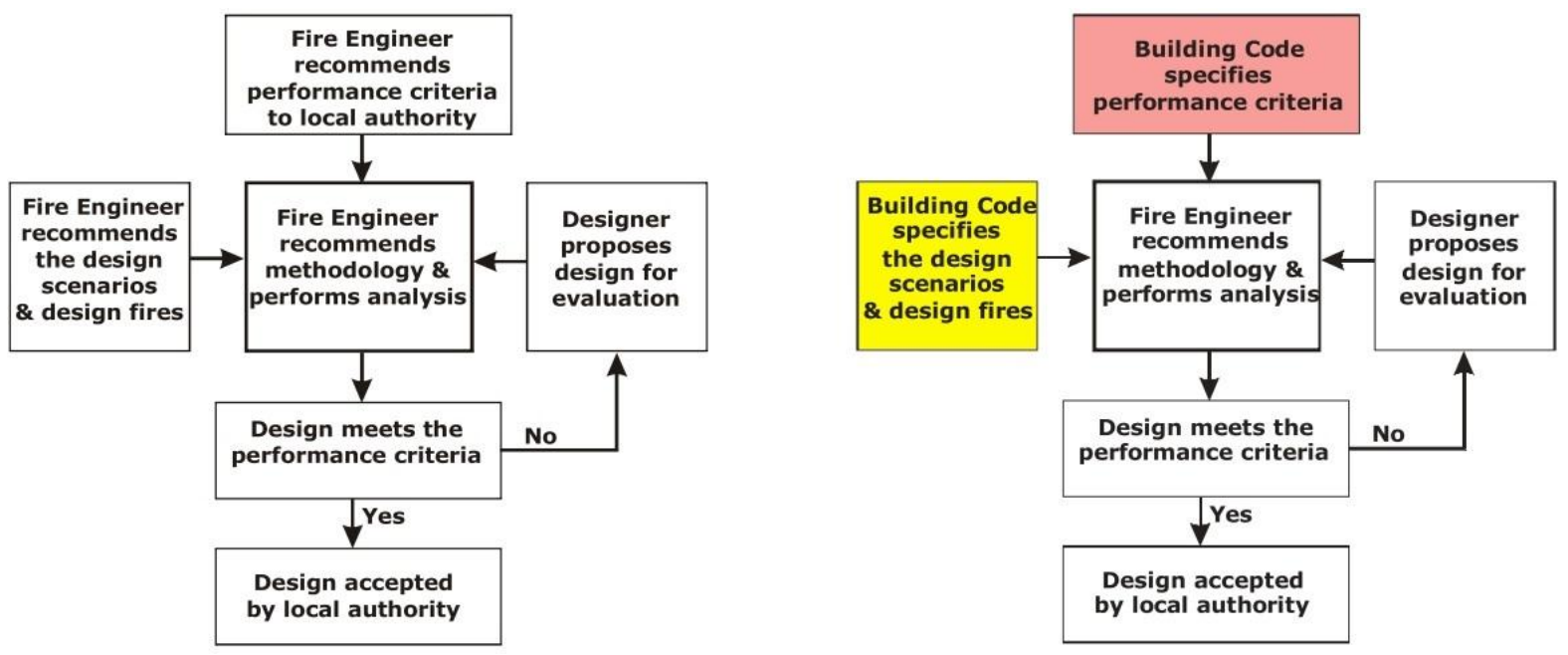

Figure 4: : On the left is the previous practice and on the right is the current approach (Source: Wade et al, 2007).

The fire safety performance-based code has similar criteria to the NZBC. However, this research includes criteria and objectives from the NZBC and others that the experts mention. The NZBC criteria and objectives are stated above (Section: Criteria and Objectives), but it does not include property loss and impact on the environment. Property loss is not considered as an objective that must be included because it serves the owners. Impact on the environment used to be an objective in the previous code but it was removed after the amendment took place in 2012 as it has been covered by the resource management act.

\subsection{Pilot Study:}

The pilot study was conducted to establish an overall idea of the duration to complete the interview and find any issues with the questions or presentation (Fink, 2006). Then after the surveys and interviews were transcribed, the analysis process took place to train and understand the issues with analysis process. Also, the experts would help in developing and refining the questions. Further, it gave an indication to the sort of information expected. Then, amendments to the draft survey were done to establish a final copy.

\subsubsection{Pilot Study Results}

The pilot study commenced on the $14^{\text {th }}$ July 2012 . The interviews were with experts in different professions such as architecture and design lasted for 45 minutes. The interviews 


\section{Chapter Three: Phase One Methodology}

went well but because the trial interviewees were from disciplines that lacked knowledge about fire safety the questions were very difficult to answer. Nonetheless, the feedback received in terms of the performance of the interviewer and the clarity of the questions was beneficial. The main points were:

- More comprehensive introduction

- Explaining the questions more not only read them out

- Explanation on the features

- General layout of the interview

A practice study was done to establish the time it would take to write up a transcript for an interview that would last for no more than an hour. Three times, 5 minutes writing practice was done and it showed that the time to transcribe 5 minutes of a speech would range between $35-40$ minutes. Also, three times, 1 minute trials were done and the average to transcribe a 1 minute speech was approximately 7 minutes. Thus, it was concluded that 1 hour of speech would take approximately 8 hours of transcribing. Furthermore, to understand and practice the interview analysis, two articles were taken to analyse using the grounded theory. Open coding and selective coding stages were done only for two articles; theoretical coding was not done because it requires similar text to compare between. The two articles were about sustainability and fire safety, but the purpose of the analysis was to be familiar with the grounded theory method. The text was read three times and notes (memoing) were written each time. Then the notes are converted into categories, subcategories and themes. After, the text was then broken down into sentences and/or paragraphs and categorised according to content. Some of the text were applicable to two or more categories and were placed as such; these were removed at the final stages to avoid repetition. Next, the categories that were irrelevant to sustainability and fire safety were deleted. Subsequently, the remaining categories were reorganised into sentences and paragraphs that flew coherently. Finally, the findings of the articles were reported on. Each of these articles took about two days to analyse and report on the findings. The purpose of this study was to establish a time and understand how to complete the interviews analysis and whether the chosen analysis type is appropriate. 


\section{Chapter Three: Phase One Methodology}

\subsection{Conclusion}

Buildings were selected on the bases of being green to find the common features. Also, all assessment of buildings from other publications showed that the assessment criteria and objectives are extracted from the country's building code. For this reason, the NZBC criteria were used as means of assessing the features only.

The pilot study revealed problems with the presentation of the questionnaires and the interview questions; these were mainly language and layout issues. Further, duration of interviews and transcribing were required to be established as the text analysis technique was dependent of length of the transcriptions. The grounded theory was used on articles to give an indicative duration for the analysis and the issues. It was illustrated that few steps from the grounded theory were not necessary or were not appropriate in this case. Moreover, to maintain consistency between interviews, the questions must be the same. 


\section{Chapter Four: Survey Results}

\subsection{Survey Results}

\subsection{Questionnaires and Interviews Results}

Only 5 fire engineers were available for interviews. The interviews commenced on the $17^{\text {th }}$ September 2012, and ended on the $17^{\text {th }}$ October 2012. The results from the interviews were sent back to the engineers for editing and checking. The results from the questionnaires differed between respondents in terms of ranking of the features as expected. Therefore, a scoring system was established to determine which feature had the most impact on life safety according to the experts, table 4 shows the top 5 features with their score. The features that are ranked as 1 are the worst, the number attributed to it was 5,2 is 4,3 is 3,4 is 2 , and 5 is 1 . This means that if atrium was ranked 1 twice, 2 once then it was calculated as $2 \times 5+1 X 4=14$. The same scoring system was used to find the highest score meaning the worst; DSF, atrium and storage area are identified as of very similar risk level. Still, DSF was considered the worst.

\begin{tabular}{|c|c|c|c|c|}
\hline Ranking & Features & Weight & Top 5 Features & Score \\
\hline 1 & $\begin{array}{c}\text { Atrium } \\
\text { Atrium } \\
\text { Storage Area } \\
\text { DSF }\end{array}$ & 5 & DSF & 15 \\
\hline 2 & $\begin{array}{c}\text { DSF } \\
\text { Storage Area } \\
\text { VAV } \\
\text { Atrium }\end{array}$ & 4 & Atrium & 14 \\
\hline 3 & $\begin{array}{c}\text { Materials } \\
\text { Materials } \\
\text { DSF } \\
\text { DSF }\end{array}$ & 3 & Storage Area & 13 \\
\hline 4 & $\begin{array}{c}\text { Storage Area } \\
\text { Materials } \\
\text { Green Roof } \\
\text { Storage Area }\end{array}$ & 2 & Materials & 8 \\
\hline 5 & $\begin{array}{c}\text { VAV } \\
\text { VAV } \\
\text { RWHS } \\
\text { PV Cells }\end{array}$ & 1 & & 4 \\
\hline
\end{tabular}




\section{Chapter Four: Survey Results}

The top five features are listed above. DSF is chosen only and analysed further because of the following:

- It has scored the highest, meaning it is considered the feature that most threatens life safety.

- Limited literature was found in regards to fire safety

- One of the fire engineers was involved in a design of DSF overseas, and the engineer ranked it as having the most significant risk.

- All five fire engineers mentioned that there is a potential issue with DSF and not enough attention has been paid to this subject.

\subsection{Objectives and Assessment/Analysis}

In regard to all the green features listed in the questionnaire the performance design objectives, potential risk of the green feature on fire safety, and assessment of these features are all the same. The engineers stated that all aspects above are covered by the Verification Method 2 (VM2). Acceptable solutions were used and it had contained tables that prescribes what was required and the sort of safety features that need to be installed for compliance. However, the VM2 provided the basis of performance design. The VM2 now provides fire design scenarios that must be met and it allows the engineers to use any mitigation measure and does not restrict the number of mitigation measures used as long as it shows compliance with the criteria and objectives set by the NZBC. Hence, no additional criteria, objectives, and assessment were mentioned in the interviews other than VM2 to show compliance.

\subsection{DSF}

All the fire engineers referred to the amended NZBC criteria and objectives. One of the engineers mentioned that depending on the interpretation of the building code the green features go under certain categories for example DSF goes under concealed spaces and vertical spread of fire categories, and depending on the argument the Council would approve the design. The main concern that the engineers raised was smoke and fire spread through the cavity, as the main mitigation measure is the closing off of the system in fire 


\section{Chapter Four: Survey Results}

events. If the system does not close due to failure as the alarm signal did not get to the system through the BMS (Building Management System) or due to fire damage to the closure of their controls then smoke spreads to other floors and fire can spread to floors above. Another miscellaneous issue mentioned is DSF would confuse the fire service to where the seat of fire is, if the fire service does not know the building has DSF. However, another engineer had stated "access for fire fighting is positive" because there will be less smoke spread compared to an atrium.

There are many mitigation measures that can be used in within the double skin, but their effectiveness is unknown. These include:

- Automatic fire sprinklers.

- Positively pressurise the facade. However, one of the engineers commented that usually the exterior facade has openings; in this case pressurising will be ineffective.

However, most engineers mentioned that installing smoke extracts would eliminate the risk of smoke spreading because the smoke is buoyant and the facade area is small. Hence, a smoke extraction is effective and ensuring the cavity closes off in the event of fire would keep the fire and smoke trapped in the area of origin; further, engineers also mentioned that DSF is similar to atrium and it should be dealt with the same way in terms of risk and mitigation measures.

\subsection{Atrium}

Four of the fire engineers had put down that atria has significant implication for fire safety because it spreads smoke quickly which would affect more people. However, benefits include potentially better visibility, better environment for fire fighters to operate in; still it could be negative. In terms of structural stability it is usually positive because the overall temperature is less. Search and rescue operations are more difficult because of the large volumes as well as the pre-movement of people, because some people need to see or smell the smoke until they move. Depending on the detection system people might take longer to move assuming a false alarm. Another issue with atrium is it would cause more smoke 


\section{Chapter Four: Survey Results}

damage to the building. The issue with atria is it is design specific, for example whether floor plates open to the atrium, short travel distances away from the opening, a low occupancy, relative to the number of exits, a fast response detection system, location of fire, fire load etc. Hence, atria affect fire safety positively or negatively. If atria are designed appropriately it is significantly positive as one of the engineers mention reflecting on personal experience.

There are many mitigation measures that were mentioned by the fire engineers, the common were smoke detection systems and smoke extracts. Although sprinklers were mentioned some had doubted their effectiveness stating "sprinklers might have a role", while others had said that sprinklers are mainly to keep the temperature of the structure stable and reduce spread of fire. Nonetheless, the literature and one of the engineers stated that sprinklers would cool down smoke; as a result the smoke sinks back down and will be lower than the sprinklers level, in this case the smoke extraction is ineffective especially if it is natural ventilator driven. Further, the literature and another engineer said a reservoir is required as it would contain the smoke and the extraction process would be easier. However, not all engineers confirmed the effectiveness of smoke reservoir because as stated earlier it all comes down to the detection system and movement of people.

Atria have a significant negative impact on fire safety because in many cases occupies the centre of the building. Also, because atria connect more than one floor and allow offices to be open to plan. Smoke and fire spread becomes an issue, because of the lack of compartmentation and the driven stack effect to circulate the air around. Moreover, mitigation measures of atria are unknown in terms of performance and whether it could control fire and smoke spread efficiently. Installing automatic sprinkler system at the top of the atrium is of limited benefit as sprinkler response will be slower. Also, as the smoke rises it cools down and it would be buoyant at a level which requires more smoke to accumulate and get hot enough to activate the fire sprinklers. The second issue is when the sprinklers are activated; the water would cool down the smoke and distorted and pushes away to other floor or allow it to sink back again. Furthermore, poor design also worsens the situation further as some designs integrate fire escape routes through the atrium which 


\section{Chapter Four: Survey Results}

would exposes occupants to smoke and inhaling toxins. However, the best mitigation measure that is used in atria is a smoke extraction system. This system seems to be efficient in removing smoke and increases the visibility of occupant when evacuating. There is the issue of pressurisation as well. In a proper design all floors should be pressurised to push and keep the smoke in the atrium to allow the smoke extractors to extract the smoke efficiently. Having said that, in some cases the smoke is not accumulating in the atrium and in turn the smoke extraction system would not help because it would cause pressure differences in the building enhancing the spread of smoke.

\subsection{Storage Area (Recyclables)}

Usually storage or rubbish areas contain large amounts of materials that are combustible and such rooms tend to be full of these materials. Hence, it creates a significant fire ignition source and in some buildings, the room also contains machines to treat the materials. For example plastics and cardboard, are usually crushed and compacted at the room which creates a potential ignition source. Further, most storage areas are at the basement of the building which means it is already fire separated from the upper floor which is a requirement in the NZBC. However, although the rooms are fire separated, in some cases damage still occurs to the building while the fire separation stays intact. This has potential issues with structural stability and smoke development. Moreover, there is the issue of odour with storage areas, although it has no effect on fire safety. Currently the building code requires fire separation for these areas, but fire sprinklers are not required. Some of the engineers said it is very helpful to install sprinklers to suppress and control fire development while others perceived having sprinklers is an over the top solution due to significant cost of installation. Also, ventilation lobbies aids in fire and odour, but it is not a common practice in NZ. Another, mitigation measure that was mentioned in the interviews is management of the area, and it was agreed that management techniques are not reliable. As a result, further mitigation measures are required on top of the NZBC requirement to reduce the risk of fire occurring in storage areas. 


\section{Chapter Four: Survey Results}

\subsection{Sustainable/Recyclable Combustible Materials}

In regards to materials the engineers said that it does not matter whether the materials are recyclable, sustainable or green because the building code has certain limitations and requirements for fire spread and smoke propagation from finish surfaces. Hence, if the materials are not compliant with the NZBC it cannot be used and it is the responsibility of the manufacturers to test their products. However, mitigation measures to reduce fire spread are sprinklers and encapsulation of the material with a fire rating materials. Nonetheless, encapsulation will defeat the idea of a green material.

\subsection{Variable Air Volume System}

VAV and other HVAC systems are covered in the building code, and the requirement is to prevent fire and smoke spread from the place of origin to other parts of the building. This is the main issue; other issues arise with HVAC normally at retrofitting a new building and no considerations for connecting the system to the fire alarm. The only mitigation measures that were mentioned at the interviews were shutting down of the system in terms of smoke or fire dampers and fan stopping running. If the fan keeps running and the dampers close, there is no problem and if the fan stop running and the dampers did not close then there is no problem. However, the only issue is multiple failures, then a serious issue occurs, but usually no assessments are done for multiple failures. Nonetheless, there is a probability that this scenario would occur.

\subsection{Green Roof/ Walls}

All the interviewees classified green roofs or walls as having low risk. The risks that were mentioned were that it could collapse in a fire event and could potentially spread fire to adjacent buildings. However, in terms of mitigation measures for roofs is fire rating it only if it has a walkway on top. Regarding the fire spread to adjacent buildings it could be resolved by adding a product over the material but that would defeat the purpose of green.

\subsection{Rainwater Harvesting System}

Rainwater harvesting system is also not considered by the respondents to be a significant issue. The main concern is the placement of the tank. Most buildings in New Zealand install 


\section{Chapter Four: Survey Results}

the water tanks at the basement of the building rather than the roof. The roof is used to collect rainwater and through pipes the water is drained into the tank. If the tank is placed on the roof, in a fire event the structure will collapse quicker because the extra dead load of the water tank if it is not accounted for in some cases. If the tank is placed in the basement of the building no issues are raised. Nonetheless, there are other issues that are not directly related to fire safety for example using rainwater for fire suppression which might corrode the pipes due to the cleanliness of the water. Further, some buildings have their water collection somewhere far from the building which requires pipes underground to drain the water. This would cause some of the pipes to collapse and in turn stop water collection. This is mentioned because if a cost benefit analysis is done such aspects must be taken into account. Further, an engineer stated that it would be more feasible to run water mains to the sprinkler system rather than a tank that collects water because the water would need to be filtered which is costly.

\subsection{Photovoltaic Cells}

The issue with electrical generation system is the same with appliances and other electrical equipment which is connections. PV cells generate electricity and it is transferred through wires, when loose connections happen as the Target store in California, fuses are caused which would cause the PV cells to ignite resulting in a fire (Jackson, 2009). Therefore, PV cells and fire safety are not considered as a significant fire hazard. Consideration of proper integration is necessary. These include many factors such as installing a manual shut down system that would be easily visible and accessible when fire occurs because it is highly disadvantageous when a fire occurs and the PV cells keeps working. The main issue is fire fighters will not be able to suppress the fire with water because the building will be electrified which jeopardises the safety of the evacuees and the fire fighters. The fuses in the fuse box are needed to be pulled out to shut off the PV cells. Also, PV Cells adds load to the roof which may cause an earlier collapse, and usually fire prevention is not addressed in PV cells. However, mitigation measures include fire collars and coating the cables with fire resistance paint. 


\section{Chapter Four: Survey Results}

\subsection{Wind Turbines}

None of the engineers mentioned that wind turbines create an issue for fire safety except one said "in a fire event it could fall on someone."

\subsection{Chilled Beams}

Chilled beams are also not regarded as posing a risk on safety except stratification may occur where not expected and pose a risk to occupant safety. However, a mitigation measure would be potential mechanical extraction are required where it would not if more conventional HVAC was used. 


\section{Chapter Five: Phase Two Methodology}

\subsection{Phase Two Methodology}

FDS is used to simulate different parameters and scenarios that were considered as having the most negative impact on fire safety. The parameters were established from the survey results, while the scenarios were chosen from the VM2.

\subsection{FDS and Smokeview}

Fire Dynamics Simulator is a Computational Fluid Dynamics (CFD) software that predicts fire and smoke spread through fluid flow. The software resolves numerical equations for low speed fluid flow concentrating on the smoke and radiation from the fire. Smokeview is a software that is designed for FDS to produce animations and images of the output results (McGrattan et al, 2010).

\subsection{Limitations of FDS}

FDS is a sophisticated software for modelling fires in buildings; still it has limitations that could affect its accuracy. These include:

- Unorthodox shapes and surfaces are very hard to model.

- One combustion reaction can be modelled, no matter how many fuels are present.

- Fire suppressions cannot be well modelled.

- Grid resolution limits the accuracy of the combustion process.

- Complex models run-time is in days or weeks depending on the size of the model. (Spearpoint, 2008).

\subsection{Pilot Study and Illustrations}

After the interviews were completed and the results were established a pilot study was conducted on a $5 \mathrm{mX5m}$ two floor room with double facade to determine the important aspects and factors to be modelled. Also, it was to determine a time for the program to run as mentioned above complex models would require several days to complete. The pilot study showed that after 900 seconds of model running time the glass does not break, and increasing the mesh size would reduce the running time significantly The output of the FDS 


\section{Chapter Five: Phase Two Methodology}

file illustrated 900 seconds in total, but it measures at 0.9 second intervals. Accordingly, 1001 cells are shown in Excel instead of 900 cells. Also, the time for the tenability requirement breach are counted on the basis on the number of cells. However, because the programme did not count at 1 second intervals it was calculated as; the number of cells that exceeded the tenability requirement was multiplied by 0.9 to give the numbers of seconds exactly. Then, because there were 9 sensors on each floor for $\mathrm{CO}$ and visibility the time in seconds for the breach was divided by 9 to give an average time for the entire floor. With a $0.1 \mathrm{~m}$ mesh the model ran over a day but with a $0.5 \mathrm{~m}$ the model ran 2 hours. Furthermore, the input and output requirements were all done according to the VM2. The purpose of using FDS was to determine and validate the concerns and mitigation measures that were raised at the interviews because they all are opinions and perceptions. The decision on using FDS was because the software is free, and literature has illustrated that vast publications on FDS validation which were all in favour of FDS. Moreover, other software such as PyroSim and C Fast are interfaced or based on FDS (PyroSim, 2012).

\subsection{BRANZFIRE}

BRANZFIRE is a zone model software that simulates room fires (BRANZ, $n, d$ ). The use of this software in this research was to provide an activation time for sprinklers and smoke detection to implement in FDS for controlled fire modelling. A pilot study was conducted on the use of the software with reference to the figures used from the VM2 in terms of sprinklers and smoke detectors sensitivity. It was illustrated that the activation time of both sprinklers and smoke detectors differ depending on the size of the room. First a $10 \mathrm{~m} \times 10 \mathrm{~m}$ model was used to find the activation time of the fire safety features and to be familiar with the software. However, the results were different from the actual size model of $70 \mathrm{~m} \times 70 \mathrm{~m}$. Thus, the detection time for the actual model for sprinklers and smoke detectors are $324 \mathrm{sec}$ and $38 \mathrm{sec}$ respectively. The time activation of sprinklers was implemented in FDS and assuming that the sprinklers would control the fire only but for the smoke detectors activation time is not used in FDS as it is a warning system not a fire suppression or a control system. 


\section{Chapter Five: Phase Two Methodology}

\subsection{Model Geometry}

Seven out of the 50 green buildings contained either or both atria and double skin facade. These were analysed in terms of floor area and number of levels. The floor area and number of levels varied significantly, the chosen geometry is $4900 \mathrm{~m}^{2}$ and 3 levels excluding ground floor. The DSF connects the top 3 floors from a single elevation. Furthermore, the height of each floor is $3 \mathrm{~m}$; the $3 \mathrm{~m}$ is divided to $2.7 \mathrm{~m}$ clear space and $0.3 \mathrm{~m}$ for services. The figures used above are typical and because FDS requires a long time to analyse the inputs, the minimum size of a green building is modelled.

However, if the chosen floor area is used, sprinklers are required to be installed to comply with the building code because the VM2 states that if the number of occupants exceeds 1000 persons then sprinklers must be fitted. This is assuming that $10 \mathrm{~m}^{2}$ per person as outlined in the VM2 for office buildings. In this case it is not clear how different design aspects of the DSF would affect smoke spread. Therefore, a smaller model is used of $30 \mathrm{~m} \times 30 \mathrm{~m}$ size to reduce the running time of the model to create more scenarios and also to create a realistic case that would comply with the VM2 because the number of occupants is less than 1000. Furthermore, in a bigger building the reservoir is larger which means more smoke can accumulate at the space above $2.7 \mathrm{~m}$. As a result smaller buildings are less safe than large buildings. Modelling difference scenarios are applied to the small model and then the worst and best case scenarios are from the small models are modelled in a large building to compare the difference in results.

The smaller models have been modelled in BRANZFIRE to establish an activation time of the sprinkler system and smoke detection because the pilot study illustrated that the size of the building would impact on the activation time of the sprinkler system but not on the smoke detection system. The result was that sprinklers activated at $215 \mathrm{~s}$ while smoke detectors were the same as the bigger model. This is because that the large model has more space to contain the smoke which would result in less heat concentration at the sprinklers than the smaller model, but the smoke detectors are affected by the density of smoke while rising which is the same across all models assuming the ceiling height is the same. 


\section{Chapter Five: Phase Two Methodology}

The mesh size used was $0.5 \mathrm{~m}$ for all simulations because smoke spread was the focus which would not require a very small mesh size and it would be highly unorthodox in this scenario. However; the smaller the mesh size the more accurate the results potentially are. Nonetheless, the running time of the software would increase significantly and could easily reach to a week.

The effective air flow coefficient (EAFC) of grilles has an impact on smoke spread pattern, because the more open the area the quicker the smoke will spill and spread. However, the smaller the coefficient air flow the more time the occupants at upper levels have time to egress. However, according to Zhao, grilles EAFC is 0.67 usually (Zhao et al, 2003). Hence, on this basis the grilles are modelled and are the same across all models.

Each simulation model was designed with one to three different parameters and each has the same points of measurements for CO and visibility. On each floor 9 different locations for points' measurement were place at $2.0 \mathrm{~m}$ high for each $\mathrm{CO}$ and visibility as illustrated in figure 5. The figure illustrates level 1 only, the location of fires and its different locations of measurements. Also, it shows the placement of leakage with reference to VM2, walking grille, open windows, exterior vent, interior and exterior facade. These types of measurements and locations are done according to the VM2 requirements for challenging fire and robustness check scenarios at vital places. 


\section{Chapter Five: Phase Two Methodology}

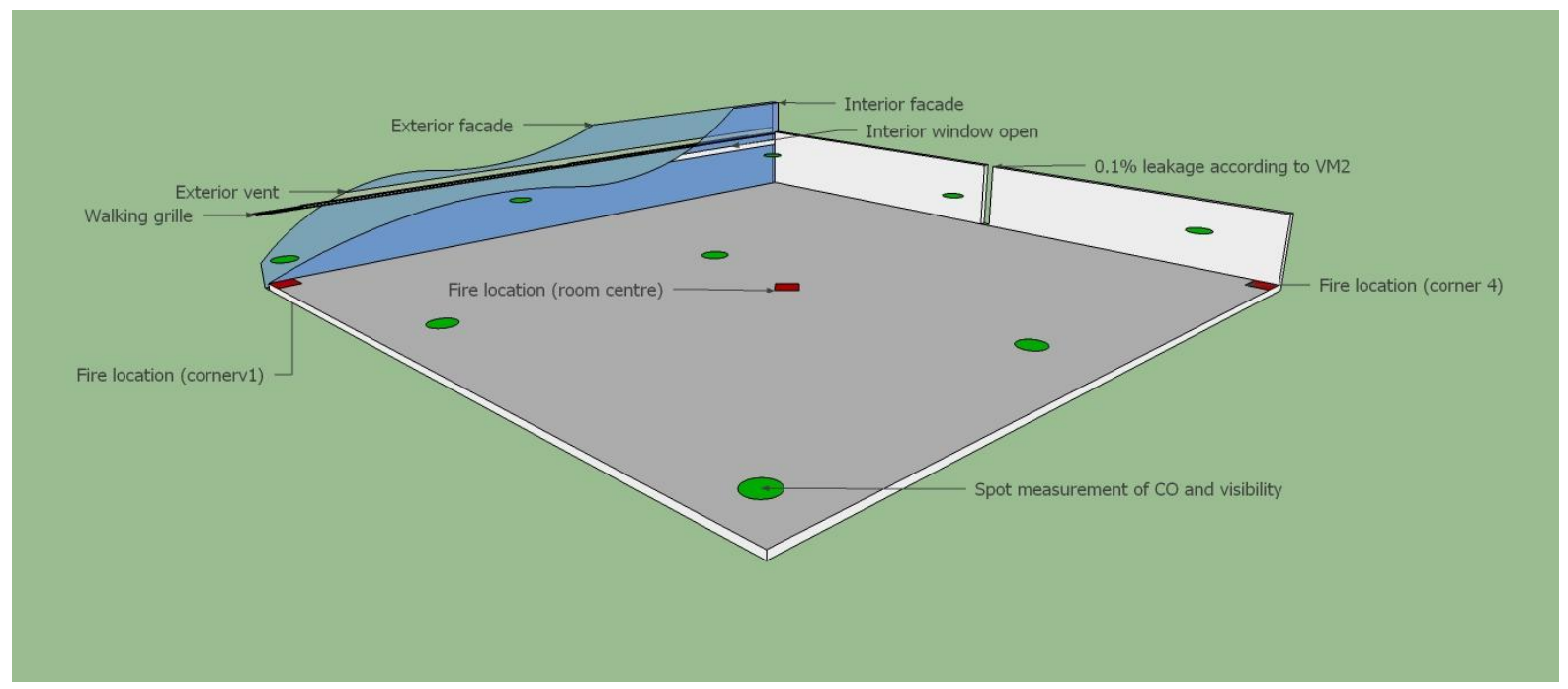

Figure 5: Model parameters and aspects implemented in FDS.

\subsection{Modelling Scenarios}

1. Location of fire

There are ten places in the building to place the fire and all are at the first level. These are:

- Inside the DSF

- At each corner of the building

- By the facade centre of the room

- Middle of the room

- Middle of the back wall of the room

- At the middle between each corner

However, some places are similar and are the inverse or opposite for example a fire at the corner of the room by the facade is the same as the opposite side exactly, but the smoke movement is opposite. Therefore, three fire placements were used which are shown in figure \# above. The main difference in the fire placement is the smoke movement and speed of spread.

2. Automatic fire sprinklers 


\section{Chapter Five: Phase Two Methodology}

A building where the number of occupants exceeds 1000 person requires fire sprinklered to be fitted. In this case, the small model had only two scenarios were sprinklers are used but for the two large modes both were sprinklered because the number of occupants is 1260 assuming $10 \mathrm{~m}^{2}$ for each person according to VM2. Hence, one of the scenarios would be investigating the building with and without sprinklers as well as establishing a matrix with the other scenarios to determining the effectiveness of each as separate and combined parameters.

3. Openings size of the interior facade

Poirazis (2006) provides opening effective areas of interior facade between $0 \%-25 \%$ depending of the type of window. The size of the opening has a significant influence on the amount and speed of smoke spread around the building. The bigger the opening the faster the smoke would spread. Further, a NZ website has sizes of windows which are aluminium frame and the size is $1.2 \mathrm{mX1.2 \textrm {m }}$ (Nulook, 2012). Thus, the effective area of the casement is $0.36 \mathrm{~m}^{2}$.

\section{Opening of exterior facade}

Usually some types of skins have openings to the exterior as well as the interior. Hence, in a fire event if the exterior facade is open then it is perceived that smoke spread would be slower. Thus, the amounts of toxic gases are reduced and the visibility is potentially better. In regard to the open size of the exterior facade, the same size was used as the interior facade opening area.

\section{Top facade is open}

Most or even all DSF have openings at the bottom to let air in and an opening at the top to exhaust the air out. In relation to a fire event the bottom opening has an insignificant effect on fire but the top opening perceived as having a significant influence because smoke is 


\section{Chapter Five: Phase Two Methodology}

warmer than air. Resulting in a rise of smoke and exhausting out at the top. Also, the bigger the opening area the more smoke is extracted. However, this is neglecting the effect of weather conditions. Nonetheless, the opening is not big enough to extract smoke quickly and in large amounts without fan extracts.

\section{Size of DSF cavity}

The size of the cavity would affect smoke density because the larger the cavity between the glazing the more smoke that can be accumulated as it acts as a reservoir. This would result in a decrease of smoke and toxic gas concentration as well as increase the available time of escape. However, the disadvantage of having a large cavity is cost only but no fire safety issue compared to a smaller cavity. A small cavity is perceived to impact on the available time to escape because there is less area for the smoke to accumulate in.

Six aspects are outlined above that are perceived as having the most significant impact on smoke spread. These were put in 14 different scenarios that would illustrate the affect of DSF on smoke spread according to the NZBC requirements (see table 5). The six aspects are modelled individually and combined together to determine their effects on smoke spread. Also, two large models of $4900 \mathrm{~m}^{2}$ were designed only for the best and worst of the scenarios. Then, these were compared to the smaller models to find the difference in the tenability. These large models have the same parameters as the smaller models but because it is a requirement in the building code that sprinklers must be installed in buildings that occupy 1000 person or more. The reason behind using the smaller models is small buildings do not usually use sprinklers and having sprinklers in all of the buildings would not illustrate the true effect of the DSF. It is also a way to test the usefulness of sprinklers. Hence, the larger models are fire controlled after 324s as already established using BRANZFIRE. 


\section{Chapter Five: Phase Two Methodology}

Table 5: Scenarios simulated in FDS.

\begin{tabular}{|c|c|c|c|c|c|c|}
\hline & $\begin{array}{l}\text { Detection } \\
\text { System }\end{array}$ & $\begin{array}{l}\text { Fire } \\
\text { location }\end{array}$ & $\begin{array}{l}\text { Interior facade } \\
\text { opening area }\end{array}$ & $\begin{array}{l}\text { Exterior } \\
\text { facade }\end{array}$ & $\begin{array}{l}\text { Top opening of } \\
\text { DSF frame }\end{array}$ & $\begin{array}{l}\text { Cavity } \\
\text { width }\end{array}$ \\
\hline $\begin{array}{l}\text { Base } \\
\text { model }\end{array}$ & $\begin{array}{l}\text { Smoke } \\
\text { detector }\end{array}$ & $\begin{array}{l}\text { Room } \\
\text { centre }\end{array}$ & $25 \%$ & Closed & Closed & $0.5 \mathrm{~m}$ \\
\hline $\begin{array}{l}\text { Scenar } \\
\text { io } 1\end{array}$ & $\begin{array}{l}\text { Smoke } \\
\text { detector }\end{array}$ & Corner 1 & $25 \%$ & Closed & Closed & $0.5 \mathrm{~m}$ \\
\hline $\begin{array}{l}\text { Scenar } \\
\text { io } 2 \\
\end{array}$ & $\begin{array}{l}\text { Smoke } \\
\text { detector }\end{array}$ & Corner 4 & $25 \%$ & Closed & Closed & $0.5 \mathrm{~m}$ \\
\hline $\begin{array}{l}\text { Scenar } \\
\text { io } 3 \\
\end{array}$ & $\begin{array}{l}\text { Automatic } \\
\text { fire sprinkler }\end{array}$ & $\begin{array}{l}\text { Room } \\
\text { centre }\end{array}$ & $25 \%$ & Closed & Closed & $0.5 \mathrm{~m}$ \\
\hline $\begin{array}{l}\text { Scenar } \\
\text { io } 4\end{array}$ & $\begin{array}{l}\text { Smoke } \\
\text { detector }\end{array}$ & $\begin{array}{l}\text { Room } \\
\text { centre }\end{array}$ & Closed & Closed & Closed & $0.5 \mathrm{~m}$ \\
\hline $\begin{array}{l}\text { Scenar } \\
\text { io } 5\end{array}$ & $\begin{array}{l}\text { Smoke } \\
\text { detector }\end{array}$ & $\begin{array}{l}\text { Room } \\
\text { centre }\end{array}$ & $12.50 \%$ & Closed & Closed & $0.5 \mathrm{~m}$ \\
\hline $\begin{array}{l}\text { Scenar } \\
\text { io } 6\end{array}$ & $\begin{array}{l}\text { Smoke } \\
\text { detector }\end{array}$ & $\begin{array}{l}\text { Room } \\
\text { centre }\end{array}$ & $25 \%$ & Open & Closed & $0.5 \mathrm{~m}$ \\
\hline $\begin{array}{l}\text { Scenar } \\
\text { io } 7\end{array}$ & $\begin{array}{l}\text { Smoke } \\
\text { detector }\end{array}$ & $\begin{array}{l}\text { Room } \\
\text { centre }\end{array}$ & $25 \%$ & Closed & Open & $0.5 \mathrm{~m}$ \\
\hline $\begin{array}{l}\text { Scenar } \\
\text { io } 8 \\
\end{array}$ & $\begin{array}{l}\text { Smoke } \\
\text { detector }\end{array}$ & $\begin{array}{l}\text { Room } \\
\text { centre }\end{array}$ & $25 \%$ & Closed & Closed & $1.0 \mathrm{~m}$ \\
\hline $\begin{array}{l}\text { Scenar } \\
\text { io } 9 \\
\end{array}$ & $\begin{array}{l}\text { Smoke } \\
\text { detector }\end{array}$ & $\begin{array}{l}\text { Room } \\
\text { centre }\end{array}$ & $25 \%$ & Closed & Open & $1.0 \mathrm{~m}$ \\
\hline $\begin{array}{l}\text { Scenar } \\
\text { io } 10\end{array}$ & $\begin{array}{l}\text { Smoke } \\
\text { detector }\end{array}$ & $\begin{array}{l}\text { Room } \\
\text { centre }\end{array}$ & $\begin{array}{l}25 \% \text { (1st level } \\
\text { only) }\end{array}$ & Closed & Open & $0.5 \mathrm{~m}$ \\
\hline $\begin{array}{l}\text { Scenar } \\
\text { io } 11\end{array}$ & $\begin{array}{l}\text { Smoke } \\
\text { detector }\end{array}$ & $\begin{array}{l}\text { Room } \\
\text { centre }\end{array}$ & $\begin{array}{l}25 \% \text { (1st level } \\
\text { only) }\end{array}$ & Closed & Open & $1.0 \mathrm{~m}$ \\
\hline $\begin{array}{l}\text { Scenar } \\
\text { io } 12\end{array}$ & $\begin{array}{l}\text { Smoke } \\
\text { detector }\end{array}$ & $\begin{array}{l}\text { Room } \\
\text { centre }\end{array}$ & $25 \%$ & Open & Open & $0.5 \mathrm{~m}$ \\
\hline $\begin{array}{l}\text { Scenar } \\
\text { io } 13\end{array}$ & $\begin{array}{l}\text { Automatic } \\
\text { fire sprinkler }\end{array}$ & $\begin{array}{l}\text { Room } \\
\text { centre }\end{array}$ & $25 \%$ & Open & Open & $0.5 \mathrm{~m}$ \\
\hline
\end{tabular}

\subsubsection{Base model}

It is a requirement that every building must have smoke detectors. However, sprinklers are fitted under certain criteria. The base model scenario reflects on the minimum requirement set out in C-Clause of the building code. Also, the VM2 had listed a scenario called 'Robustness Check' which is simulating a building assuming a failure of one of the main systems which is in this case windows close off shutting as the engineers stated. The building code states that it is not compulsory to install sprinklers in buildings that have less than 1000 occupants, which is one of the bases that some of the small models did not have 


\section{Chapter Five: Phase Two Methodology}

a suppression system. The location of the fire is assumed at the middle of the room to illustrate a fair placement, as close to the facade increases the time for smoke to spread to upper floors and far away from the facade decreases the time of spread. Hence, common sense suggests that the fire would be placed at the middle of the room. In terms of exterior opening of facade is rarely used as NZ buildings with double skin facade do not state that their exterior facade is operable. Further, depending on the air circulation that is required for the building the top of the facade is either open or closed and the width of the cavity is a minimum of $0.5 \mathrm{~m}$ which all the green buildings with DSF used that width due to the fact that it decreases the total leasable area.

\subsubsection{Scenarios 1 and 2}

The two scenarios were similar to the base model, nonetheless, the only difference is the fire location. In the first scenario the fire is close to the facade at the corner and the second scenario the fire is away from the facade and opposite to the corner of scenario 1 . This is because it is perceived that if the fire is close to the facade the situation is worst and the further the fire is away from the facade the better in terms of the time that takes the smoke to reach upper floors. Thus, the scenarios determine whether fire location is an issue.

\subsubsection{Scenario 3}

This scenario is similar to the base model except that automatic fire sprinklers were added. In FDS the fire sprinklers are set to control the fire after $215 \mathrm{~s}$ and the burning rate would stay the same. The scenario is to test the role of sprinklers due to the fact that some buildings install sprinklers for safety reasons although it is not a requirement.

\subsubsection{Scenario 4}

This scenario assumed that the system closes down and smoke does not spread to upper floors as the engineers stated. Instead the smoke is contained in at the place of fire origin. This gives an indication on how severe are the tenability in terms of visibility and fractional dose of carbon monoxide. 


\section{Chapter Five: Phase Two Methodology}

\subsubsection{Scenario 5}

This scenario was similar to the base model but the only difference was that the opening area of the facade is less. In this case, it was determined whether the opening area of the interior windows would affect smoke spread and to what extent.

\subsubsection{Scenario 6}

There are different types of DSF, one of these is the exterior facade either that opens or contains vents at walking grilles level of the facade. It was assumed that the maximum opening or vent size would be similar to the interior facade of $25 \%$ only. Therefore, the exterior facade opening was designed accordingly. The purpose for this scenario was to determine what sort of effect would and open exterior facade has on smoke spread.

\subsubsection{Scenario 7}

Most or even all DSF have an opening at the top of the facade frame for air circulation. This is perceived as having a major influence on smoke spread, because the opening at the top will act as an exhaust vent. Further as the cavity area is small and smoke rises in its nature, hence, smoke is extracted and thus smoke and other toxic gases are reduced as well as giving more time for occupants to evacuate.

\subsubsection{Scenario 8}

All green buildings with DSF in NZ have a cavity size of $0.5 \mathrm{~m}$ which is the minimum size. However, other countries around the world have cavity size of $1.0 \mathrm{~m}$. Hence, this scenario was to determine what sort of effect the cavity size has on smoke spread.

\subsubsection{Scenario 9}

This scenario was similar to number 7 , but the only difference was the cavity size was larger. Hence, the opening top of the facade was also larger. This might result in better smoke extraction or similar to a scenario 7. 


\section{Chapter Five: Phase Two Methodology}

\subsubsection{Scenario 10 and 11}

These two scenarios were designed to determine how useful would it be to link the DSF with the place of fire origin only with different cavity sizes. The bigger the cavity sizes the more smoke that can it withhold. Hence, can the cavity act as a reservoir?

\subsubsection{Scenario 12}

Scenario 12 assumed that the facade is operable and the building is high tech. However, no safety considerations were integrated into the design. Hence, it investigated whether having open facade to the exterior and open top is enough to mitigate the issue of smoke spread through the DSF.

\subsubsection{Scenario 13}

This scenario was designed to be the most significant under the robustness check scenario were the interior windows fail to shut down. The building as assumed to be equipped with sprinklers to control the fire, exterior vents, and open facade to extract the smoke through natural ventilation. As a result, it was to determine whether such design is the most appropriate in small building and the most compliant with the NZBC.

\subsection{List of Assumptions in FDS and BRANZFIRE}

Assumptions were made to simplify the model design in FDS and BRANZFIRE. The assumptions are likely to affect the accuracy of the output results but not significantly. These include:

- Weather conditions are ignored such as wind.

- Interior or exterior windows have no direction of opening and it was represented as a hole.

- Walkway grilles in between the facade were dealt with as an obstruction and an open area instead of a mesh shape, because of the mesh size.

- Heights of windows and ceiling were typical heights. 


\section{Chapter Five: Phase Two Methodology}

- Bottom of the frame of the facade was closed, because smoke does not sink and get extracted from the bottom.

- Top of the facade was completely open, while in reality it is not, however FDS cannot design diagonal planes; as a result it was considered to be fully open.

- The holes modelling the walkway grilles are offset from one level to the other.

- Smoke detectors, sprinklers, and glazing were not designed into FDS because they do not activate and glazing does not brake as there is not enough heat. Thus, glazing was represented as an obstruction.

- Small model sizes are the typical size used as an office building, but the large model was according to the smallest green building size.

- The larger models were assumed to have services that occupied $700 \mathrm{~m}^{2}$, but the smaller building did not.

- Fire size, location of sensors, leakage design and size, sprinklers and smoke detectors properties were all designed according to VM2. 


\section{Chapter Six: FDS Results}

\subsection{FDS Results}

\subsection{Results of the Scenarios}

The results of the scenarios are shown below in table 6 and the results for the large models are shown in table 7. The data showed that $\mathrm{CO}$ is not an issue except when the fire location is at the corner then $\mathrm{CO}$ is exceeded at one sensor only as it is placed near the fire. However, visibility requirements were breached in all scenarios, but differed in terms of the duration of visibility below $10 \mathrm{~m}$.

Table 6: Small Models Results.

\begin{tabular}{|c|c|c|c|c|c|c|}
\hline \multirow[b]{2}{*}{ Scenario } & \multicolumn{2}{|l|}{ Level 1} & \multicolumn{2}{|l|}{ Level 2} & \multicolumn{2}{|l|}{ Level 3} \\
\hline & $\begin{array}{l}\text { Duration } \\
\text { of CO } \\
\text { exceeding } \\
\text { FED } 0.3\end{array}$ & $\begin{array}{l}\text { Duration } \\
\text { of visibility } \\
\text { below } \\
10 \mathrm{~m}\end{array}$ & $\begin{array}{l}\text { Duration } \\
\text { of CO } \\
\text { exceeding } \\
\text { FED } 0.3\end{array}$ & $\begin{array}{l}\text { Duration } \\
\text { of visibility } \\
\text { below } \\
10 \mathrm{~m}\end{array}$ & $\begin{array}{l}\text { Duration } \\
\text { of CO } \\
\text { exceeding } \\
\text { FED } 0.3\end{array}$ & $\begin{array}{l}\text { Duration } \\
\text { of visibility } \\
\text { below } \\
10 \mathrm{~m}\end{array}$ \\
\hline Base model & 0 & 864 & 0 & 586 & 0 & 699 \\
\hline 1 & 850 & 852 & 0 & 807 & 0 & 835 \\
\hline 2 & 383 & 870 & 0 & 580 & 0 & 734 \\
\hline 3 & 0 & 751 & 0 & 431 & 0 & 544 \\
\hline 4 & 0 & 865 & 0 & 0 & 0 & 0 \\
\hline 5 & 0 & 867 & 0 & 503 & 0 & 616 \\
\hline 6 & 0 & 866 & 0 & 464 & 0 & 609 \\
\hline 7 & 0 & 867 & 0 & 576 & 0 & 31 \\
\hline 8 & 0 & 864 & 0 & 572 & 0 & 670 \\
\hline 9 & 0 & 866 & 0 & 192 & 0 & 692 \\
\hline 10 & 0 & 866 & 0 & 0 & 0 & 0 \\
\hline 11 & 0 & 862 & 0 & 0 & 0 & 0 \\
\hline 12 & 0 & 866 & 0 & 490 & 0 & 0 \\
\hline 13 & 0 & 755 & 0 & 340 & 0 & 0 \\
\hline
\end{tabular}

Table 7: Large Models Results

\begin{tabular}{|c|c|c|c|c|c|c|}
\hline \multirow[b]{2}{*}{ Scenario } & \multicolumn{2}{|l|}{ Level 1} & \multicolumn{2}{|l|}{ Level 2} & \multicolumn{2}{|l|}{ Level 3} \\
\hline & $\begin{array}{l}\text { Duration } \\
\text { of CO } \\
\text { exceeding } \\
\text { FED } 0.3\end{array}$ & $\begin{array}{l}\text { Duration } \\
\text { of visibility } \\
\text { below } \\
10 \mathrm{~m}\end{array}$ & $\begin{array}{l}\text { Duration } \\
\text { of CO } \\
\text { exceeding } \\
\text { FED } 0.3\end{array}$ & $\begin{array}{l}\text { Duration } \\
\text { of visibility } \\
\text { below } \\
10 \mathrm{~m}\end{array}$ & $\begin{array}{l}\text { Duration } \\
\text { of CO } \\
\text { exceeding } \\
\text { FED } 0.3\end{array}$ & $\begin{array}{l}\text { Duration } \\
\text { of visibility } \\
\text { below } \\
10 \mathrm{~m}\end{array}$ \\
\hline Best Case & 299 & 615 & 0 & 0 & 0 & 0 \\
\hline Worst Case & 504 & 227 & 0 & 191 & 0 & 213 \\
\hline
\end{tabular}




\section{Chapter Six: FDS Results}

\subsubsection{Base Model}

The model illustrated that $\mathrm{CO}$ is not an issue; however, visibility is, as visibility requirement is breached significant taking into account that the model run time is 900 seconds. In other words, occupants on level 1 have 36 seconds to escape, on level $3201 \mathrm{sec}$, and on level 2 314sec. Furthermore, according to BRANZFIRE the time it takes the smoke detector to activate is 38 seconds, so after the fire starts the occupants have 38 seconds less to escape. In regards to level 1 , this means that after the smoke fills up the room then the alarm would activate. However, this is unreal; therefore, there is a potential issue with BRANZFIRE underpredicting smoke detector response compared to FDS.

\subsubsection{Scenario 1 and 2}

Comparing between scenarios 1 and 2 is because both purpose is about location of fire. In terms of CO levels only scenarios 1 and 2 exceed the amount by large difference in regards to time. However, CO limits are exceeded by one sensor only which is placed over the fire. Other sensors did not exceed the 0.3 FED limit, the 9 sensors were distributed throughout the room evenly. Further, when the fire was placed at the centre of the room there was also a sensor on top of the fire but the sensor did not reach the limit of CO FED. This is because the smoke was distributed evenly in each direction which reduced the amount of $\mathrm{CO}$ at that particular sensor. Nonetheless, for scenarios 1 and 2 the sensors and location of fire was at the corner which means smoke is accumulated at that corner particularly which caused the increase in co levels. On the other hand, comparing scenarios 1 and 2 there was a significant difference in the time of CO that exceeded the limit. Scenario 1 had a fire at the corner by the facade and the interior facade was open which meant there was a quicker transport of smoke to other levels and hence higher levels of $\mathrm{CO}$, which caused the sensor to detect more CO time wise.

In regards to visibility, scenario 1 exceeded the base model time for levels 2 and 3, but not level 1 because the fire was close to the facade which means smoke travels quicker to upper floors through the cavity and less to the fire place of origin. However, the difference was not significant for level 1 but significant to upper levels. It was the same case with the second scenario. However, comparing the base model with scenario 2 they were similar. Thus, 


\section{Chapter Six: FDS Results}

comparing the three scenarios together shows that fire location lessons or increases fire safety significantly.

\subsubsection{Scenario 3}

AFS were fitted in this scenario to control the fire spread. It was illustrated that there was an increase in visibility across all three levels compared to the base model. However, the increase was not significant because the model allowed the fire to grow to $1 \mathrm{MW}$ in 215 seconds after the burn rate stayed the same. Therefore, the model input was to maintain the same burning rate after the sprinklers were activated which in turn kept the smoke production and propagation the same after the period of activation. There are three scenarios in real situation; the first is the sprinklers suppress the fire, the second the sprinklers control the fire, and the third sprinklers reduce fire growth. It is an unpredictable situation especially for open plan offices as materials and furniture play a big role in this, and these three situations have a significant impact on visibility and $\mathrm{CO}$, although, $\mathrm{CO}$ was not an issue in this case.

\subsubsection{Scenario 4}

This scenario assumes that the window system of the facade closes off as soon as the alarm signal reaches the BMS. However, the alarm signal is usually connected to the smoke detectors, which means that some of the smoke travels to the upper floors from the cavity in the 38 seconds of the detection time. This was not calculated in FDS because opening and closing windows at certain times cannot be specified in FDS and it was listed as an assumption that in the 38 seconds that smoke would not reach the upper floor. Besides, even if the smoke does it should not affect the tenability significantly as little smoke would have penetrated other levels. Nonetheless, comparing the first level with the base model illustrates that there is no difference, as the visibility does not increase or decrease in level 1.

\subsubsection{Scenario 5}

The fifth scenario was exactly the same as the base model, but the only difference is that the size of windows opening was less by a half. For all floors CO was not an issue except for visibility, level 1 was similar to the base model. However, levels 2 and 3 there was a 


\section{Chapter Six: FDS Results}

difference of approximately 80 seconds for visibility. This is because the smoke has less area to escape from level 1 and is more difficult to spread across the entire levels above due to the EAFC is less.

\subsubsection{Scenario 6}

Some exterior facades have either operable windows or vents for ventilation. Therefore, this scenario used this parameter to determine its affect on smoke extraction. Comparing the data to the base model, level 1 was similar but levels 2 and 3 differ by a couple of minutes in terms of increasing visibility. The size of the exterior windows or vents was the same size as the interior windows which were $0.3 \mathrm{~m}$. Nonetheless, their performance was questionable because the slits were vertical resulting in smoke being extracted when it was pushed against the facade. However, vents allow more time for occupants to escape and CO levels were very low and that fulfils the building code requirements. Though, the main assumption made in this case was weather conditions were neglected, because it is not possible to model exterior conditions in FDS and in the engineering practice they are neglected. Hence, the effect of the exterior vents or windows could act as suctions causing an increase and distortion of smoke.

\subsubsection{Scenario 7}

Most if not all DSF have an opening at the top for ventilation. The data extracted from FDS illustrates that level 1 and 2 are similar to the base model, but the third level there was a significant increase in visibility. This is because instead of the smoke accumulating at the top of the cavity it was extracted naturally which reduces the amount of smoke entering level 3. However, there appeared to be an accumulation in the cavity at the first two levels due to the walkway grilles which caused the first two levels to be similar to the base model. It can be said that having a top opening in the facade is useful to the highest floor only. Further, CO levels are not an issue.

\subsubsection{Scenario 8 and 9}

The changed parameter in scenario 8 was the size of the cavity. FDS output results showed that there was insignificant differences between the cavity sizes as the figures established are similar to that of the base model. Also, with scenario 9 which had a bigger cavity size 


\section{Chapter Six: FDS Results}

and an open top there was no difference in level 1, and at level 3 the time for visibility decreased unlike scenario 7; while level 2 time visibility increased significantly. Hence, the conclusions that are drawn from this is that the cavity was too small to act as a reservoir and there is no correlation between the cavity size and the opening top of the facade. Further, the size of cavity and the top opening is not proportional to the amount of smoke that it can withhold and extract. However, $\mathrm{CO}$ was not an issue in the two scenarios.

\subsubsection{Scenario 10 and 11}

These two scenarios were similar to scenario 4 , but it utilised the cavity size and open top of the facade while levels 2 and 3 interior windows were closed, but visibility was not affected. The purpose of these scenarios was to increase the visibility at the level of fire origin. However, in both cases the visibility was similar to the base model; concluding and verifying that the cavity cannot be used as reservoir and natural smoke extractors do not obtain the capacity to extract smoke in large volumes because it is dependent on smoke buoyancy. In terms of $\mathrm{CO}$ it is non-problematic.

\subsubsection{Scenario 12 and 13}

The scenario was designed with the robustness check which would cause the interior windows to stay open, but at the same time the facade was assumed to have open exterior vent plus the top of facade was open as well. In regards to CO levels no issue appeared, however, level 1 was similar to the base model, level 2 was better, level 3 was not effected in anyway by the smoke. This means that these openings are capable of extracting the smoke by taking advantage of the buoyancy but not for level 2 . The reason behind this is the walking grilles, as when the smoke rises it penetrates the grilles which cause friction and smoke spill that rebounds the smoke as it strikes the grille. Also, for level 3 no grilles were placed above the windows, hence, no smoke rebound occurred. Scenario 13 was the same but AFS were fitted which potentially increased the visibility by controlling the fire which also results in less smoke being produced. Thus, levels 1 and 2 have better visibility.

\subsubsection{Best Case Scenario}

The best case scenario resembles scenario 11 exactly; however, the main differences are larger floor area and rooms are sprinklered which is a requirement as the building occupies 


\section{Chapter Six: FDS Results}

more than 1000 person. The results illustrated that levels 2 and 3 are non-problematic in terms of the tenability; nevertheless, level 1 has an issue with visibility but it is less of an issue compared to the smaller model. This is because the reservoir is larger and the smoke produced is controlled as the fire is controlled by sprinklers. Moreover, the sensor of CO FED above the fire exceeded the normal limit which is natural because of the source of the fire, but this issue did not arise in the smaller model due to the fact that sprinklers were not used. Sprinklers reduced buoyancy which caused the sensor to detect a breach of CO FED. Nonetheless, it is not an issue because people do not tend to be at the place of fire and if they were then they are dead.

\subsubsection{Worst Case Scenario}

The worst case scenario resembles scenario 2 where the fire was placed at the corner near the facade. The main differences are the same as the best case scenario. The results showed that the tenability is significantly better than scenario 2 throughout all three levels because of a larger reservoir and sprinklers to control the fire. In terms of CO FED it was exceeded at the location of the fire only. 


\section{Chapter Seven: Discussion}

\subsection{Discussion}

Looking at the overall picture, the fire level or the place of fire origin is the worst in terms of tenability, then the third level and finally the middle level. However, if the top of the facade is open then the figures change in favour of the third floor. Adding sprinklers to the building would not have a significant impact on visibility in terms of the time. Sprinklers adds over 100 seconds of sight to visibility. The most important part is making sure that the system closes off in the event of fire as the engineers stated earlier because at the 900 second, the glass did not break, in other words the temperature did not reach 500 degrees Celsius as outlined in VM2. Opening size of the interior facade and exterior opening does not have a significant impact on smoke reduction. Moreover, the location of the fire is vital as it can increase or decrease the time of occupants escape significantly. Also, the cavity is too small to act as a reservoir. Thus, in terms of the most positive parameters the impacts on fire safety are:

1. The shutdown of the system.

2. Sprinkler control system.

3. Open top of the facade.

4. Open exterior facade.

5. Size of cavity and opening size of interior facade.

In regards to the large models, the code requires sprinklers to be installed. Furthermore, due to the large size of the building the smoke reservoir of the ceiling and cavity size of DSF is larger than the small model. As a result it is expected that a larger building would perform better than a small building in terms of smoke spread and the effect on tenability. Further, $\mathrm{CO}$ is not an issue at any level except for where the fire is located which is logical.

The literature review raised the issue of glazing breaking under high temperatures, but from the FDS model this issue was not observed, as glass may break if fire is next to it and flames impinge on the glass. Further, it is stated that the wider the cavity the better it is as smoke will be impinged against the exterior glazing comparing $1.0 \mathrm{~m}$ to a $2.0 \mathrm{~m}$ cavity. However, the scenarios compared $0.5 \mathrm{~m}$ to a $1.0 \mathrm{~m}$ and it was observed that there is no difference in smoke 


\section{Chapter Seven: Discussion}

movement and the cavity size is not related to smoke spreading to upper and adjacent floors. Nonetheless, the difference between this research and Chow et al $2006 \& 2007$ is that Chow et al conducted a full scale experiment and this research used FDS. Moreover, the sizes of the experiments were smaller than the FDS and according to Gritch, 2010 FDS results are validated against small model and not large models. As a result, there is a difference between Chow et al findings and the author of this thesis. Also, it was agreed from both the literature and the FDS models that smoke movement and spread are dependent on the stack effect.

Chow et al did not mentioned any mitigation measures that would reduce the impact of the DSF on the building, except for the use of tempered glazing and small sheets of glazing as the authors had an issue of glass breaking. However, the interviews with the fire engineers revealed that there are not many mitigation measures that are used for DSF except the shutdown of the windows to prevent the smoke from travelling up the cavity. This was confirmed by the FDS models that closing the windows are the best mitigation measures and installing sprinklers throughout the building to minimise fire spread and smoke propagation. Although, pressurisation was mentioned as a mitigation measure it was not possible to design this using FDS, and one of the conditions for pressurisation to work is the cavity must be a closed space. Plus in some of facades this is not possible because of the openings to the exterior environment. Moreover, it was also suggested to use smoke mechanical extracts to exhaust the smoke, but this could not be designed using FDS as well. On the other hand, natural ventilation extracts are modelled but it showed no major effect on smoke reduction. 


\section{Chapter Eight: Conclusion}

\subsection{Conclusion}

It was found from the literature that DSF has the most significant negative impact on fire safety. Although, atria is the worst if no mitigation measures are incorporated within the building. However, the NZBC has provisions for atria; therefore, the risks and it solutions are well established, but DSF is a newer feature and it was not covered by the literature very well. Further, other features such as storage area, VAV system, green roof etc have minor affect on fire safety and mitigation measures are known. Also, a review of green features in the $50 \mathrm{NZ} \mathrm{GBC}$ rated buildings revealed the common green features used. The NZBC standard analyses might have problems with such features because some requires testing and other requires modelling to show compliance with the NZBC requirements.

The interviews with the 5 fire engineers established that DSF is the worst feature in their opinion because there is little knowledge about the risk and mitigation measures. Nonetheless, atria were also considered the worst but because the risks and mitigation measures are well known and many publications covers atria well; hence, DSF ended up as the worst. Further, storage area was the third in the ranking as having a high risk but the NZBC has provisions for storage and rubbish areas. Other features such as PV cells, chilled beams, and green materials have little to no risk.

One of the three most highly ranked in terms of risk is DSF. DSF was analysed further with FDS a CFD program and BRANZFIRE zone model program because it is the least well documented in the literature. FDS was used to determine the parameters that are mentioned in the literature and by the engineers that would decrease fire safety and mitigation measures to eliminate the risk. Hence, 14 scenarios were designed and the main findings are:

- Closing the interior facade windows is vital. Thus, a manual closing points are required if the windows do not close automatically.

- Sprinklers maybe required to be installed as it adds approximately 2 minutes to the escape time. Whether to install or not to install would depend on the value of ASET vs RSET. 


\section{Chapter Eight: Conclusion}

- DSF cavity cannot act as a reservoir and thus the size has no effect on smoke spread.

- Exterior vents and open top of facade has an insignificant impact on smoke extraction.

- Upper levels have more of an issue of smoke filling than middle levels.

- Walkway grilles have insignificant effect on smoke rise.

- Open top or open exterior facade has a very insignificant affect on smoke extraction.

Thus, sustainable or green features have either negative or positive impacts on fire safety. For features that pose risk there are mitigation measures that can be used to eliminate the risk for example double skin facade would also require smoke curtains in case the windows fail to shut down. However, this adds to the cost of construction; as a result, owners need to know their goals before implementing the feature, because a win-win situation is not possible in this case.

\subsection{Future Research}

There are other works that are required to carry research further and to determine the effect of DSF. These include:

- FDS needs to be validated for large buildings.

- DSF is required to be designed for a specific building. This will give an insight on the building issues rather than indicative concerns.

- ASET vs RSET are required for specific and general buildings to determine whether DSF prevents people from escaping as it reduces ASET. 


\section{References}

\section{References}

Aldrich, R. (2011). Alternative energy. National Institute of Building Sciences. WBDG. Retrieved on 07/03/2012. From: http://www.wbdg.org/resources/alternativeenergy.php

Bastings, D. (1988). Fire safety in atrium buildings. BRANZ study report. Building Research Association of New Zealand.

Bednar, M. J. (1986). The new atrium. School of Architecture, University of Virginia. McGraw-Hill.

Berdahl, P. (1995). Building energy efficiency and fire safety aspects of reflective coatings. Energy and Buildings, (22), 187-191.

Black, W. Z. (2009). Smoke movement in elevator shafts during a high-rise structural fire. Fire Safety Journal, (44), 168-182.

Borden, I., \& Ray, K. R. (2006). The dissertation: An architecture student's handbook: Second Edition. Taylor \& Francis. Architectural Press, Burlington.

BRANZ. (n,d). BRANZFIRE - Zone Model. Retrieved on 09/12/2012. From: http://www.branz.co.nz/cms display.php?sn=74\&st=1

Buchanan A. H., Deam, B. L., Fragiacomo, M., Gibson, T., and Morris, H. (n,d). Fifteen years of performance-based design in New Zealand. Auckland, New Zealand.

Burnard, P. (1991). A method of analysing interview transcripts in qualitative research. Nurse Education Today, 11, p.461-466. 


\section{References}

Bystrom, A., Cheng, X., Wickstrom, U., \& Veljkovic, M. (2012). Full-scale experimental and numerical studies on compartment fire under low ambient temperature. Building and Environment, 51, p.255-262.

Carter, M., Lee N., Oliver, E., \& Post, M. (2011). Promoting the Design of Buildings that are Fire Safe and Sustainable. A review for Fire Protection Association Australia. Worcester polytechnic Institute.

Chami-Castaldi, E., Reynolds, N. and Wallace, J. (2008). Individualised Rating-Scale Procedure: a Means of Reducing Response Style Contamination in Survey Data?. The Electronic Journal of Business Research Methods, 6 (1), p. $9-20$.

Charters, D. A., \& Mitchell, J. F. (2007). The potential role and contribution of fire safety to sustainable buildings. BRE Fire and Security. Interflam.

Chow, C. L., \& Chow, W. K. (2005). Evacuation with smoke control for atria in green and sustainable buildings. Building and Environment, (40), 195-200.

Chow., C. L., and Steemers, K. (n,d). Possible conflicts on smoke control in buildings with natural ventilation. Department of Architecture, the Martin Centre for Architectural and Urban Studies. University of Cambridge, UK.

Chow, W. K. (2001). Discussion on applying the American fire safety evaluation system for business occupancies in Hong Kong. International Journal on Engineering Performance-Based Fire Codes, 3 (2), 92-97.

Chow, W. K. (2002). Proposed Fire Safety Ranking System EB-FSRS for existing highrise nonresidential buildings in Hong Kong. Journal of Architectural Engineering, 8, (4), p.116 $-124$. 


\section{References}

Chow, W. K., Hung, W. Y., Geo, Y., Zou, G., \& Dong, H. (2007). Experimental study on smoke movement leading to glass damage in double-skin facade. Construction and Building Materials, (21), 556-566.

Chow, W., K., \& Hung, W., Y. (2006). Effect of cavity depth on smoke spreading of double-skin facade. Building and Environment, (41), 970-979.

Chow, W. K, \& Lui, G. C. H. (2002). A proposed fire safety ranking system for karaoke establishments and its comparison with the NFPA-fire safety evaluation system. Building and Environment, 37, p.647-656.

FABRAL. (n,d). Beyond Insulation, Phase change: A high-performance energy saving material. FABRAL Architectural System.

Fellegi, I. P. (2003). Survey methods and practices. Ministry of Industry. Canada

Fink, A. (2006). How to conduct surveys: A step-by-step guide; Third Edition. Sage Publications. London, UK.

Folmer, E., \& Bosch, J. (2004). Architecting for usability: a survey. The Journal of Systems and Software, 70, p. $61-78$.

Gates, A. (2012). Determining the modelling input parameters for HVAC systems in New Zealand commercial buildings. School of Architecture and Design. Victoria University of Wellington.

Glaser, B. G. and Strauss, A. L. (1967). The discovery of grounded theory strategies for qualitative research. Aldine Transaction, USA. 


\section{References}

Graham, C. I. (2009). High-performance HVAC. National Institute of Building Sciences. WBDG. Retrieved on 07/03/12. From: http://www.wbdg.org/resources/hvac.php

Gritch, T., \& Eason, B. (2010). Building envelope design quide - Atria systems. National Institute of Building Sciences. WBDG. Retrieved on 4/03/2012. From: http://www.wbdg.org/design/env atria.php

Gritzo, L. A., Doerr, W., Bill, R., Ali, H., Nong, S., \& Krasner, L. (2009). Technical Report: The influence of risk factors on sustainable development. FM Global Research Division. Norwood.

Hadjisophocleous, G.V., and Benichou, N. (1999). Performance criteria used in fire safety design. Automation in Construction, 8, p.489-501.

Hao-wei, Y., Wen-li, D., Dong, L., Rogner, A., \& Jing-wei, L. (2011). Simulation of fullscale smoke control in atrium. Procedia Engineering, (11), 608-613.

Harland, A., Mackay, C., \& Vale, B. (n,d). Phase changing materials in Architecture. Victoria University of Wellington. New Zealand

Hoffman, R. R. (1987). The problem of extracting knowledge of experts from the perspective of experimental psychology. Al Magazine, 8 (2), p.53-67.

Horsky, J., McClogan, K., Pang, J. E., Melnikas, A. J., Linder, J. A., Schinpper, J. L., and Middleton, B. (2010). Complementary methods of system usability evaluation: Surveys and observations during software design and development cycles. Journal of Biomedical Informatics, 43, p. $782-790$. 


\section{References}

Hu, L.H., Yang, L.Z., Chow, W.K., Li, Y.Z., \& Huo, R. (2007). Modeling fire-induced smoke spread and carbon monoxide transportation in a long channel: Fire Dynamics Simulator comparison with measured data. Journal of Hazardous Materials, 140, p.293-298.

Human Resources and Skills Development Canada (HRSDC). (2011). Common causes of fire. Labour. Retrieved on 08/03/2012. From:

http://www.hrsdc.gc.ca/eng/labour/fire protection/prevention/fire causes.shtml

Ibrahim, M. N., Ibrahim, M. S., Mohd-Din, A., Abdul-Hamid, K., Yunus, R. M., \& Yahya, M. R. (2011). Fire risk assessment of heritage building - perspectives of regulatory authority, restorer and building stakeholder. Procedia Engineering, 20, p.325 - 328.

Ibrahim, M. N., Ibrahim, M. S., Mohd-Din, A., Abdul-Hamid, K., Yunus, R. M., \& Yahya, M. R. (2011). The development of fire risk assessment method for heritage building. Procedia Engineering, 20, p.317 - 324 .

Jackson, P. (2009). Target roof PV fire of 4-5-09 9100 Rosedale Hwy Bakersfield, California. Memorandum: Development Services/Building Department.

Jones, M., and Alony, I. (2011). Guiding the use of grounded theory in doctoral studies - an example from the Australian Film Industry. International Journal of Doctoral Studies, 6, p.95-114.

Liew, J. Y. R. (2004). Performance based fire safety design of structures - A multidimensional integration. Advances in Structural Engineering, 7 (4), p. 311 - 333.

Krause, U., Grosshandler, W., \& Gritzo, L. (2012). The international FORUM of fire research directors: A position paper on sustainability and fire safety. Fire Safety Journal, (49), 79-81. 


\section{References}

Mahlman, R. J. (2007). Fire protection/life safety in a sustainable design world. Fire Protection Engineering. Retrieved on 13/03/2012. From:

http://fpemag.com/archives/article.asp?issue id=43\&i=314

Mason, M. (2010). Sample size and saturation in PhD studies using qualitative interviews. Forum Qualitative Sozialforschung / Forum: Qualitative Social Research, 11(3), Art. 8. Retrieved on 08/06/2012. From: http://www.qualitativeresearch.net/index.php/fqs/article/view/1428/3027\#g12

McGrattan, K., Hostikka, S., Floyd, J., Baum, H., Rehm, R., Mell, W., \& McDermott, R. (2010). Fire Dynamics Simulator (Version 5) Technical Reference Guide. Volume 1: Mathematical Model. NIST, U.S. Department of Commerce.

Meacham, B. J. (1997). SFPE perspectives on performance-based fire safety design. Society of Fire Protection Engineers, 1, p.18-25.

Meroney, R. N., \& Banks, D. (2004). Smoke and fire in building atria. Wind effects on buildings and environment. USA.

Milke, J. A. (1999). Using multiple sensors for discriminating fire detection. Department of Fire Protection Engineering. University of Maryland, USA.

Miller, C. (2011). Extensive vegetative "Green" roofs. National Institute of Building Sciences. WBDG. Retrieved on 5/03/20112. From: http://www.wbdg.org/resources/greenroofs.php

Mokka Glossary. (n,d). Environmental information. Retrieved on 16/06/2012. From: http://enfo.hu/mokka/db2/glossary.php?lang=en\&pattern=\&search type=all\&char=all\&db type=mysql\&todel $=$ 


\section{References}

Moskowitz, P. D, Conveney, E. A., Rabinowitz, S., \& Barancik, J. I. (1983). Rooftop photovoltaic arrays: Electric shock and fire health hazards. Biomedical and Environmental Assessment Division, Department of Energy and Environment, Brookhaven National Laboratory, Upton, NY. Solar Cells, (9), 327-336.

NAHB Research Centre. (n,d). Emergency power backup system: Continued access to electrical service during power outages. Building Systems. Retrieved on 07/03/2012. From: http://www.toolbase.org/Building-Systems/Electrical-Electronics/emergency-powerbackup-systems

NAHB Research Centre. $(n, d)$. Fuel cells: Converts the energy of hydrogen into electrical energy without the need for combustion. Building Systems. Retrieved on 07/03/2012. From: http://www.toolbase.org/Building-Systems/Electrical-Electronics/chpfuel-cell

NAHB Research Centre. $(n, d)$. Recycled content carpet: Said to be more resilient and colorfast than virgin fiber carpet. Building Systems. Retrieved on 07/03/2012. From: http://www.toolbase.org/Building-Systems/Floors/recycled-content-carpet

Newsham, G. R., Mancini, S., \& Birt, B. J. (2009). Do LEED-certified buildings save energy? Yes, but.... Energy and Buildings, (41), p. 897-905.

New Zealand Building Code (NZBC). (1992). Fire Safety. Clauses C1, C2, C3, C4. Building Industry Authority. Wellington.

Nielsen, J. (2006). Quantitative studies: How many users to test? Retrieved on 08/06/2012. From: http://www.useit.com/alertbox/quantitative testing.html 


\section{References}

Nulook. (2012). Windows and Doors: Awing and casement windows weathertight. Retrieved on 06/12/2012. From:

http://www.nulook.co.nz/index.pl?page=awning windows weathertight\&m=113

Paul, W. L., \& Taylor, P. A. (2008). A comparison of occupant comfort and satisfaction between a green building and a conventional building. Building and Environment, (43), p. 1858-1870.

Poirazis, H. (2006). Double skin facade: A literature review. Department of Architecture and Built Environment. SHC, Sweden.

Pope, N.D., \& Bailey, C.G. (2006). Quantitative comparison of FDS and parametric fire curves with post-flashover compartment fire test data. Fire Safety Journal, 41, p.99-110.

PyroSim. (2012). PyroSim. Retrieved on 09/12/2012. From:

http://www.thunderheadeng.com/pyrosim/

Qin, T. X., Guo, Y. C., Chan, C. K., \& Lin, W. Y. (2009). Numerical simulation of the spread of smoke in an atrium under fire scenario. Building and Environment, (44), 56-65.

Sartori, I. \& Hestnes, A. G. (2007). Energy use in the life cycle of conventional and low-energy buildings: A review article. Energy and Buildings, (39), p. 249-257.

Scofield, J. H. (2009). Do LEED-certified buildings save energy? Not really.... Energy and Buildings, (41), p.1386-1390.

Shen, T., Huang, Y., Chien, S. (2008). Using fire dynamic simulation (FDS) to reconstruct an arson fire scene. Building and Environment, 43, p.1036-1045.

Shipp, M. (2007). Constructing the future. BRE, 31, 4-6. 


\section{References}

SIG Insulation. (n,d). A guide to sustainable insulation materials. SIG Insulation

Smith, P. F. (2007). Sustainability at the cutting edge. Emerging technologies for low energy buildings. Second edition. Architectural press. p52-66.

Smith, T. M., Fischlein, M., Suh, S., \& Huelman, P. (2006). A comparison of the LEED and Green Globes systems in the US. The Carpenters Industrial Council (CIC).

Spearpoint, M. (2008). Fire engineering design guide: Third edition. New Zealand centre for advanced engineering. CAENZ, Christchurch, New Zealand.

Stec, A. A., \& Hull, T. R. (2011). Assessment of the fire toxicity of building insulation materials. Energy and Buildings (43), 298-506.

Strong, S. (2011). Building integrated photovoltaics (BIPV). National Institute of Building Sciences. WBDG. Retrieved on 05/03/2012. From: http://www.wbdg.org/resources/bipv.php

Taylor, B. (2006). The teen key principles of green fire. Walker Fire Protection. Australia.

Tavares, R. M. (2008). Prescriptive codes vs. performance-based codes: which one is the best fire safety code for the Brazilian context?. Safety Science Monitor, 12 (1), p.1 - 10.

Tidwell, J. \& Murphy, J. J. (2010). Bridging the Gap-Fire Safety and Green Buildings. A fire and Building Safety Guide to Green Construction. National Association State Fire Marshals. 


\section{References}

Turner, C. W., Neilsen, J., and Lewis, J. R. (n,d). Current issues in the determination of usability test sample: How many users is enough?. State Farm Insurance, Nielsen Norman Group, and IBM Corp.

U.S. Department of Energy. (2011). Fuel cells and renewable hydrogen. Federal Energy Management Program (FEMP). National Institute of Building Sciences. WBDG. Retrieved on 07/03/2012. From: http://www.wbdg.org/resources/fuelcell.php

U.S. Department of Energy Federal Energy Management Program (FEMP). (2011). Photovoltaics. National Institute of Building Sciences. WBDG. Retrieved on 06/03/2012. From: http://www.wbdg.org/resources/photovoltaics.php

Uuttu, S. (2001). Study of Current Structures in Double-Skin Facades. MSc thesis in Structural Engineering and Building Physics. Department of Civil and Environmental Engineering, Helsinki University of Technology (HUT), Finland.

Wade, C., Beever, P., Fleischmann, C., Lester, J., Lloydd, D., Moule, A., Saunders, N., and Thorby, P. (2007). Developing fire performance criteria for New Zealand's performance based building code. BRANZ, Conference Paper, No. 128.

Walker, A. (2010). Natural ventilation. National Institute of Building Sciences. WBDG. Retrieved on 05/03/2012. From: http://www.wbdg.org/resources/naturalventilation.php

Watt, J. M., \& Kaplan, M. E. (2001). Fire risk index for historic buildings. Fire Technology, 37, p.167- 180.

Wieczorek., C. J. (2011). Fire safety: An integral part of sustainability. Fire Protection Engineering. Fourth Quarter 2011, 52, p40-44. 


\section{References}

Wiecozorek, C. J., Ditch, B., \& Bill, R. G. (2010) Technical Report: Environmental impact of automatic fire sprinklers. FM Global Research Division. Norwood.

Yuan J., Fang, Z., Tang, Z., and Sun, J. (2011). Performance-based fire safety assessment of city underwater tunnel. procedia Engineering, 11, p.86-90.

Zhang, Y., \& Altan, H. (2011). A comparison of the occupant comfort in a conventional high-rise office block and a contemporary environmentally-concerned building. Building and Environment, (46), p. 535-545.

Zhao, B., Li, X., \& Yan, Q. (2003). A simplified system for indoor airflow simulation. Building and Environment, 38, p.543-552.

Zhao, C. M., Lo, S. M., Lu, J. A., \& Fang, Z. (2004). A simulation approach for ranking of fire safety attributes of existing buildings. Fire Safety Journal, 39, p. 557 - 576. 


\section{Appendix}

\section{Appendix}

\section{Introduction}

I am Mohammad Al-Janabi, a Masters student of Building Science studying at Victoria University of Wellington (VUW). My current research topic is 'The Impact of Green Features on Fire Safety.' I am investigating the implications of green features on fire safety. The findings of the interview will be reported on anonymously and I can withdraw myself or any information I provide within 24hours after the interview. The overall goal of the interview is to understand "How green features comply with the New Zealand Building Code (NZBC)." The objectives of this interview are to:

- Rate and rank green features in term of their implications for fire safety.

- Identify performance criteria and objectives that are used to determine the implications of green features for fire safety.

- Identify engineering tools and methodologies that are used to analyse new or innovative features.

This survey has been approved by the Human Ethics Committee of Victoria University. The interview should take around 30 - 60 minutes to complete and the responses are anonymous. The interviews will be kept until the grade is awarded for this thesis then the interviews will be deleted. Please do not hesitate to contact the researcher or the supervisors if you have any questions.

\section{$\underline{\text { Researcher }}$}

Name: Mohammad Al-Janabi

Mobile: 0212020640

E-mail: aljanamoha@myvuw.ac.nz

\section{First Supervisor}

Name: Dr Geoff Thomas

Phone: (04) 4636247

E-mail: geoff.thomas@vuw.ac.nz

\section{Second Supervisor}

Name: Dr Michael Donn

Phone: (04) 4636221

E-mail: michael.donn@vuw.ac.nz 


\section{Victoria University of Wellington}

\section{Consent to Participation in Research}

\section{The Impact of Sustainability on Fire Safety}

I have been given and have understood an explanation of this research project. I have had an opportunity to ask questions and have them answered to my satisfaction. I understand that I may withdraw myself (or any information I have provided) from this project (before data collection and analysis is complete) without having to give reasons within 24 hours after the interview.

I understand that any information I provide will be kept confidential to the researcher, and the supervisors. The published results will not use my name, and no opinions will be attributed to me in any way that will identify me. I understand that the recording of the interview will be deleted at the end of the project.

I understand that the data I provide will not be used for any other purpose or released to others without my written consent and I agree to take part in this research.

Would you like to receive a summary of the interviews study?

$\square$ Yes $\square$ No

Signed:

Name of participant:

Date: 
1) On the table below, assuming no mitigation measures please:

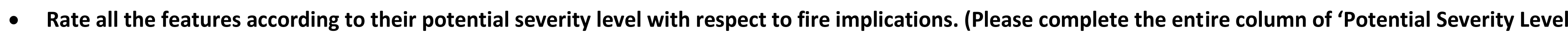

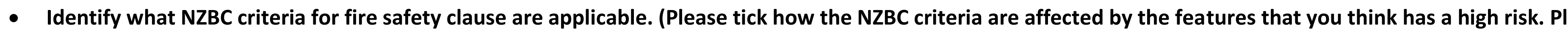
implications refer to an increases in the level of safety, while -ve implications refer to a decrease in the level of safety.

- Rank the top 5 features only that have the most negative implications on fire safety (1 being the worst).

\begin{tabular}{|c|c|c|c|c|c|c|}
\hline \multirow[b]{2}{*}{ Green Building Features } & \multirow[b]{2}{*}{$\begin{array}{c}\text { Potential Severity } \\
\text { Level }\end{array}$} & \multicolumn{5}{|c|}{ NZBC Criteria for Fire Safety } \\
\hline & & $\begin{array}{l}\text { C2: Prevention of fire } \\
\text { occurring }\end{array}$ & $\begin{array}{l}\text { C3: Fire affecting } \\
\text { areas beyond the } \\
\text { fire source }\end{array}$ & $\begin{array}{l}\text { C4: Movement to } \\
\text { place of safety }\end{array}$ & $\begin{array}{l}\text { C5: Access and } \\
\text { safety for fire } \\
\text { fighting operations }\end{array}$ & $\begin{array}{l}\text { C6: Structural } \\
\text { stability }\end{array}$ \\
\hline \multicolumn{7}{|l|}{ Natural Ventilation Systems } \\
\hline $\begin{array}{l}\text { Atrium (Fully open for lighting } \\
\text { and ventilation, } 3 \text { levels high and } \\
\text { open to all floors) }\end{array}$ & $\begin{array}{l}\text { DSignificantly -ve } \\
\text {-ve Implications } \\
\text { Neutral } \\
=+ \text { ve Implications } \\
\text { Significant +ve }\end{array}$ & $\begin{array}{l}\square \text { Not Applicable } \\
\square \text {-ve Implications } \\
\square \text { Neutral } \\
\text { +ve Implications }\end{array}$ & $\begin{array}{l}\text { Not Applicable } \\
\text {-ve Implications } \\
\text { Neutral } \\
\text { +ve Implications }\end{array}$ & $\begin{array}{l}\text { Not Applicable } \\
\text {-ve Implications } \\
\text { Neutral } \\
\text { +ve Implications }\end{array}$ & $\begin{array}{l}\text { Not Applicable } \\
\text {-ve Implications } \\
\text { Neutral } \\
\text { +ve Implications }\end{array}$ & $\begin{array}{l}\text { Not Applicable } \\
\text {-ve Implications } \\
\text { Neutral } \\
\text { +ve Implications }\end{array}$ \\
\hline $\begin{array}{l}\text { Double Skin Facade (Used for } \\
\text { ventilation with two panels of } \\
\text { glazing with a cavity of } 500 \mathrm{~mm} \\
\text { minimum, which covers a single } \\
\text { elevation, and connects all floors } \\
\text { except for the ground floor) }\end{array}$ & $\begin{array}{l}\text { Significantly -ve } \\
\text {-ve Implications } \\
=\text { Neutral } \\
+ \text { +ve Implications } \\
\text { Significant +ve }\end{array}$ & $\begin{array}{l}\square \text { Not Applicable } \\
\square \text {-ve Implications } \\
\square \text { Neutral } \\
\square \text { +ve Implications }\end{array}$ & $\begin{array}{l}\text { Not Applicable } \\
\text {-ve Implications } \\
\text { Neutral } \\
\text { +ve Implications }\end{array}$ & $\begin{array}{l}\text { Not Applicable } \\
\text {-ve Implications } \\
\text { Neutral } \\
\text { +ve Implications }\end{array}$ & $\begin{array}{l}\text { Not Applicable } \\
\text {-ve Implications } \\
\text { Neutral } \\
\text { +ve Implications }\end{array}$ & $\begin{array}{l}\text { Not Applicable } \\
\text {-ve Implications } \\
\text { Neutral } \\
\text { +ve Implications }\end{array}$ \\
\hline \multicolumn{7}{|l|}{ Mechanical Ventilation Systems } \\
\hline $\begin{array}{l}\text { Chilled Beams for Heating, } \\
\text { Ventilation and Air-Conditioning } \\
\text { (HVAC) }\end{array}$ & $\begin{array}{l}\text { Significantly -ve } \\
\text {-ve Implications } \\
\text { Neutral } \\
=+v e \text { Implications } \\
\text { Significant +ve }\end{array}$ & $\begin{array}{l}\square \text { Not Applicable } \\
\square \text {-ve Implications } \\
\square \text { Neutral } \\
\square \text { +ve Implications }\end{array}$ & $\begin{array}{l}\text { Not Applicable } \\
\text {-ve Implications } \\
\text { Neutral } \\
\text { +ve Implications }\end{array}$ & \begin{tabular}{|l}
$\square$ Not Applicable \\
$\square$-ve Implications \\
$\square$ Neutral \\
$\square$ +ve Implications
\end{tabular} & $\begin{array}{l}\text { Not Applicable } \\
\text {-ve Implications } \\
\text { Neutral } \\
\text { +ve Implications }\end{array}$ & $\begin{array}{l}\text { Not Applicable } \\
\text {-ve Implications } \\
\text { Neutral } \\
\text { +ve Implications }\end{array}$ \\
\hline $\begin{array}{l}\text { Variable Air Volume (VAV) (With } \\
\text { central fan for distribution) for } \\
\text { HVAC }\end{array}$ & $\begin{array}{l}\text { Significantly -ve } \\
\text {-ve Implications } \\
\text { Neutral } \\
=+ \text { ve Implications } \\
\text { Significant +ve }\end{array}$ & $\begin{array}{l}\square \text { Not Applicable } \\
\square \text {-ve Implications } \\
\square \text { Neutral } \\
\square \text { +ve Implications }\end{array}$ & \begin{tabular}{|l}
$\square$ Not Applicable \\
$\square$-ve Implications \\
$\square$ Neutral \\
$\square$ +ve Implications
\end{tabular} & $\begin{array}{l}\square \text { Not Applicable } \\
\square \text {-ve Implications } \\
\square \text { Neutral } \\
\square \text { +ve Implications }\end{array}$ & \begin{tabular}{|l}
$\square$ Not Applicable \\
$\square$-ve Implications \\
$\square$ Neutral \\
$\square$ +ve Implications
\end{tabular} & $\begin{array}{l}\square \text { Not Applicable } \\
\square \text {-ve Implications } \\
\square \text { Neutral } \\
\square \text { +ve Implications }\end{array}$ \\
\hline \multicolumn{7}{|l|}{ Miscellaneous Systems } \\
\hline $\begin{array}{l}\text { Green Roof/Walls (Interior and } \\
\text { exterior) }\end{array}$ & $\begin{array}{l}\text { Significantly -ve } \\
\text {-ve Implications } \\
\text { Neutral } \\
+ \text { +ve Implications }\end{array}$ & 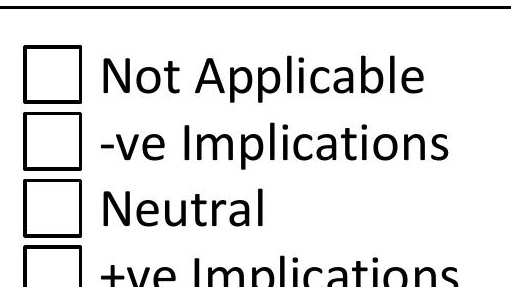 & \begin{tabular}{|l}
$\square$ Not Applicable \\
$\square$-ve Implications \\
$\square$ Neutral \\
+ve Imnlications
\end{tabular} & $\begin{array}{ll}\square & \text { Not Applicable } \\
\square & \text {-ve Implications } \\
\square & \text { Neutral } \\
& \text { +ve Imnlications }\end{array}$ & \begin{tabular}{|l}
$\square$ Not Applicable \\
$\square$-ve Implications \\
$\square$ Neutral \\
tve Imnlications
\end{tabular} & \begin{tabular}{|l}
$\square$ Not Applicable \\
$\square$-ve Implications \\
$\square$ Neutral \\
tve Imnlications
\end{tabular} \\
\hline
\end{tabular}




\begin{tabular}{|c|c|c|c|c|c|c|}
\hline \multirow[b]{2}{*}{ Green Building Features } & \multirow[b]{2}{*}{$\begin{array}{c}\text { Potential Severity } \\
\text { Level }\end{array}$} & \multicolumn{5}{|c|}{ NZBC Criteria for Fire Safety } \\
\hline & & $\begin{array}{c}\text { C2: Prevention of fire } \\
\text { occurring }\end{array}$ & $\begin{array}{l}\text { C3: Fire affecting } \\
\text { areas beyond the } \\
\text { fire source }\end{array}$ & $\begin{array}{l}\text { C4: Movement to } \\
\text { place of safety }\end{array}$ & $\begin{array}{l}\text { C5: Access and } \\
\text { safety for fire } \\
\text { fighting operations }\end{array}$ & $\begin{array}{l}\text { C6: Structural } \\
\text { stability }\end{array}$ \\
\hline \multicolumn{7}{|l|}{ Power Generation Systems } \\
\hline $\begin{array}{l}\text { Photovoltaic Cells (PV) (PV cells } \\
\text { are local on the building) }\end{array}$ & $\begin{array}{l}\text { Significantly -ve } \\
\square \text {-ve Implications } \\
\square \text { Neutral } \\
\square+\text { ve Implications } \\
\square \text { Significant +ve } \\
\end{array}$ & $\begin{array}{ll}\square & \text { Not Applicable } \\
\square & \text {-ve Implications } \\
\square & \text { Neutral } \\
\square & \text { +ve Implications }\end{array}$ & $\begin{array}{ll}\square & \text { Not Applicable } \\
\square \text {-ve Implications } \\
\square \text { Neutral } \\
\square \text { +ve Implications }\end{array}$ & $\begin{array}{ll}\square & \text { Not Applicable } \\
\square & \text {-ve Implications } \\
\square & \text { Neutral } \\
\square & \text { +ve Implications }\end{array}$ & $\begin{array}{ll}\square & \text { Not Applicable } \\
\square & \text {-ve Implications } \\
\square & \text { Neutral } \\
\square & \text { +ve Implications }\end{array}$ & $\begin{array}{ll}\square & \text { Not Applicable } \\
\square & \text {-ve Implications } \\
\square & \text { Neutral } \\
\square & \text { +ve Implications }\end{array}$ \\
\hline $\begin{array}{l}\text { Wind Turbine (The turbines are } \\
\text { local on the building) }\end{array}$ & $\begin{array}{l}\square \text { Significantly -ve } \\
\square \text {-ve Implications } \\
\square \text { Neutral } \\
\square+\text { ve Implications } \\
\square \text { Significant +ve } \\
\end{array}$ & $\begin{array}{ll}\square & \text { Not Applicable } \\
\square & \text {-ve Implications } \\
\square & \text { Neutral } \\
\square & \text { +ve Implications }\end{array}$ & $\begin{array}{l}\square \text { Not Applicable } \\
\square \text {-ve Implications } \\
\square \text { Neutral } \\
\square \text { +ve Implications }\end{array}$ & $\begin{array}{ll}\square & \text { Not Applicable } \\
\square & \text {-ve Implications } \\
\square & \text { Neutral } \\
\square & \text { +ve Implications }\end{array}$ & $\begin{array}{ll}\square & \text { Not Applicable } \\
\square & \text {-ve Implications } \\
\square & \text { Neutral } \\
\square & \text { +ve Implications }\end{array}$ & $\begin{array}{l}\square \text { Not Applicable } \\
\square \text {-ve Implications } \\
\square \text { Neutral } \\
\square \text { +ve Implications }\end{array}$ \\
\hline
\end{tabular}

Please add or identify other green features that have implications on fire safety?

\begin{tabular}{|c|c|c|c|c|c|c|}
\hline \multirow[b]{2}{*}{ Green Building Features } & \multirow[b]{2}{*}{$\begin{array}{c}\text { Features Severity } \\
\text { Level }\end{array}$} & \multicolumn{5}{|c|}{ NZBC Criteria } \\
\hline & & $\begin{array}{l}\text { C2: Prevention of } \\
\text { fire occurring }\end{array}$ & $\begin{array}{c}\text { C3: Fire affecting } \\
\text { areas beyond the fire } \\
\text { source }\end{array}$ & $\begin{array}{l}\text { C4: Movement to } \\
\text { place of safety }\end{array}$ & $\begin{array}{c}\text { C5: Access and } \\
\text { safety for fire } \\
\text { fighting operations }\end{array}$ & $\begin{array}{l}\text { C6: Structural } \\
\text { stability }\end{array}$ \\
\hline & $\begin{array}{l}\square \text { Significantly -ve } \\
\square \text {-ve Implications } \\
\square \text { Neutral } \\
\square+\text { +ve Implications } \\
\square \text { Significant +ve } \\
\end{array}$ & $\begin{array}{l}\square \text { Not Applicable } \\
\square \text {-ve Implications } \\
\square \text { Neutral } \\
\square \text { +ve Implications }\end{array}$ & $\begin{array}{ll}\square & \text { Not Applicable } \\
\square \text {-ve Implications } \\
\square \text { Neutral } \\
\square \text { +ve Implications }\end{array}$ & $\begin{array}{l}\square \text { Not Applicable } \\
\square \text {-ve Implications } \\
\square \text { Neutral } \\
\square \text { +ve Implications }\end{array}$ & $\begin{array}{ll}\square & \text { Not Applicable } \\
\square & \text {-ve Implications } \\
\square & \text { Neutral } \\
\square & \text { +ve Implications }\end{array}$ & $\begin{array}{l}\square \text { Not Applicable } \\
\square \text {-ve Implications } \\
\square \text { Neutral } \\
\square \text { +ve Implications }\end{array}$ \\
\hline & $\begin{array}{l}\text { Significantly -ve } \\
\text {-ve Implications } \\
\square \text { Neutral } \\
\square+\text { +ve Implications } \\
\square \text { Significant +ve } \\
\end{array}$ & $\begin{array}{l}\square \text { Not Applicable } \\
\square \text {-ve Implications } \\
\square \text { Neutral } \\
\square \text { +ve Implications }\end{array}$ & $\begin{array}{ll}\square & \text { Not Applicable } \\
\square \text {-ve Implications } \\
\square \text { Neutral } \\
\square \text { +ve Implications }\end{array}$ & $\begin{array}{l}\square \text { Not Applicable } \\
\square \text {-ve Implications } \\
\square \text { Neutral } \\
\square \text { +ve Implications }\end{array}$ & $\begin{array}{ll}\square & \text { Not Applicable } \\
\square \text {-ve Implications } \\
\square \text { Neutral } \\
\square \text { +ve Implications }\end{array}$ & $\begin{array}{ll}\square & \text { Not Applicable } \\
\square \text {-ve Implications } \\
\square \text { Neutral } \\
\square \text { +ve Implications }\end{array}$ \\
\hline
\end{tabular}




\section{Appendix}

2) For (e.g. Atria) what are the performance design objectives you set generally and how do you achieve them? (5)

3) How do you measure the performance of the objectives and the methodology you set? (5)

4) What is the method of implementing mitigation measures for (e.g. Atria)? (5)

5) Please state a worst case scenario which you analyse in your practice (e.g. Atria)? (5)

6) Is there anything else you would like to share?

Note: (5) Means the question will be repeated 5 times for the 5 different features with significant negative implications 


\section{Glossary}

\section{Glossary}

Box window facade:

Chimney effect:

Corridor facade:

Green/Sustainable features:

Multi-Story facade:

Shaft box facade:

Stack effect:
Box glazing around the window only that is not connected to other windows.

The movement of air within a building that is driven by buoyancy.

Double skin facade covers a single story only and connects all windows from one elevation for ventilation purposes.

Features that are used in green or sustainable buildings that are perceived to be environmentally friendly.

Double skin facade covers and connects an entire elevation for ventilation purposes.

A set of box windows facade that are connected to vertical shafts to increase stack effect.

See chimney effect. 